This is the post-print accepted manuscript in Macromolecular Bioscience: Khan, Z.M., Wilts, E., Vlaisavljevich, E., Long, T.E., \& Verbridge, S.S. (2021). Electroresponsive Hydrogels for Therapeutic Applications in the Brain. Macromolecular Bioscience. https://doi.org/10.1002/mabi.202100355

\title{
Electroresponsive Hydrogels for Therapeutic Applications in the Brain
}

Zerin M. Khan, Emily Wilts, Eli Vlaisavljevich, Timothy E. Long, and Scott S. Verbridge*

Z. M. Khan, Dr. E. Vlaisavljevich, Dr. S. S. Verbridge

Virginia Tech - Wake Forest University School of Biomedical Engineering and Sciences Virginia Tech

Blacksburg, VA 24061, USA

E-mail: sverb@vt.edu

Dr. E. Wilts

Department of Cellular and Physiological Sciences

University of British Columbia

Vancouver, BC V6T 1Z3, CA

Dr. T. E. Long

Biodesign Center for Sustainable Macromolecular Materials and Manufacturing

Arizona State University

Tempe, AZ 85287, USA

Keywords: electroconductive hydrogels, controlled delivery, biosensors, neural electrode interface, neural stem cell differentiation

\begin{abstract}
Electroresponsive hydrogels possess a conducting material component and respond to electric stimulation through reversible absorption and expulsion of water. The high level of hydration, soft elastomeric compliance, biocompatibility, and enhanced electrochemical properties render these hydrogels suitable for implantation in the brain to enhance the transmission of neural electric signals and ion transport. This review provides an overview of critical electroresponsive hydrogel properties for augmenting electric stimulation in the brain. A background on electric stimulation in the brain through electroresponsive hydrogels is provided. Common conducting materials and general techniques to integrate them into hydrogels are briefly discussed. This review focuses on and summarizes advances in electric stimulation of electroconductive hydrogels for therapeutic applications in the brain, such as for controlling delivery of drugs, directing neural stem cell differentiation and neurogenesis, improving neural biosensor capabilities, and enhancing neural electrode-tissue interfaces. The key challenges in each of these applications are discussed and recommendations for future research are also provided.
\end{abstract}




\section{WILEY-VCH}

\section{Introduction}

Neurons in the brain communicate by transmitting electric signals, ${ }^{[1,2]}$ which is important for their functional expression, differentiation, and survival. ${ }^{[3]}$ Transmembrane potentials and probability of action potentials occurring are affected by both exogenously induced and local endogenous electric fields ${ }^{[4]}$ which can inhibit or excite neuronal networks, modify their plasticity, ${ }^{[5]}$ and probe neural patterns to alleviate brain disorders and diseases. ${ }^{[6]}$ For instance, electroconvulsive shock therapy was first applied in 1938 to treat severe depression and is one of the oldest forms of electrical stimulation therapy. ${ }^{[7,8]}$ Neural activity can be recorded and modulated with neural probes ${ }^{[9]}$ to stimulate specific neural tissues and restore lost neurological functions ${ }^{[10]}$ by establishing a functional electrical connection. ${ }^{[11]}$ Various types of electrodes, such as intracortical needle electrodes, can interface with tissue and help recover normal neural function in patients with central nervous system (CNS) disorders. ${ }^{[11,12]}$ Nam and colleagues assert that for proper biointegration during electric stimulation, the ideal neural interface material must: 1) couple to neural tissue without inciting damage through physical and chemical compatibility, 2) possess an electric conductivity which enhances signal acquisition, and 3) minimize chronic and acute inflammatory responses through improved biocompatibility. ${ }^{[13]}$

Hydrogels comprise a crosslinked, 3D network of synthetic or natural polymer chains in a hydrating medium. ${ }^{[14,15]}$ Hydrogels which are biodegradable, hydrophilic, biocompatible, as well as those that possess low antigenicity and immunogenicity make these materials promising for neural scaffolds and devices. ${ }^{[16,17]}$ Due to their electrochemical properties, conductive polymers have also garnered interest as an interface for neural probes ${ }^{[18]}$ for their ability to transport ionic and electronic charges while concurrently promoting cell proliferation and adhesion. ${ }^{[15]}$ Electroconductive composites integrate conducting materials into hydrogels to combine the ideal properties of both materials and were first developed in 1991. ${ }^{[19]}$ These electroactive hydrogels are ionically and electrically conductive ${ }^{[20]}$ to enhance the scaffold's electrochemical properties and endow mechanical compliance through high water content. ${ }^{[21]}$ Stimuli responsive electroconductive hydrogels were first developed by Guiseppi-Elie and colleagues as electrochemical biosensors. ${ }^{[22]}$ Electric fields are easy to apply and offer a high degree of tunability for desired outcomes through the control of parameters such as the electric field strength. Since hydrogels undergo reversible changes in volume in response to electric stimuli, these platforms are advantageous as neural tissue engineering substrates. ${ }^{[23,24]}$ Electroresponsive hydrogel implants in the brain therefore have the potential to enable 


\section{WILEY-VCH}

numerous therapeutic applications with tunable electric stimulation schemes to control the release of payloads, promote neural cell growth and differentiation, and serve as a biocompatible and conductive interface for enhancing signal transmission in neural biosensors and electrodes in vivo.

Externally applied electric fields inside the brain tend to be weak and non-uniform when subcutaneous tissue, skull, and skin shunt and redirect current. ${ }^{[25]}$ An ex vivo study conducted by Voroslakos and colleagues indicated that soft tissues and skull shunt approximately $60 \%$ $75 \%$ of the current away from the brain. ${ }^{[4]}$ As such, it is critical to optimize the electric stimulation dosing parameters for specific applications in the brain. For example, the electrode type, size, material, and location of implantation are all important considerations during electric stimulation treatment. ${ }^{[26]}$ The electric waveform, including its shape, frequency, and intensity, as well as the pulse profile and parameters such as duration and amplitudes, are all contributing factors which govern the pattern of current flow in vivo. ${ }^{[26,27]}$ A review on how transcranial direct current stimulation improves physical performance in healthy individuals revealed a high variation in the experimental outcomes across different studies, highlighting a need to systematically standardize the electric stimulation parameters like intensity and duration. ${ }^{[28]}$

Electric stimulation efficacy also largely depends on neural cell geometries, densities, ion channel distributions, and the extent of shunting in the extracellular matrix. ${ }^{[4]}$ Electric stimulation can be regulated by controlling the properties of electroconductive hydrogels to establish uniform electric fields. However, Heo and colleagues note that differences in outcomes may still arise from inherent variations in cellular microenvironments and cell lines employed in studies; it is therefore prudent to further investigate the combinatorial effects of electric fields and substrate properties on neural applications. ${ }^{[29]}$ The results from cell culture and animal model studies can help translate and extrapolate the results to human subjects due to considerable interspecies neural network similarities between animal models and their counterpart human disorders. ${ }^{[30,31]}$ And yet, the responses of different cell lines depend on the electric stimulation parameters employed, highlighting the need yet again to establish standardized electric stimulation methods to better evaluate research outcomes. ${ }^{[32]}$ An added layer of complexity exists, since the design, fabrication, and properties of hydrogels also contribute to the biomedical outcomes of electric stimulation in the brain. ${ }^{[33]}$ 


\section{WILEY-VCH}

This review seeks to address these gaps by conducting a comprehensive review on electroresponsive hydrogels for therapeutic applications in the brain. While Guiseppi-Elie had previously reviewed electroconductive hydrogels, the researcher had focused on biomaterial synthesis, characterization, and a general overview of biomedical applications. ${ }^{[34]}$ More recently, Shi and colleagues reviewed electroconductive natural polymer based hydrogels. ${ }^{[32]}$ However, neither review focused on neural applications and a discussion on direct electric stimulation and its parameters were outside the scope of the papers. Since soft brain tissue and neural signaling require specific mechanical and electrical properties, hydrogels need to be adapted for biological, electrical, and mechanical compatibility with brain tissue. This review paper therefore focuses on research that has applied electric stimulation to electroconductive hydrogels in the brain. The process of electric stimulation in the brain is briefly highlighted. A background on electroresponsive hydrogels and the rationale for using these materials to improve electric stimulation in the brain is also highlighted. Key fabrication techniques to synthesize these composite electroactive hydrogels and the mechanism of electric stimulation through these conductive materials are also discussed. This review identifies four key applications of electroresponsive hydrogels and highlights the consequent advances in controlled delivery of therapeutic agents (Section 6.1), neural stem cell differentiation and neurogenesis (Section 6.2), neural biosensors in vivo (Section 6.3), and neural electrode interfaces in the brain (Section 6.4). A summary of the electroconductive materials used for each key study, as well as the specific electric stimulation parameters, hydrogel electric properties, cell culture or animal model used, and hydrogel biocompatibility are provided. This synthesized information will aid future researchers in identifying and standardizing the optimal electric field parameters and hydrogel materials for specific electric stimulation outcomes in the brain. The challenges in each application, as well as recommendations for future research, are also discussed.

\section{Electric Stimulation in the Brain}

Although bioengineers and electrophysiologists have studied cellular responses to electric fields, ${ }^{[35]}$ the actual mechanism of electric stimulation in the brain is still not well understood. ${ }^{[36]}$ Researchers have postulated that the mechanisms change excitatory and inhibitory functions which alter particular neurotransmitter levels in the brain. ${ }^{[36]}$ To confer therapeutic benefits, electric stimulation procedures are often performed in repetition, implying changes in the CNS require a cumulative effect. ${ }^{[36]}$ The short term plasticity and effect of electric stimulation are purportedly mediated by changes in ion channels and neurotransmitters. ${ }^{[36]}$ Electric stimulation 


\section{WILEY-VCH}

with chronic, repetitive processes can control neuronal networks and their subsequent activation ${ }^{[37]}$ by regulating neurotrophic factors. ${ }^{[36]}$ As an example, deep brain stimulation can be administered repeatedly through surgically implanted electrodes ${ }^{[38]}$ with multiple highly focal contacts that target particular regions of the brain ${ }^{[8]}$ and can decrease resting and postural tremors in Parkinson's disease. ${ }^{[39]}$ To control motor symptoms associated with Parkinson's, the voltage for deep brain stimulation ranges from $2.4-4.4 \mathrm{~V}$, pulse width ranges from $67-138$ $\mu \mathrm{s}$, and frequency from $143-173 \mathrm{~Hz}^{[40]}$

Compared to deep brain stimulation, transcranial electrical stimulation (TES) is minimally invasive. ${ }^{[4]}$ TES places two or more extracranial electrodes on the scalp/skull and uses the potential difference between electrodes to generate a current that accesses the brain without directly contacting neural tissue. ${ }^{[41]}$ TES applies weak electric currents up to $0.8 \mathrm{~A} / \mathrm{m}^{2}$ for 40 minutes per stimulation session to affect glial cells, nerve cells, and vessels. ${ }^{[42,43]}$ The most common TES technique is transcranial direct current stimulation (tDCS), which alters neural activity by applying prolonged and constant weak currents (1 - $2 \mathrm{~mA})$ to hyperpolarize or depolarize neurons and modulate the resting membrane potential and ion channels. ${ }^{[44-46]}$ During tDCS, the degree of polarity, strength, and stimulation determine both the direction and duration of excitability change. ${ }^{[47]}$ Transcranial direct current stimulation can improve verbal recognition memory tasks in Alzheimer's patients ${ }^{[48]}$ and also promote and restore functional balance in stroke patients. ${ }^{[49]}$ Electrically stimulating cranial nerves can also treat neuropsychiatric disorders $^{[26]}$ and neurological disorders, ${ }^{[50]}$ while neuronal activation additionally confers neuroprotective effects by improving blood flow. ${ }^{[51]}$

Although a seminal study by Nitsche and Paulus noted the modulation effects of TES were restricted to the area under the electrode,${ }^{[46]}$ electric stimulation activates neurons in sparsely distributed sets, ${ }^{[52]}$ as TES often fails to uniformly stimulate a cortical region. ${ }^{[53]}$ The modulatory effects of electrical stimulation, such as alterations in neural activity and oscillation entrainment, may therefore occur on a system-wide, global scale neural network level. ${ }^{[54]}$ While most CNS disorders encompass neural networks spanning over wide regions of the brain, ${ }^{[36]}$ it is often prudent to localize treatment to targeted neurons in a region to maximize therapeutic effects and reduce undesired effects on adjacent networks. ${ }^{[4]}$ TES may also produce electric fields too weak to depolarize cortical neurons or generate action potentials. ${ }^{[53]}$ However, increasing TES current further exacerbates issues of non-focality when peripheral stimulation 


\section{WILEY-VCH}

and current distributions to surrounding regions increase. ${ }^{[53]}$ To improve TES focality with strong currents, Grossman and colleagues utilized multi-electrode montages to apply temporal interference stimulation in mice brains. ${ }^{[55]}$ The electric fields from electrodes were shifted slightly in frequency to enable modulation within an envelope by altering the current magnitudes, as illustrated by Figure 1. Even though this stimulation technique can activate neurons without affecting overlying cortical neurons, achieving high spatial resolutions with small focal volumes is still challenging.

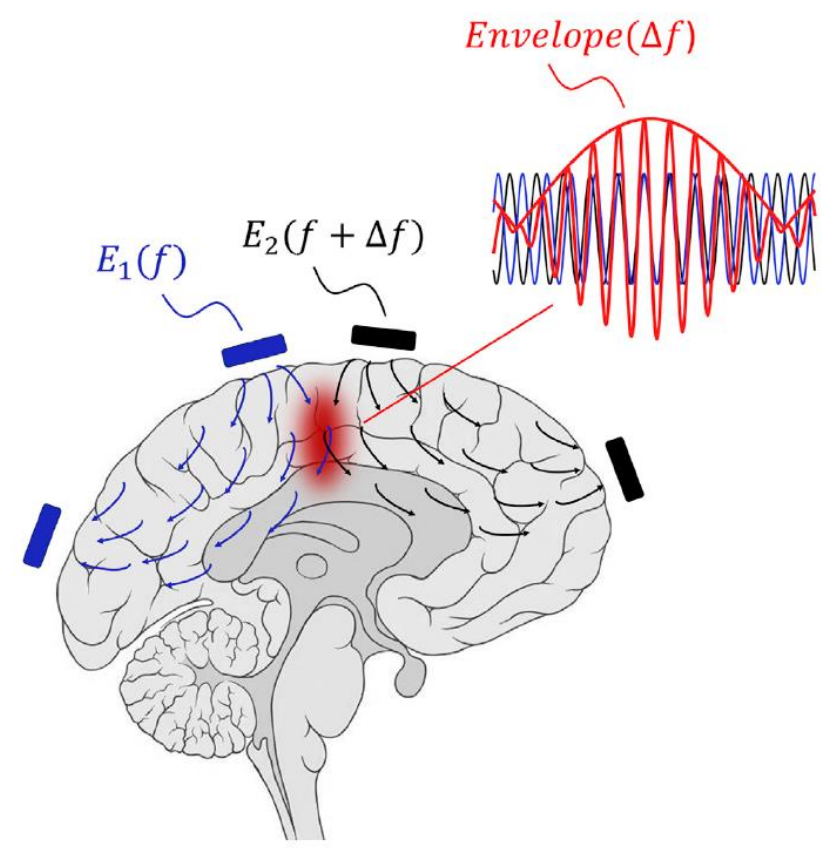

Figure 1. Temporal interference uses depth selectivity to electrically stimulate neurons with multiple electric fields. Reproduced under the terms of the Creative Commons CC-BY license. ${ }^{[55]}$ Copyright 2017, Cell Press.

In addition to electric stimulation, neural probes can also record neuronal firing action potentials for studying neural networks. ${ }^{[56]}$ Neurophysiological monitoring techniques, such as electrocorticography subdural electrodes placed on the surface of the scalp or in the cortex, can map brain function with a high spatial resolution to identify the pathological lesions crucial for diagnosing and treating disorders like epilepsy. ${ }^{[57,58]}$

A major concern with chronic neural electrodes is the elicitation of neuroinflammatory responses, including neuron degeneration and foreign body reactions. ${ }^{[59]}$ Insertion of implants disrupts the blood-brain-barrier and ruptures blood vessels which exacerbate the tissue response, ${ }^{[60]}$ while micromotions proximal to the implant further sustain injuries and inflammatory responses. ${ }^{[61]}$ Serum proteins adsorbed on the probe surface trigger an acute 


\section{WILEY-VCH}

response to activate macrophages and microglia, ${ }^{[11]}$ which secrete reactive oxygen species and lytic enzymes to degrade the foreign material and damage neurons. ${ }^{[11]}$ Astrocytes are also activated when microglia secrete proinflammatory cytokines such as interleukin-6, interleukin1 , and tumor necrosis factor alpha. ${ }^{[62,63]}$ This entire process, known as astrogliosis, increases the number of abnormal, activated, and proliferating astrocytes to form dense glial scars around electrodes (Figure 2). ${ }^{[12]}$ The reactive inflammatory cells and acute edema are eventually replaced by scar tissue when the acute response evolves into a chronic response under the continuous presence of the foreign implant. ${ }^{[1,64]}$ The implant becomes encapsulated with a fibrous capsule comprising vascularized tissue in the outer layer, a concentric fibrous tissue, and an inner layer with macrophages. ${ }^{[65]}$ This glial scar tissue also impairs the electric stimulation and signal recording efficacies ${ }^{[66,67]}$ due to the increased barrier between target neurons and the implant, ${ }^{[11]}$ which acts as an insulation to decrease the charge injection capacity and increase the impedance. ${ }^{[68]}$ For example, Suner and colleagues compared a hundred microelectrodes implanted into the primary motor cortex of monkeys for three months and against implantation for one and a half years. ${ }^{[69]}$ The researchers noted that fibrous encapsulation around the electrode likely led to a loss of function in the neural recording capabilities for both scenarios.

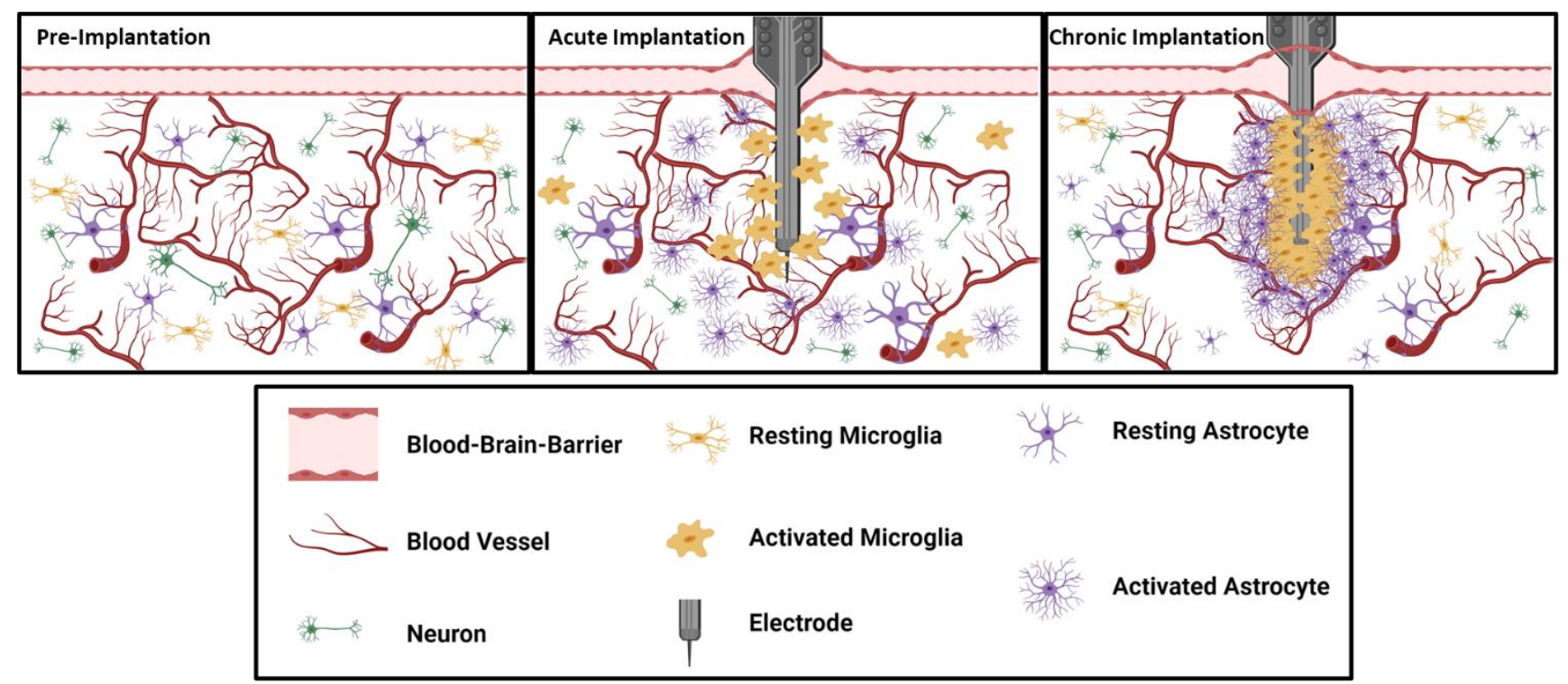

Figure 2. Schematic diagram of astrogliosis and the subsequent glial encapsulation upon insertion of a stiff intracortical electrode in the brain. Implantation of the electrode disrupts the blood-brain-barrier and activates both microglia and astrocytes. The activated microglia and astrocytes migrate toward and surround the probe in response to signaling factors. Over time, these cells encapsulate the electrode and form a glial scar which acts as a barrier and decreases the transmission of electric signals. Created with BioRender.com. 


\section{WILEY-VCH}

For implanted medical devices like cardiac pacemakers and hip replacements, the formation of fibrous tissues can be beneficial by keeping the device anchored in place. ${ }^{[34]}$ However, chronic implantation can hamper neuroprosthetic devices. Oxidative stress events at the tissue-device interface activate chemical redox reactions on the electrode surface, and the formation of reactive oxygen species leads to neuron cytotoxicity and probe corrosion. ${ }^{[70]}$ Electroresponsive hydrogels can minimize these undesired consequences of using electrodes and probes directly on tissues for electric stimulation by establishing uniform electric fields which remain constrained to predetermined regions in the brain. These hydrogels can also minimize the mechanical mismatches that lead to strong inflammatory responses.

\section{Electroresponsive Hydrogels: Synthesis and Common Conducting Materials}

Electroconductive materials such as graphene, carbon nanotubes, and metallic particles enable electric signal transmission between biological systems and neural electric devices. ${ }^{[33,71]}$ Coating electrodes with high surface area nanomaterials can decrease impedances and increase the charge transfer. ${ }^{[72]}$ Yet, these electroconductive materials may elicit a chronic inflammation in vivo, while their robust synthesis processes and lack of biodegradability do not make them ideal as long term implants. ${ }^{[73]}$ Electroconductive polymers address this gap, as they are highly conjugated, possess spatially extended $\pi$ bonds and electroconductivities similar to other conducting materials, and their biocompatibilities are tunable through polymer chain lengths and end groups. ${ }^{[34,71]}$ For example, conductive oligomers are short enough for renal elimination, ${ }^{[71]}$ and modifying the surface of implants with conductive polymers can promote angiogenesis and improve probe sensitivity. ${ }^{[74]}$ However, both in vitro ${ }^{[75]}$ and in vivo ${ }^{[76]}$ studies demonstrate that metal electrodes can cause conductive coatings to delaminate with repeated and long term electric stimulation. Coupled with mechanical friability ${ }^{[77]}$ and a tendency to become brittle, these phenomena eventually lead to loss of the conductive material on the surface. ${ }^{[78]}$ The potential overoxidation of conductive polymers can also produce reactive species ${ }^{[34]}$ which is why these materials alone are not widely used in medical devices. ${ }^{[77]}$

Incorporating electroconductive materials into hydrogels can mitigate some of these issues. Hydrogels have been significant in the biomaterials field since the early 1950s. ${ }^{[79]}$ Upon being hydrated and reaching equilibrium with an aqueous medium, the forces in the hydrogel structure are balanced between a retracting, elastic force and a swelling force arising from the solvation and subsequent expansion of macromolecular chains. ${ }^{[80]}$ The mechanical properties of 


\section{WILEY-VCH}

hydrogels can be varied by controlling the degree of crosslinking and hydration. ${ }^{[34]}$ For instance, the elastic moduli can be customized to mimic soft brain tissues with values near $10 \mathrm{kPa}$ and minimize the mechanical mismatch with metal based neural probes which possess moduli close to $100 \mathrm{GPa} .{ }^{[81,82]}$ The hydration level also impacts surface properties such as wettability and protein adsorption, correlating to biocompatibility in vitro and in vivo. ${ }^{[83]}$ Polymeric hydrogels are ideal for contacting cerebral tissue due to the reduced interfacial tension with their surrounding environment. ${ }^{[16]}$ While traditional electrodes loosely contact the cortex to result in inaccurate neural signals, ${ }^{[84]}$ the reswelling of hydrogel coatings post-implantation allows electrodes to anchor and be adhesive toward brain tissues. ${ }^{[58,65]}$

The bioactivity of electroconductive hydrogels is conferred by a culmination of factors like mechanical properties, hydration, surface chemistry, and surface topology. ${ }^{[34]}$ Hydrogels can act as stretchable ionic conductors, ${ }^{[85]}$ and coatings only minimally impact the electrode's electrochemical properties, since porous structures enable the permeation and absorption of buffer solution and ions to maintain high conductivities. ${ }^{[86]}$ However, He and colleagues report hydrogel coatings insulate the electrodes and can reduce electroconductivity to limit signal transmission. ${ }^{[16]}$ Therefore, hydrogel conductivities ought to be optimized to permit electrical stimulations at lower voltages for better tolerance in vivo. ${ }^{[16]}$

Electroactive hydrogels can incorporate conductive fillers or polymers into the hydrophilic matrix ${ }^{[87]}$ by doping, blending, or introducing chemical modifications ${ }^{[32]}$ to produce $3 \mathrm{D}$ biomimetic structures which increase the electroconductivity and enable charge transfer. ${ }^{[16]}$ Yet, randomly distributed metallic particles in a polymer matrix generally have low durability and are disordered ${ }^{[88]}$ In contrast, hydrogels which develop the electroconductive polymers within the matrix can seamlessly integrate dissimilar polymers in an interpenetrating network, thereby reducing the brittle friability and mechanical stiffness by an order of magnitude without compromising electrochemical properties. ${ }^{[21,89]}$ Unlike the inorganic nature of metals and semiconductors, the organic properties of conductive polymers promote favorable interactions with the biological environment. ${ }^{[34]}$ Since both polymer constituents are stimuli responsive, they can be crosslinked, copolymerized, and/or grafted as hybrid hydrogels, where the hydrogel may serve as the dominant and continuous constituent for polymerizing conductive polymers or vice versa, where the conductive polymer serves as the dominant and continuous constituent for polymerizing the hydrogel. ${ }^{[34]}$ 


\section{WILEY-VCH}

Hydrogels more commonly serve as the dominant component and backbone of electroconductive hydrogel composites. ${ }^{[34]}$ Compared to natural hydrogels, synthetic hydrogel production entails low costs and a high degree of control during synthesis, which allows the mechanical properties, degradation rates, chemical compositions, and structures to be reproducible. ${ }^{[90]}$ The absence of biological impurities in these hydrogels also lowers the risk of acquiring an immune response. ${ }^{[90]}$ Poly(ethylene glycol), or PEG, hydrogels are commonly used to develop 3D neural networks ${ }^{[91]}$ and serve as a biocompatible coating layer on the surface of microelectrode arrays. ${ }^{[92]}$ On the other hand, poly(vinyl alcohol), or PVA, is a nondegradable poly hydroxyl polymer under most physiologic conditions ${ }^{[93]}$ and is often used in tissue engineering for its mechanical strength. ${ }^{[94]}$ The most widely patented, commercialized, and researched polymers for biomedical applications are hydrogels containing polyhydroxyethylmethacrylate (pHEMA), which have hydration levels similar to brain tissue when swelled with $40 \%$ water content, are easy to sterilize by autoclaving, and are hydrolytically stable. ${ }^{[95,96]}$

Natural carbohydrate polymers are also used as hydrogel backbones due to their biodegradability, biocompatibility, and tunability. ${ }^{[71]}$ These polysaccharide polymers possess long monosaccharide segments bonded together with glycosidic bonds, similar to glycoproteins. ${ }^{[71]}$ For example, alginate can crosslink ionically, model neural tissue, and is favored due to its low cytotoxicity and ability to gel under mild conditions. ${ }^{\left[{ }^{97-99]}\right.}$ Hyaluronic acid (HA) is a polyanionic polysaccharide in the extracellular matrix of the brain, and its lack of immunogenicity makes it an ideal backbone for grafting conductive copolymers into the coatings of neural probes. ${ }^{[12]}$ The solubility of these natural polymers in aqueous solutions eases the fabrication of conductive hydrogels. ${ }^{[100]}$ Since these polymers possess an abundance of functional groups like amine, amino, hydroxyl, and carboxyl in their molecular chains, these materials have high hydrophilicities that are ideal for synthesizing hydrogels. ${ }^{[101]}$

Polypyrrole (PPy) is widely studied as a conductive polymer for its high electroconductivity, low oxidative potential, and aqueous solubility of its monomers. ${ }^{[102]}$ It decreases the distance mobile charge carriers must traverse prior to electron transfer and enhances biocompatibility by reducing biofouling, which is associated with protein adsorption and an immune response. ${ }^{[103,104]}$ Among the various conductive polymers, polyaniline (PANI) also possesses intrinsic electroconductive properties. ${ }^{[105]}$ Since PANI undergoes reversible redox reactions to 


\section{WILEY-VCH}

exist in three oxidative states, it is an ideal material for scaffolds which require switchable properties between resistive and conductive states upon electric stimulation. ${ }^{[106]}$ Compared to PPy, poly(3,4-ethylenedioxythiphene), or PEDOT, is touted for its superior electrochemical stability $^{[107]}$ and is often synthesized with PANI under aqueous conditions to yield dual conduction of ions and electrons to reduce impedances when interfacing with biological systems. ${ }^{[108]}$ Poly(3,4-ethylenedioxythiphene) polystyrene sulfonate (PEDOT:PSS), a mixture of the polymers PEDOT and polystyrene sulfonate (PSS), is also known for endowing electrical properties and chemical stability through direct interactions with cells compared to other electroactive polymers. ${ }^{[109]}$ In fact, Javadi and colleagues assert PEDOT:PSS is the most promising conductive polymer and is employed in hybrid systems for its high conductivity, good processability, and dispersibility in polar solvents. ${ }^{[110]}$ Overall, conducting polymers such as PPy, PEDOT, PANI, and PSS have been used to develop electroconductive hydrogels for applications as neural interfaces in electrodes, ${ }^{[92]}$ bioelectronics and biosensors, ${ }^{[111]}$ and neural tissue engineering scaffolds. ${ }^{[112]}$

Carbon nanotubes (CNTs) are highly stable conducting fillers in hydrogels, possessing an electroactivity and chemical inertness that do not change with the environment or time, and have been used in biosensors, tissue scaffolds, and neural devices. ${ }^{[16]}$ These electroactive materials are also highly flexible and resemble neural tissue when rolled in layers of $\mathrm{sp}^{2}$ bonded carbon atoms. ${ }^{[13]} \mathrm{CNT}$ coatings on neural devices have been demonstrated to increase charge transfer, decrease impedance, and enhance the neural recording both in vitro and in vivo, ${ }^{[114]}$ while their interactions with neural cells further improve signaling and cellular communication upon electric stimulation. ${ }^{[113]}$ In fact, incorporating CNTs can increase the electroconductivity by a factor of 100,000 compared to hydrogels comprising only polysaccharide polymers such as nanocellulose. ${ }^{[115]}$

Graphene is another carbon-based conducting filler that was first isolated from graphite in 2004 with a facile synthesis process and comprises a thick layer of single $\mathrm{sp}^{2}$ hybridized carbon atoms in a 2D honeycomb lattice structure. ${ }^{[98,116,117]}$ While graphene sheets display high in-planar electric conductivity, their trans-planar conductivity decreases with low graphene loading, and the charge transfer efficiency between sheets is further limited by the matrix material. ${ }^{[110]}$ However, its thermal conductivities and electron mobilities are comparable to metals, ${ }^{[18]}$ as the large aspect ratio and high surface area of graphene fillers impart excellent electrical conducting properties to composites. ${ }^{[119]}$ The antibacterial properties make graphene and its derivatives 


\section{WILEY-VCH}

particularly attractive for biomedical applications ${ }^{[120]}$ such as drug delivery systems and biosensors $^{[121]}$, as well as in gene vectors and bioelectrodes. ${ }^{[117]}$ Since it is impractical to develop hydrogels with graphene alone, ${ }^{[122]}$ graphene derivatives like graphene oxide or reduced graphene oxide are usually integrated with polymers. ${ }^{[98,123]}$ As an example, graphene oxide can enhance interactions with mammalian cells, microbials, and proteins at the interface, making them ideal for biological platforms. Qiao and colleagues systematically investigated the effect of graphene oxide on their polyacrylic acid hydrogels and found that increasing the concentration of graphene oxide affected the hydrogel electroconductivity and physical properties such as porosity, mechanical characteristics, and color. ${ }^{[24]}$ Hence, it is important to optimize the hydrogel fabrication process and compositions to tune properties toward desired electroresponsive behavior and cellular interactions. This optimization step is especially critical to tailor electroresponsive hydrogels toward specific biomedical applications in the brain to impart desirable therapeutic outcomes.

\section{Fabricating Electroresponsive Hydrogel Composites for Neural Interfaces}

It is difficult to homogeneously integrate conductive materials into hydrogel matrices and allow dissimilar materials to occupy the same volume ${ }^{[124]}$ with both electrical and chemical stability. ${ }^{[90]}$ The most common method for coating neural probes is to electrochemically deposit conductive materials into a preformed hydrogel matrix ${ }^{[89]}$ and add anionic dopant molecules such as PSS ${ }^{[102]}$ or CNTs. ${ }^{[125]}$ Doping confers a charge transfer in the matrix through either oxidation or reduction to produce unbound, charged carriers. ${ }^{[22]}$ During polymerization, the mobile dopant molecules diffuse to ensure a charge balance, ${ }^{[89]}$ while the ratio of dopant molecules to conductive monomer units is maintained between 0.2 to 0.4 to guarantee that one out of every three or four monomers contains the dopant. ${ }^{[126,127]}$ However, mobile dopants poorly integrate the conductive polymer into the hydrogel matrix, and most composites eventually separate with only partial interpenetrating networks. ${ }^{[89]}$ Green and colleagues developed a method to improve integration by chemically attaching dopants into the hydrogel to force the conductive polymer to grow along with the hydrogel polymer network when forming the interpenetrating system. ${ }^{[128]}$ In alternative designs, Gorman and colleagues also developed micropatterned thiol self-assembling monomers, ${ }^{[129]}$ while Zhou and colleagues developed pHEMA brushes as templates for PPy electrodeposition. ${ }^{[130]}$ 


\section{WILEY-VCH}

The type of dopant is an important consideration, since it impacts the biomaterial's electrical, mechanical, and biological properties. ${ }^{[33]}$ Although hydrogels' bioactive dopants can endow biofunctionality to boost cellular interactions, ${ }^{[131]}$ most bioactive dopants are large molecules such as fragments of peptides or proteins $(1-23 \mathrm{kDa})$ that reduce the hydrogel cohesion and increase the delamination, mechanical friability, and degradation. ${ }^{[78,132]}$ Baek and colleagues noted that large dopant molecules generated hydrogels with higher stiffnesses and a tendency to undergo brittle failure due to limited electrodeposition efficiency. ${ }^{[133]}$ On the other hand, dual doping can help alter charge densities in a concentration dependent manner and improve molecular conformations. ${ }^{[131]}$ Compared to single dopant molecules, when PANI is doped with both p-toluenesulfonate and sulfuric acid, certain molar ratios of the co-dopants synergistically improve the electroconductivity. ${ }^{[134]}$ Since dopants impact the hydrogel performance, future research should develop new dopants to improve the electrochemical, mechanical, and biological properties of electroconductive hydrogels. ${ }^{[135]}$ The chemical structures of common electroconductive polymers and the doping mechanism of PEDOT are illustrated by Figure 3A.

The most popular method for fabricating electroconductive hydrogels is chemical oxidative polymerization of the conducting polymer within the hydrogel network, ${ }^{[34]}$ as illustrated by Figure 3B. An oxidant initiates the synthesis of the conductive monomers, which are concurrently integrated with non-conducting hydrogel components as anionic dopant molecules. ${ }^{[34]}$ Compared to traditional methods, the alternative interfacial polymerization technique is more effective and economical, since electroactive polymers form at the interface of the water or organic solvent and permeate into the hydrogel matrix spontaneously. ${ }^{[136]}$ In contrast, acrylate chemistry is often preferred for coating implantable devices, as polymerizing the hydrogel networks with heat or ultraviolet light is facile. ${ }^{[104]}$ Crosslinking and grafting reactions can combine conductive polymers with natural polymers, such as proteins (gelatin and collagen) and polysaccharides (alginate, chitosan, hyaluronic acid, and cellulose). ${ }^{[32,137]}$ In all cases, it is important to regulate monomer concentrations to control hydrogel characteristics such as solvent swelling dynamics, mechanical and physical properties like rigidity and strength, hydration, and responses to stimuli such as the temperature, $\mathrm{pH}$, or electric field. ${ }^{[104]}$ For CNTs, a two-step method can grow high density single walled carbon nanotubes (SWNTs) in the substrate for subsequent transfer to the hydrogel surface through immobilization. ${ }^{[138]}$ Although unconstrained CNT growth can harm cells with their high aspect ratios and any accumulation may damage tissues and vital organs, entrapping CNTs into hydrogel matrices can overcome 


\section{WILEY-VCH}

these limitations. ${ }^{[139]}$ PEG-based hydrogels containing well dispersed CNTs have displayed high neural viability, reduced stiffness, and high electric conductivity. ${ }^{[140]}$

(A) polystyrene sulfonate (PSS)
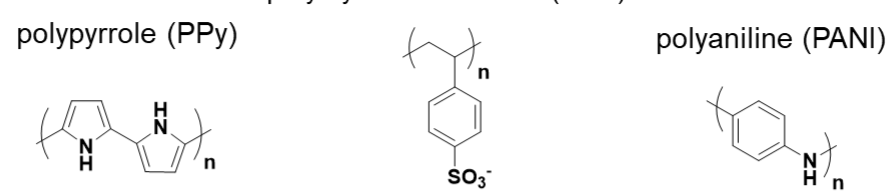

Doping mechanism of poly(3,4-ethylenedioxythiphene) (PEDOT)

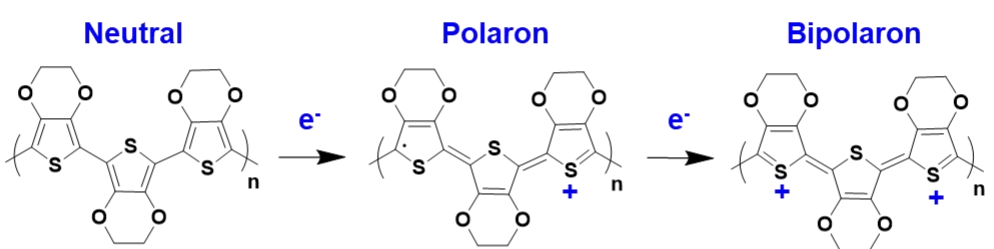

(B)

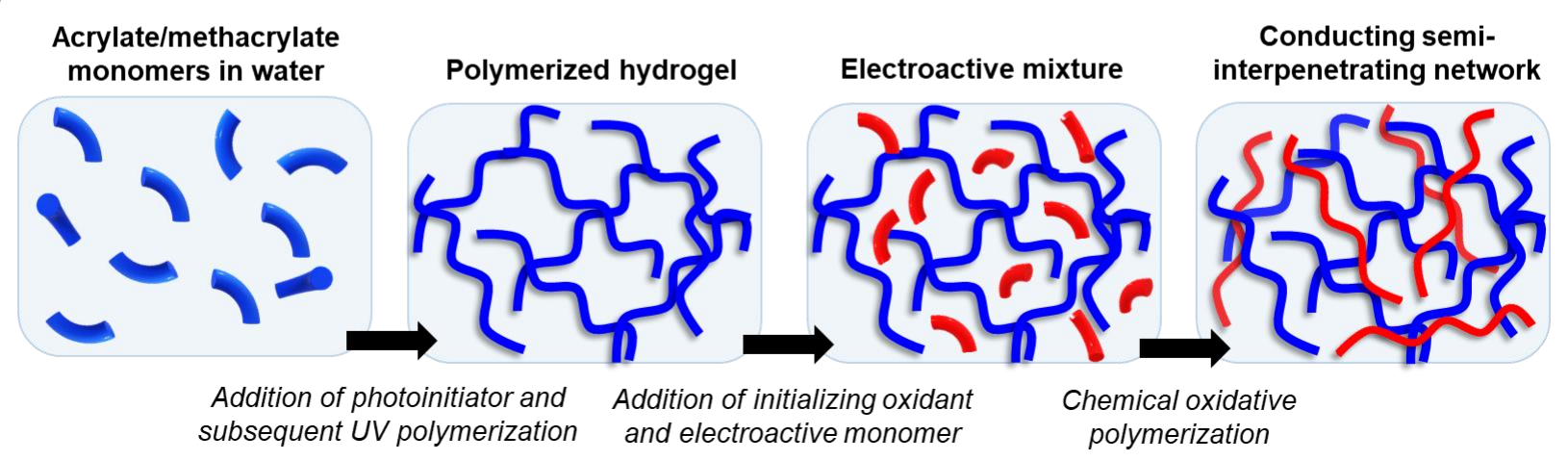

Figure 3. Overview of common conducting polymers and methods for synthesizing electroresponsive hydrogels. (A) Chemical structures of common electroconductive polymers and the doping mechanism of poly(3,4-ethylenedioxythiphene) (PEDOT). (B) Generalized schematic of chemical oxidative polymerization.

In certain cases, the hydrophilic and anti-fouling properties of electroconductive hydrogels prevent cell attachments, ${ }^{[141]}$ which can be mitigated by functionalizing hydrogels with molecules such as gelatin and sericin to promote neuronal attachment and growth. ${ }^{[142]}$ As such, hydrogels can be modified post-fabrication with chemical functionalization ${ }^{[143]}$ and surface modifications to strengthen bonding and covalent interactions between hydrogels and neuroprosthetic devices. ${ }^{[34]}$ These modifications can direct the responses of hydrogels to electric fields and guide their interactions with surrounding cells. Furthermore, functionalization can develop biomimetic matrices to recapitulate the brain neural microenvironment and enhance neural cell survival, as demonstrated by Sarkar and colleagues' neuroprotective, self-assembled hydrogel to treat traumatic brain injury. ${ }^{[144]}$ 


\section{WILEY-VCH}

\section{Electric Stimulation in Electroresponsive Hydrogels}

Electric fields applied to ionizable polymers can electrochemically modulate the hydrogel swelling and deswelling behavior. ${ }^{[34]}$ Direct current voltages produce stress gradients in the hydrogel environment and change the local $\mathrm{pH}$ when electrolysis, electrophoresis, and electroosmosis occur together. ${ }^{[145]}$ This electrical potential difference expels water and causes the hydrogel structure to deswell and collapse, subsequently leading to the electrophoretic transportation of mobile counterions and hydrated molecules. ${ }^{[32,34]}$ Even when hydrogels in an aqueous environment are subjected to electric fields, the changes in the electric field polarity induce an asymmetric ion distribution to generate an osmotic pressure difference, which alters the hydrogel physical dimensions for it to bend, expand, and shrink. ${ }^{[32,146]}$ An increased osmotic pressure elevates the internal ion concentration and causes hydrogels to swell, ${ }^{[24]}$ while deswelling occurs when the external ion concentration increases due to a decrease in the osmotic pressure. ${ }^{[24]}$ The electroosmotic, electrostatic, electrorestrictive, and electrophoretic interactions within hydrogels therefore impact their electroresponsive behaviors, which are further influenced by hydrogel properties like the extent of crosslinking and charge density, as well as electric stimulation parameters like the voltage. ${ }^{[24]}$ Hence, tunable hydrogel properties such as porosity, mechanical strength, electroconductivity, and degradation can be coupled to electric stimulation parameters to tailor hydrogel electroresponsive behaviors toward specific neural applications in the brain. A summary of tunable hydrogel parameters and the hydrogel properties they impact is provided by Figure 4. 


\section{WILEY-VCH}

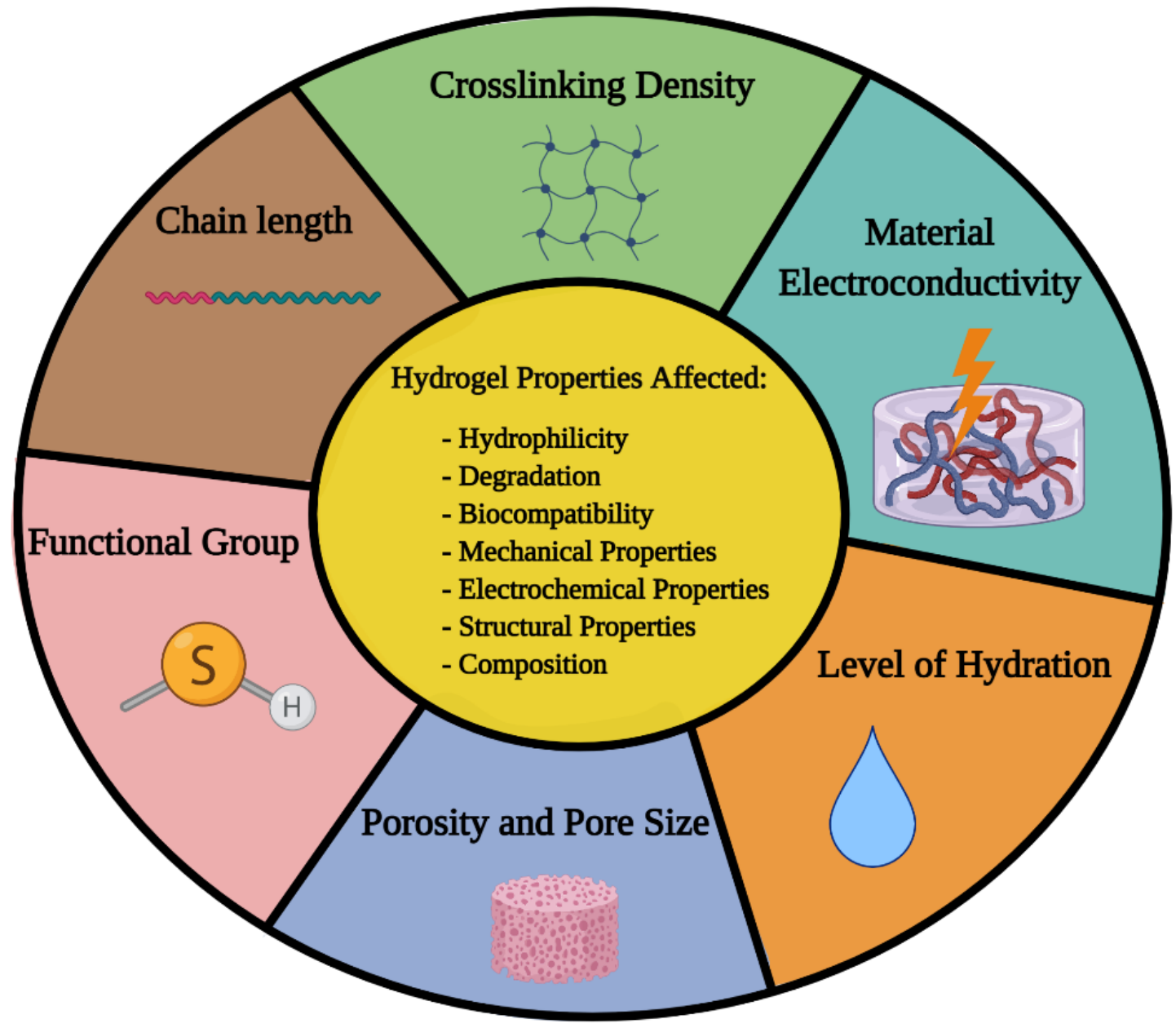

Figure 4. Overview of hydrogel parameters which can be varied and tuned to control different hydrogel properties. Created with BioRender.com

\section{Applications of Electroresponsive Hydrogels}

The subsequent sections of this review highlight advances in electrical stimulation of electroresponsive hydrogels in the brain. Specifically, the four key applications focus on controlling the release and delivery of therapeutic payloads, directing neural stem cell differentiation and neurogenesis, and enhancing neural interfaces for biosensors and neural electrodes (Figure 5). The importance of using electroresponsive hydrogels for each application is highlighted, followed by a discussion on key tunable parameters in the hydrogel for the target application, as well as an overview of the state of the field and key challenges in the area. A table summarizing the electric field parameters, hydrogel material and electrochemical properties, cells/animal models, and outcomes for each study are provided to help researchers derive trends and optimize the parameters for specific applications. 


\section{WILEY-VCH}

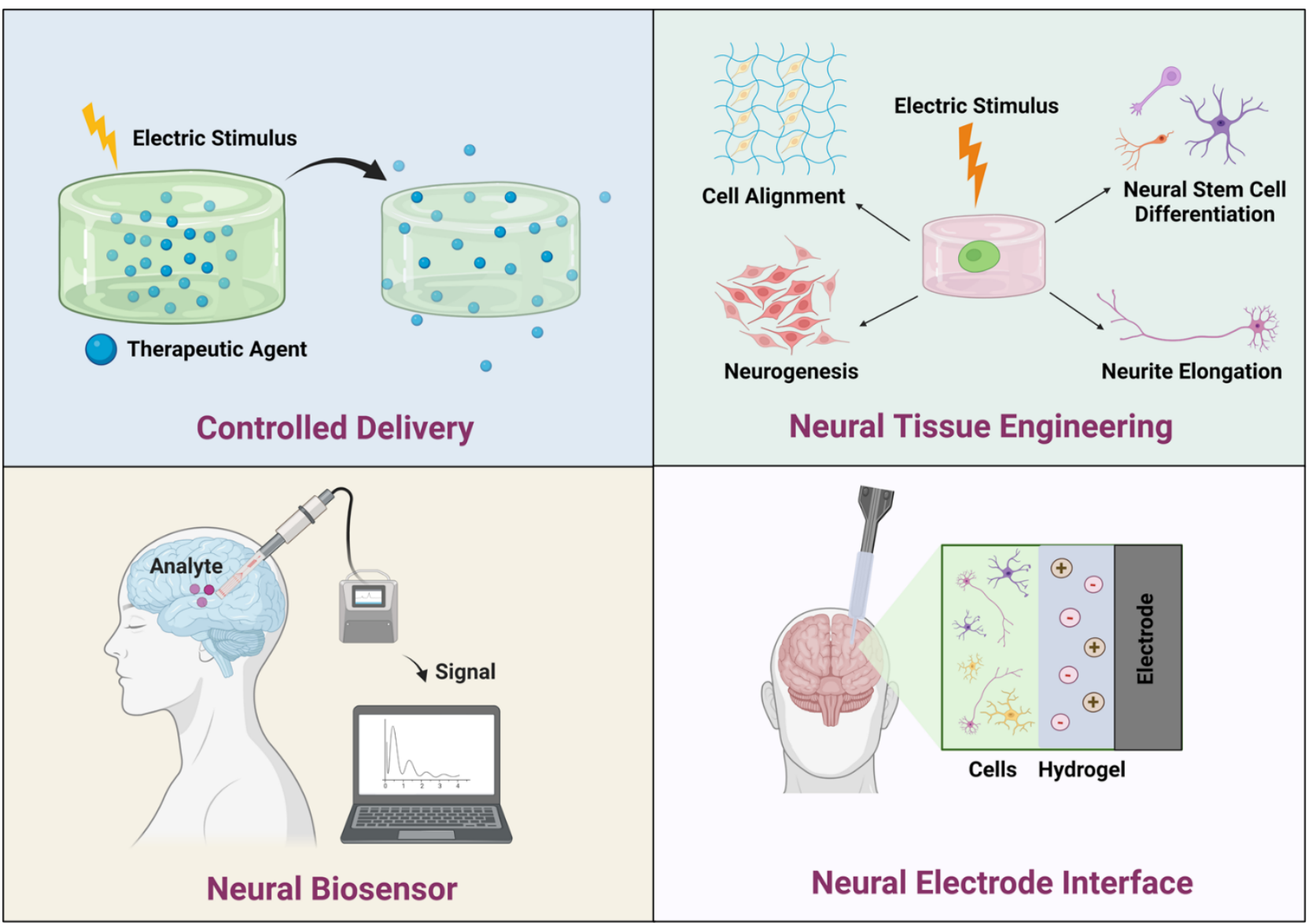

Figure 5. Applications for electrically stimulating electroresponsive hydrogels. Created with BioRender.com

\subsection{Controlled Delivery}

The blood-brain-barrier (BBB) is an interface between neural tissues and blood ${ }^{[147]}$ composed of endothelial cells, astrocytes, pericytes, neurons, and tight junctions interacting together. ${ }^{[148]}$ Its selectivity is an obstacle for delivering drugs to the brain, as for example, approximately $99 \%$ of chemotherapeutic drugs in development are unable to cross the BBB to treat brain cancer. ${ }^{[147]}$ To address this gap, transcranial focused ultrasound can be employed in conjunction with a systemic injection of microbubbles to permeabilize the BBB and enable drug delivery, although temporal control with this method is difficult, ${ }^{[149]}$ the peripheral immune response is activated, ${ }^{[150]}$ and microbubbles fail to sustain a uniform bubble cloud beyond tens of pulses. ${ }^{[151]}$ In another approach, electric fields can apply high-frequency electroporation to spatiotemporally modulate the $\mathrm{BBB}$ disruption to enable drugs to enter and accumulate in the brain. ${ }^{[152,153]}$ However, neither technology can regulate a pulsatile or sustained drug release, nor is drug delivery targeted to specific tissues, since the therapeutic agents are administered systemically to cross the BBB. This problem can be circumvented by using a biomaterials approach to load hydrogels with therapeutic agents at high efficiencies ${ }^{[154]}$ and implanting the 


\section{WILEY-VCH}

materials in situ to localize drug release at specific sites. ${ }^{[155]}$ The highly porous nature of hydrogels allows them to absorb water solubilized agents, and the storage volume capacity enables them to act as reservoirs for drug delivery through passive diffusion. ${ }^{[90,96]}$ When the hydrogels carrying therapeutic agents are implanted in the target tissue, the concentration gradient leads to the outward diffusion of the agent and dispersion into the environment. ${ }^{[96]}$ Hydrogels also protect their payloads from enzymatic degradation in vivo. ${ }^{[105]}$ While physical stimuli such as light, temperature, sound, magnetism, and pressure can modulate the release, electric stimuli are particularly advantageous for controlling delivery. ${ }^{[121]}$

\subsubsection{Key Tunable Parameters and Properties}

Electroresponsive hydrogels can control the quantity and duration of drug release using electric stimuli. ${ }^{[105]}$ Conductive polymers possess redox-switching properties which allow small molecules to move in and out of the hydrogel in response to electric stimuli, ${ }^{[125]}$ while release profiles can be tuned by controlling electric field parameters such as duration, frequency, and strength. ${ }^{[121]}$ The electric field changes the polarity and ruptures the hydrogel matrix, ${ }^{[156]}$ as the directional movement of ions due to the voltage and osmotic pressure causes the hydrogel to contract, deform, and release the agents. ${ }^{[157,158]}$ The hydrogel pore size is an important property for controlling delivery, since it regulates the swelling and deswelling characteristics during the hydrogel's response to an electric field. ${ }^{[121]}$ Furthermore, optimizing electric stimulation parameters may enable a pulsatile release profile by switching the electric field on or off for a high degree of on-demand control to suit patient specific needs. ${ }^{[121]}$ A sustained release from hydrogels may also be beneficial to reduce the frequency with which drugs need to be administered in a clinical setting. ${ }^{[159]}$

\subsubsection{State of the Field}

Although electric stimulation may be applied with invasive electrodes, electroconductive hydrogels can also respond to endogenous electric fields during the onset of abnormal neural activity. For example, an epileptic seizure is unpredictable ${ }^{[160]}$ and leads to irregular synchronous neural electrical activity. ${ }^{[161]}$ Conventional lipophilic antiepileptic drugs such as phenytoin sodium (PHT) are preventive measures and cannot control the onset of epilepsy. ${ }^{[159 \text {, }}$ 161] In order to address this issue, Ying and colleagues developed brain targeting electroconductive hydrogel nanoparticles small enough to pass through the BBB and release the loaded PHT in response to endogenous electric fields produced by an epileptic seizure. ${ }^{[159]}$ Angiopep-2 peptides (ANG) with an affinity for brain tissue ${ }^{[162]}$ were conjugated to the 


\section{WILEY-VCH}

nanoparticle surface, while PHT drugs were encapsulated inside (Figure 6A). The PHT release was rapid and sustained for 24 hours in vitro when subjected to currents from $50-500 \mu \mathrm{A}$, a range corresponding to $5-50 \mathrm{mV} / \mathrm{m}$ and similar to endogenous electric fields during a seizure when potentials can reach $20 \mathrm{mV} / \mathrm{m}$. Even though background PHT release did occur without electrical stimulation, the cumulative passive release was significantly lower than during stimulation.

Wang and colleagues ${ }^{[161]}$ performed a follow up study by varying the nanoparticle polymer concentrations and assessing the seizure-triggered release of PHT with three different induced seizure rat models. ${ }^{[163]}$ The PHT release concentrations correlated with the severity of the epileptic seizure, demonstrating that the nanoparticle's electroresponsive behavior depended on the electric field potential. Compared to controls, an increase in PHT release was observed in the conjugated nanoparticles due to the targeted delivery conferred by ANG ligands ${ }^{[162]}$, while their PEGylation and small size prolonged circulation in the bloodstream. ${ }^{[163]}$ The hydrogel electroresponsive behavior and conductivity also correlated with the concentration of poly(sodium 4-vinylbenzene sulfonate) in the hydrogel, since it accelerated the ionization of sulfo groups.

In addition to endogenous electric fields, electroresponsive hydrogels can enable pulsatile drug release with electric stimulation. Servant and colleagues previously developed poly(methacrylic acid) based hydrogels containing pristine multiwalled carbon nanotubes (pMWNT) capable of on-demand drug delivery, and yet, repeated electric stimulation eventually damaged the matrix structure with each cycle. ${ }^{[164]}$ The researchers recently addressed this issue with a hydrogel platform comprising well dispersed graphene sheets to release drugs in a pulsatile manner upon electric stimulation due to reversible deswelling, as indicated by Figure 6B. ${ }^{[121]}$ Unlike pMWNTs, which aggregate during polymerization, graphene displays better dispersion and homogeneity, thereby conferring flexibility and enhancing hydrogel mechanical properties. Compared to pMWNT, these graphene hydrogels also possessed a lower bulk resistivity and allowed a lower voltage to incite the same level of drug release. Radiolabeled ${ }^{14} \mathrm{C}$-sucrose were loaded into the hydrogel to model small hydrophilic agents and implanted into the upper dorsal region of CD-1 mice. Upon electric stimulation, a pulsatile release profile was obtained, with the mice incurring significantly less damage to the skin than the control groups without the hydrogel, indicating that graphene improved the biocompatibility. 


\section{WILEY-VCH}

Graphene also reduced resistive heating and decreased the likelihood of high, necrotic tissue temperatures during chronic electric stimulation regimes.

(A)

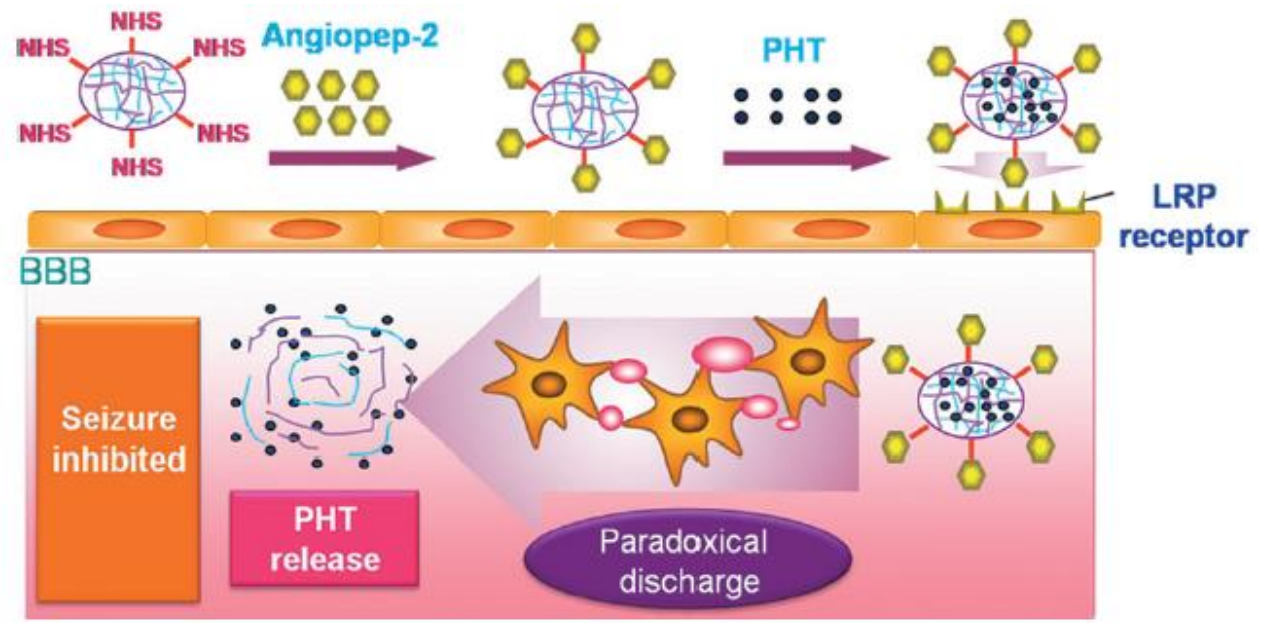

(B)
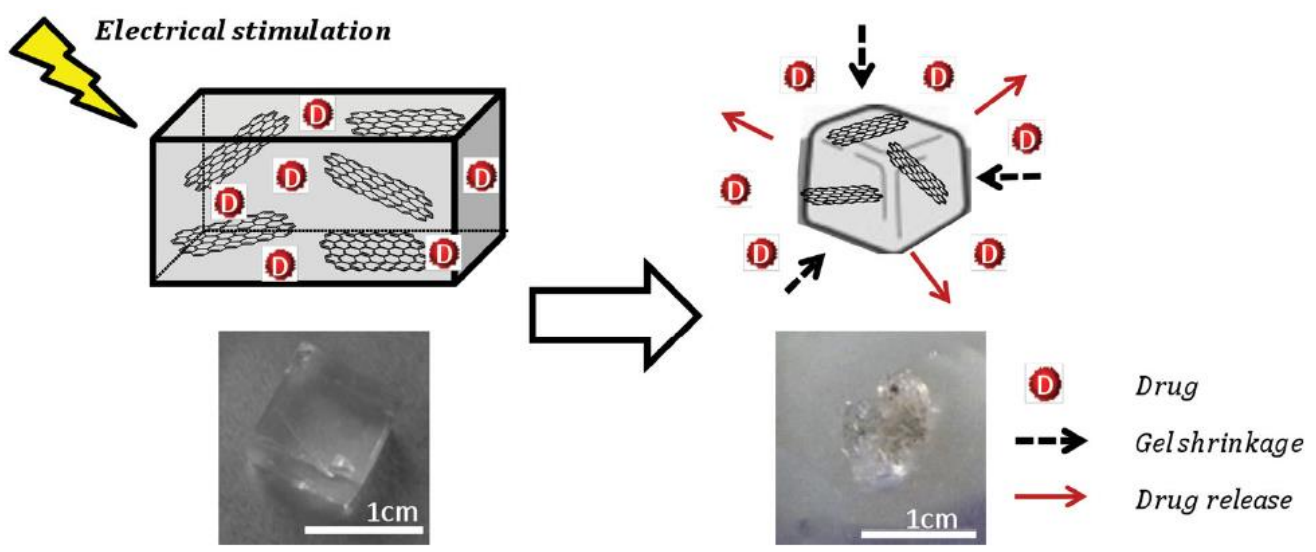

Figure 6. Controlled delivery of drug payloads from electroresponsive hydrogels with endogenous and externally applied electric fields. (A) Electroresponsive hydrogel nanoparticle loaded with PHT drug and modified with brain targeting angiopep-2 ligand for antiepileptic treatment. Reproduced with permission. ${ }^{[159]}$ Copyright 2014, John Wiley and Sons. (B) Application of direct current electric field induces the pulsatile release of drug payloads from hydrogel with ON/OFF switchable capability due to reversible deswelling of hydrogel matrix. Adapted with permission. ${ }^{[121]}$ Copyright 2014, John Wiley and Sons.

Multifunctional electroresponsive hydrogels can be used for synchronous, multistep treatment processes. Alizadeh and colleagues developed a carbohydrate-based cyrogel which simultaneously promotes the differentiation of mesenchymal stem cells into dopaminergic neurons and possesses on-demand electroresponsiveness. ${ }^{[71]}$ After loading the hydrogels with the anti-inflammatory drug Dexamethasone (DEX) and applying an electric field of $0.5 \mathrm{~V}$, DEX release with an on-off pattern was demonstrated. Although DEX electrostatically interacted with aniline pentamer in the hydrogel to decrease the initial burst release due to the 


\section{WILEY-VCH}

repulsion forces present in the media, the passive release of DEX without electric stimulation was still continuously prevalent in accordance with the Kosmeyer-Peppas model, since the polymer chains displayed rubbery behavior with increasing mobility. ${ }^{[165]}$ The regenerative capacity of the scaffold was evident when primary olfactory ecto-mesenchymal stem cells were cultured in a monolayer on the hydrogel. These cells differentiated into dopaminergic neurons under neurotrophic factors with improved proliferations on the 3D hydrogel system. Hence, this platform can potentially act as a functional substrate and source of dopaminergic neurons to treat neurodegenerative disorders.

Huang and colleagues also developed a multi-stimuli responsive, implantable neural optoelectrode coated with a hydrogel gene loaded platform (Figure 7A). ${ }^{[17]}$ Electrical stimulation invoked on-demand delivery of nonviral gene vectors for transfection into target neurons by electroporating the hydrogel coating, while the subsequent expression of these optogenetic plasmids modulated neural activity upon optical stimulation. Alternative current pulses ranging from $125-500 \mu \mathrm{A}$ were applied to investigate DNA release, and the average cumulative release increased with current (Figure 7B). These optoelectrode probes were inserted into mice and subjected to $250 \mu \mathrm{A}$, a current shown by the researchers to promote gene transfection in the mouse brain. Photoevoked neural activities illustrated that this multi-stimuli responsive system can synchronously monitor neural electrical signals through a single implantation without necessitating additional surgeries. 
(A)

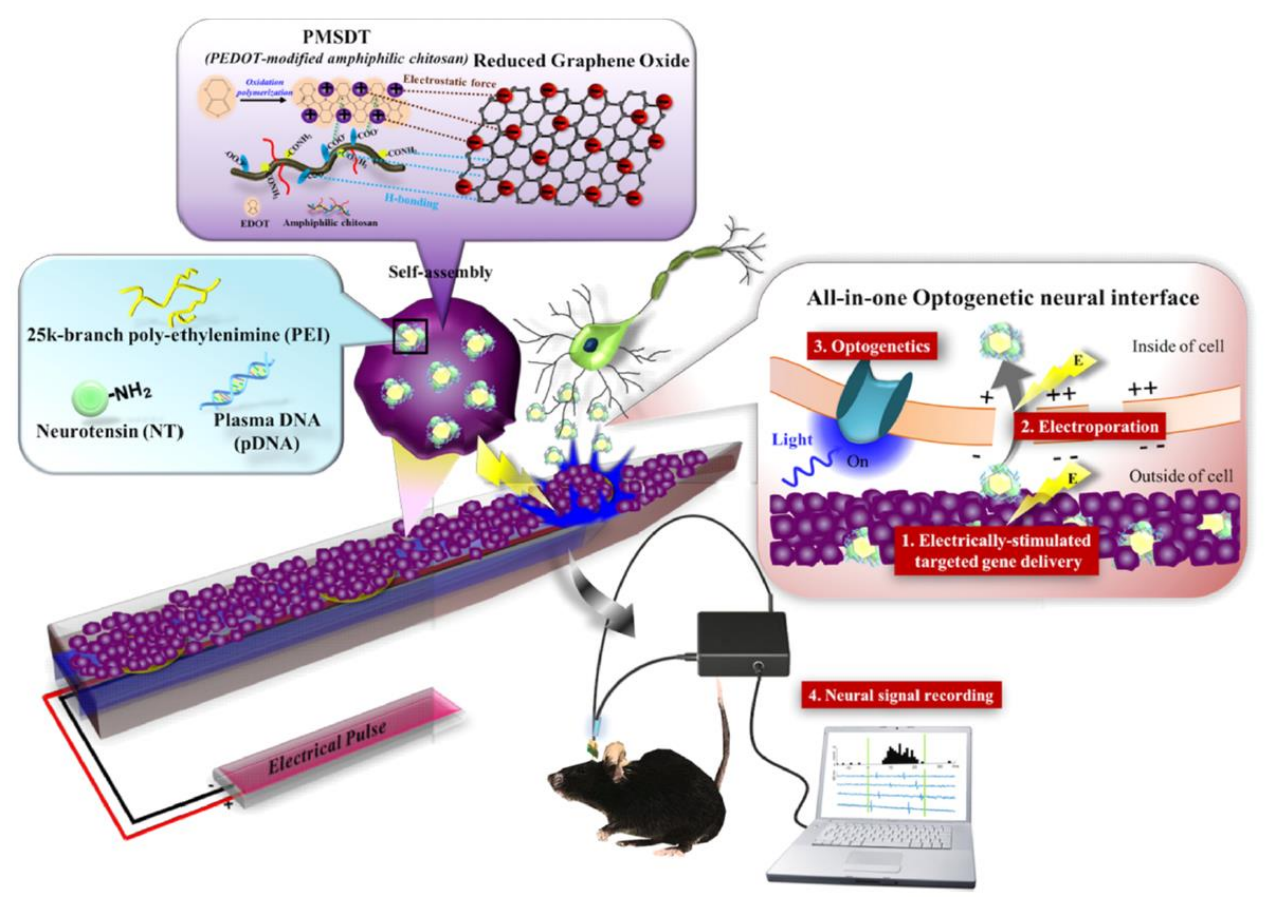

(B)

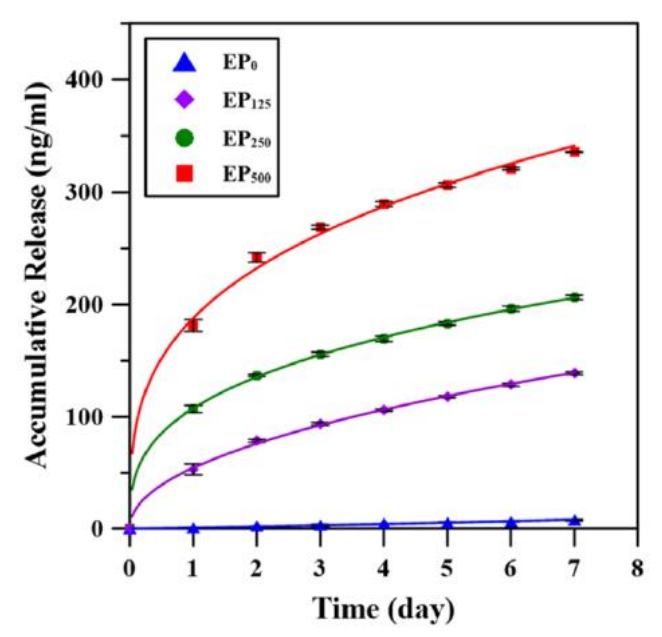

Figure 7. Multifunctional and electroresponsive hydrogel coated neural probe for controlled and targeted gene delivery, neural signal recording, and optoactivated gene transfection. (A) Schematic representation of gene-embedded bioelectrodes on a neural implant. (B) Average cumulative release of plasmid DNA from the neural implant with electroporation at current intensities of $0,125,250$, and $500 \mu \mathrm{A}$. Reproduced with permission. ${ }^{[117]}$ Copyright 2019, American Chemical Society.

To circumvent the BBB altogether, Akilo and colleagues developed an injectable mucogel for nose-to-brain delivery of therapeutic agents through the direct passage between the nasal mucosa and the CNS. ${ }^{[105]}$ The researchers developed fifteen different hydrogel formulations by systematically varying the concentration of the thermosensitive Pluronic F127 polymers, chitosan, and PANI, while hydroxypropyl methylcellulose (HPMC) concentrations remained 


\section{WILEY-VCH}

constant. The release profile upon electric stimulation was pulsatile with on-off switchable characteristics, while the passive release was mitigated with mucoadhesive HPMC polymers and chitosan slowing the payload release.

\subsubsection{Key Challenges}

One of the biggest challenges associated with controlling delivery from hydrogels is the passive release of the agents without electric stimulation. Whether the passive release is sustained and continuous with slow elution or follows a more rapid burst release profile, it hinders the ondemand delivery of therapeutic agents. The interaction between the hydrogel components and materials is critical, as enhanced entrapment can ensure the molecules do not escape unless an electric field affects the polymer matrix structure. Hence, it is important to optimize the interactions between the conducting materials, polymers, and the payloads. Strategies to mitigate the passive release of payloads from electroresponsive hydrogels are highlighted in Section 7.1. A summary of the hydrogel material components, the payload and their corresponding release profiles, electric stimulation parameters, cell culture or animal models, and the resulting outcomes from each of the studies discussed is provided by Table 1. As is evident from the table, the electric field parameters for the studies reported ranged from $0.5 \mathrm{~V}$ $-10 \mathrm{~V}$ and $50-500 \mu \mathrm{A}$, while the durations of electric stimulation were maintained under one minute. Pulsing schemes should seek to minimize damage to the hydrogels to prevent premature degradation and complete release of the payloads. 
WILEY-VCH

Table 1. Electroresponsive hydrogels for controlled delivery of therapeutic agents with electric stimulation.

\begin{tabular}{|c|c|c|c|c|c|c|c|c|}
\hline $\begin{array}{l}\text { Hydrogel Polymer and } \\
\text { Electroconductive } \\
\text { Materials }\end{array}$ & Disease & $\begin{array}{c}\text { Cell Model/Animal } \\
\text { Model/Human Subject }\end{array}$ & $\begin{array}{c}\text { Electric } \\
\text { Stimulation } \\
\text { Parameters }\end{array}$ & $\begin{array}{l}\text { Hydrogel } \\
\text { Electric } \\
\text { Properties }\end{array}$ & $\begin{array}{l}\text { Agent Released and } \\
\text { Release Profile }\end{array}$ & $\begin{array}{c}\text { Hydrogel } \\
\text { Biocompatibility }\end{array}$ & Outcome & Ref \\
\hline $\begin{array}{l}\text { 2-dimethylamino ethyl } \\
\text { methacrylate } \\
\text { (DMAEMA), Styrene, } \\
\text { Poly(sodium 4- } \\
\text { vinylbenzene sulfonate) } \\
\text { (NaSS), Acrylate- } \\
\text { poly(ethylene glycol)-N- } \\
\text { hydroxysuccinimidylester } \\
\text { (ACLT-PEG-NHS), and } \\
\text { N,N'-methylene } \\
\text { bisacrylamide (MBA) }\end{array}$ & Epilepsy & $\begin{array}{l}\text { bEnd3 mouse brain } \\
\text { microvascular } \\
\text { endothelial cells and } \\
\text { Sprague-Dawley rats }\end{array}$ & $\begin{array}{l}50-500 \mu \mathrm{A} \text { for } \\
1 \mathrm{~min}\end{array}$ & --- & $\begin{array}{l}\text { Phenytoin sodium: } \\
\text { sustained release for } \\
24 \mathrm{~h}, 87.3 \% \text { released } \\
\text { with } 200 \mu \mathrm{A} \text { of electric } \\
\text { stimulation }\end{array}$ & $\begin{array}{l}\text { Low cytotoxicity } \\
\text { with } \mathrm{IC}_{50} \text { value of } \\
414.9 \mu \mathrm{g} / \mathrm{mL}\end{array}$ & $\begin{array}{l}\text { Nanoparticles } \\
\text { conjugated with brain } \\
\text { targeting peptides can } \\
\text { release and deliver } \\
\text { antiepileptic drugs upon } \\
\text { electric stimulation. }\end{array}$ & [159] \\
\hline $\begin{array}{l}\text { 2-dimethylamino ethyl } \\
\text { methacrylate } \\
\text { (DMAEMA), Styrene, } \\
\text { Poly(sodium 4- } \\
\text { vinylbenzene sulfonate) } \\
\text { (NaSS), Acrylate- } \\
\text { poly(ethylene glycol)-N- } \\
\text { hydroxysuccinimidylester } \\
\text { (ACLT-PEG-NHS), and } \\
\text { N,N'-methylene } \\
\text { bisacrylamide (MBA) }\end{array}$ & Epilepsy & Sprague-Dawley rats & $\begin{array}{l}\text { Endogenous } \\
\text { electric field } \\
\text { from epilepsy }\end{array}$ & --- & $\begin{array}{l}\text { Phenytoin sodium: } \\
\text { release concentration } \\
\text { plateaus after } 60 \mathrm{~min}\end{array}$ & --- & $\begin{array}{l}\text { Nanoparticles delivered } \\
\text { antiepileptic drugs under } \\
\text { both electrically and } \\
\text { chemically induced in } \\
\text { vivo seizure models. }\end{array}$ & [161] \\
\hline $\begin{array}{l}\text { Graphene and Poly } \\
\text { (methacrylic acid) } \\
\text { (PMAA) }\end{array}$ & --- & $\begin{array}{l}\text { SH-SY5Y } \\
\text { neuroblastoma cells } \\
\text { and CD-1 mice }\end{array}$ & $\begin{array}{l}10 \mathrm{~V} \text { direct } \\
\text { current applied } \\
\text { for } 1 \mathrm{~min} \text { at } 2 \mathrm{~h} \\
\text { intervals }\end{array}$ & $\begin{array}{l}100 \mathrm{k} \Omega \text { bulk } \\
\text { resistivity }\end{array}$ & $\begin{array}{l}\text { Radiolabeled }{ }^{14} \mathrm{C}- \\
\text { sucrose: } 5.5 \% \text { of initial } \\
\text { dose released in first } \\
\text { stimulation, } 5 \% \text { for } \\
\text { subsequent } \\
\text { stimulation, pulsatile } \\
\text { release profile } \\
\text { obtained }\end{array}$ & $\begin{array}{l}\text { No cytotoxicity or } \\
\text { inflammation with } \\
\text { SH-SY5Y cells }\end{array}$ & $\begin{array}{l}\text { Graphene enhanced } \\
\text { thermal, mechanical, } \\
\text { and electrical properties } \\
\text { and improved on- } \\
\text { demand delivery upon } \\
\text { electric stimulation in } \\
\text { vivo. }\end{array}$ & [121] \\
\hline $\begin{array}{l}\text { Alginate, Chitosan, } \\
\text { Aniline Pentamer, and } \\
\text { Agarose }\end{array}$ & $\begin{array}{l}\text { Parkinson's } \\
\text { Disease }\end{array}$ & $\begin{array}{l}\text { Primary adult human } \\
\text { olfactory ecto } \\
\text { mesenchymal stem } \\
\text { cells }\end{array}$ & $0.5 \mathrm{~V}$ & $\begin{array}{l}10^{-5} \mathrm{~S} / \mathrm{cm} \\
\text { conductivity }\end{array}$ & $\begin{array}{l}\text { Dexamethasone: } 23 \% \\
\text { released in first hour }\end{array}$ & $\begin{array}{l}\text { Favorable cell } \\
\text { viability and } \\
\text { proliferation on } \\
\text { hydrogel }\end{array}$ & $\begin{array}{l}\text { Aniline pentamer } \\
\text { enabled swelling, } \\
\text { degradation, electrically } \\
\text { stimulated drug release, } \\
\text { and the neuronal } \\
\text { differentiation of } \\
\text { mesenchymal stem cells } \\
\text { in the scaffold. }\end{array}$ & [71] \\
\hline
\end{tabular}




\section{WILEY-VCH}

Reduced graphene

oxide, Polyelectrolyte 3,4-

ethylenedioxythiophene

(EDOT)-modified

amphiphilic chitosan

(PMSDT)

Chitosan, Hydroxypropyl

methylcellulose (HPMC),

Pluronic F127,

Polyaniline (PANI)

PC12 rat adrenal
pheochromocytoma
cells and C57BL/ 6 mice

Alternative

current of 250

$\mu \mathrm{A}$ at $1 \mathrm{~Hz}$ and

$125 \mathrm{~ms}$ followed

by 3 cycles of

unipolar square

pulses for $5 \mathrm{~s}$

and rest for $10 \mathrm{~s}$

Excised rabbit nasal

$5 \mathrm{~V}$

membrane
$1.27 \pm 0.31 \mathrm{M} \Omega$
impedance

Plasmid DNA: Within 7

days, at $500 \mu \mathrm{A}$ of

electric stimulation

release reached 28

$\mathrm{ng} / \mathrm{mL}$

$80 \%$ viability of

PC12 cells

Hydrogel probe allowed

on-demand and targeted

delivery of the gene

vectors through

electroporation to

modulate neural activity.

Optimized composite

enabled nose-to-brain

delivery with electric

from 0.0314

$2.4997 \mathrm{mS} / \mathrm{cm}$

Carmustine-Nano-co-

Plex: $10.28 \%$ average

pulsatile, on-off

pulsatile, on-off
switchable release at

stimulation via on-of

zero order release

[117]

zero order kinetics 


\section{WILEY-VCH}

\subsection{Neural Stem Cell Differentiation and Neurogenesis}

Diseases such as Alzheimer's and traumatic events like car accidents cause approximately 20 million people in the United States to suffer from injuries in the nervous system ${ }^{[166,167]}$, resulting in irreversible neuron death from a halt in mitosis. ${ }^{[168]}$ Stem cell therapy can serve as a cell reservoir to restore these damaged tissues, recover impaired cells that lost their biological functionality, ${ }^{[169]}$ and secrete neurotrophic factors which provide neuroprotection and a microenvironment to promote regeneration. ${ }^{[170]}$ For example, neural stem cells (NSCs) are multipotent and can differentiate into the main components of the CNS, such as astrocytes, neurons, and oligodendrocytes. ${ }^{[171]}$ However, directly transplanting NSCs is challenging, since abnormal cell architectures develop in vivo, cells have limited survival upon implantation, and it is difficult to direct differentiation toward specific phenotypes. ${ }^{[172,173]}$ Electroconductive hydrogels can address these gaps through their soft and ductile properties by providing the necessary structural support and physicochemical cues for promoting neural cell proliferation, attachment, differentiation, neurite extension, and migration. ${ }^{[12,174]}$ The extracellular matrix (ECM) is a transferring medium among cells, and its electroconductive and biocompatible nature transmits intercellular electric signals to promote the growth and functional expression of electrically sensitive neural tissues. ${ }^{[3]}$ Hydrogels similar to or comprising natural ECM components, such as gelatin and collagen, are therefore beneficial as neural support scaffolds for cell survival. ${ }^{[3]}$

\subsubsection{Key Tunable Parameters and Properties}

The structural integrity of hydrogels is important for neural tissue engineering, ${ }^{[174]}$ while substrate elasticities should match the brain to promote NSC maturation and be stable enough to structurally support neural regeneration. ${ }^{[175,176]}$ The hydrogel degradation rate should also match the organ regeneration rate to replace damaged or lost cells effectively. ${ }^{[177]}$ Scaffold porosity plays a role, since the microstructure impacts the viability of cells loaded inside through pore sizes which regulate the transport efficiencies of oxygen, carbon dioxide, and nutrients integral for survival. ${ }^{[178]}$ However, $\mathrm{Wu}$ and colleagues determined that the hydrogel conductivity had a stronger impact on neural activity than its mechanical properties by inherently improving the neuronal gene expression without electric stimulation, ${ }^{[179]}$ since electric fields generated by electrically charged matrices provide the signals necessary for neural remodeling and growth. ${ }^{[180]}$ Bordoni and colleagues further corroborated this finding by developing a hydrogel comprising F127, alginate, and gelatin to demonstrate that SH-SY5Y 


\section{WILEY-VCH}

neuroblastoma cells can differentiate without electric stimulation, since the conductive scaffold replaces the factors necessary for inducing differentiation into a neural phenotype. ${ }^{[115]}$ Even so, a seminal study from Schmidt and coworkers determined that compared to a conductive hydrogel with PPy alone, the addition of electric stimulation generated longer PC12 neurite cells. ${ }^{[102]}$ Electric stimulation helps to align cells, ${ }^{[181]}$ extend neurite outgrowth, ${ }^{[182]}$ increase branching, ${ }^{[183]}$ guide stem cell differentiation toward specific phenotypes, ${ }^{[184]}$ and induce the production of growth factors which improve neuronal survival. ${ }^{[185]}$ Hence, electrically stimulated electroconductive hydrogels can direct NSC differentiation and neurogenesis to enhance regeneration.

\subsubsection{State of the Field}

A hydrogel's inherent physical and chemical properties can synergistically enhance NSC differentiation and neuritogenesis. For example, Javadi and colleagues developed polyurethane hydrogel composites where liquid crystal graphene oxide (GO) and PEDOT:PSS fillers synergistically improved the conductivity, as the GO maintained its liquid crystal structure for PEDOT:PSS to disperse between the parallel graphene nanosheets. ${ }^{[110]}$ Human neural stem cells (hNSCs) cultured on the composites led to extended neurite networks, proliferation, and differentiation, thereby demonstrating neuroglia support. Biphasic electric stimulation further increased mean neurite lengths to mimic neural networks. Qiao and colleagues also investigated the impact of GO concentration on a polyacrylic acid (PAA) composite's properties and responsivity to electric fields. ${ }^{[24]}$ The integration of GO was compatible, as the carboxyl and hydroxyl functional groups on GO sheets hydrogen bond with the PAA matrix. Upon electric stimulation, the hydrogel bending response increased with higher voltages, since the free ion speed increased to enhance the hydrogel bending angle and deformation rates. Applying direct current to rat bone marrow derived mesenchymal stem cells seeded on the composites generated slender filopodia, as the electric field and mechanical forces on cells synergistically impacted the cytoskeleton and differentiation. ${ }^{[186]}$

Imaninezhad and colleagues also developed PEG and MWCNT nanocomposites seeded with PC12 cells. ${ }^{[187]}$ Although the substrate composition and parameters did impact neurite outgrowth, the researchers found that regardless of the hydrogel properties, applying direct current always led to the highest neurite outgrowth, highest cell alignment, and cell clustering, which can spontaneously enhance neural activity and develop neural networks. ${ }^{[188]} \mathrm{Xu}$ and colleagues studied hNSCs seeded on a PANI-coated poly(ethylene glycol) diacrylate (PEGDA) 
hydrogel to understand the impact of different durations of electric stimulation by evaluating the cell attachment, viability, and differentiation over time. ${ }^{[12]}$ Cells subjected to longer durations of biphasic electric stimulation possessed longer neurites and spread more, while an increase in potential from $15 \mathrm{mV}$ to $75 \mathrm{mV}$ increased the neurite length. However, potentials that were too high were detrimental to the cell growth.

$3 \mathrm{D}$ printing is a favored manufacturing technique due to its ease of operation, low costs, and the various bioinks available to customize scaffolds as medical implants. ${ }^{[174]}$ Therefore, Heo and colleagues developed a hydrogel-based microwell culture system through microcontact printing techniques. ${ }^{[29]}$ Human adipose stem cell aggregates cultured in this $3 \mathrm{D}$ environment had improved ECM interactions and cell-cell signaling compared to a $2 \mathrm{D}$ culture due to the presence of tissue structures mimicking the native environment. These aggregates expressed positive neuronal differentiation markers, which increased upon electric stimulation, leading to neuronal networks and interconnections with neurites from an upregulation of protein synthesis. ${ }^{[189]}$ Since PEDOT:PSS induced cell spreading and adhesion, the researchers suggested this 3D system can enhance low adhesion affinity to promote cell aggregate formations. In a separate study, Lee and colleagues applied stereolithography 3D printing to fabricate multilayered scaffolds comprising PEGDA matrices and amine functionalized MWCNTs to support NSC proliferation and differentiation with electric stimulation. ${ }^{[174]}$ The medium porosity level at $52 \%$ led to optimal mechanical properties and printing quality, while biphasic electric stimulation indicated that high positive surface charges from MWCNTs improved the electrostatic interactions with negatively charged neural cell plasma membrane for enhanced NSC growth. ${ }^{[190]}$

Mimicking the topography of neural microenvironments can promote cell attachment, proliferation, and differentiation on scaffolds. ${ }^{[174]}$ Specifically, oriented nanostructures and microstructures in the matrix can guide directional neurite growth, especially when electric signals transmit along these paths to enhance neural function. ${ }^{[3]} \mathrm{Wu}$ and colleagues recently fabricated cell-laden hydrogel microfibers with water dispersible PPy nanoparticles to emulate the shape of nerve bundles. ${ }^{[3]}$ The hydrogel platform inherently enabled PC12 cell networks to form, as the microfibers promoted cell proliferation and spreading, while the nanoparticles maintained the electrical activity of the oriented microfibers to enhance cell elongation. These cues upregulated neurite extension, activated voltage-gated calcium ion channels, and increased 


\section{WILEY-VCH}

intracellular calcium ion levels, ${ }^{[3,19]]}$ while electric stimulation synergistically increased neurogenesis. Lee and coworkers also developed micropatterned PEG-based hydrogels ${ }^{[113]}$ containing silver nanowires (AgNWs) to form conductive networks based on a previous method. ${ }^{[192]}$ Polydimethylsiloxane stamps created parallel microridges through soft lithography, ${ }^{[193]}$ and the researchers demonstrated $200 \mu \mathrm{m}$ wide micropatterns were the optimal balance between the seeding efficiency and neurite guidance for NSC neurospheres. The spatial limitations imposed by the microridges oriented the neurite growth along the edges, and electric stimulation induced differentiation.

Most methods which fabricate complex hydrogel architectures and micropatterns use lithography-based techniques, requiring vacuum conditions, organic solvents, and elevated temperatures detrimental to polymer networks. ${ }^{[194]}$ However, Lin and colleagues used a nonlithographic process to create microstructures in a silk-gelatin hydrogel with spontaneous micropatterning (Figure 8) by depositing polylactic acid. ${ }^{[17]} \mathrm{A}$ reduced graphene oxide complex containing conjugated nanoscale nerve growth factors, polyethylenimine, and iron oxide nanoparticles was further deposited onto the grooves to enhance and guide neurite outgrowth. The researchers discovered that the polarity and outgrowth of PC12 cells can be regulated by the micropattern geometry, which impacts cell attachment, density, and orientation, as demonstrated previously. ${ }^{[195]}$ Even after 21 days of electric stimulation, neurite extension along the patterns and neurotransmission with cellular connections were detected, indicating the combined topographical, chemical, and electrical cues enhanced differentiation and neurogenesis.

Since electric stimulation is often applied invasively with probes, Lee and colleagues developed fibrous piezoelectric scaffolds comprising polyvinylidene fluoride trifluorethylene (PVDFTrFE) membranes to promote hNSC differentiation without exogenous electric fields. ${ }^{[170]} \mathrm{A}$ change or accumulation of surface electric charge on piezoelectric polymers can be generated through minute mechanical deformations when cells attach and migrate on the fibers. ${ }^{[170,180]}$ Upon seeding cells on the hydrogels, a linear relationship was observed between fiber piezoelectricity and neurite extension. Furthermore, the greatest NSC differentiation and neurite outgrowths were achieved on annealed and micron-sized, aligned scaffolds. Piezoelectric stimulation can be further controlled with an extracorporeal stimulation technique. For example, Genchi and colleagues illustrated that ultrasound waves influence the intracellular 


\section{WILEY-VCH}

calcium ion concentrations of SH-SY5Y cells in piezoelectric substrates through wireless, guided neuronal stimulation. ${ }^{[196]}$ Similarly, Hoop and colleagues found that ultrasonic waves promote wireless neuritogenesis on piezoelectric polyvinylidene fluoride substrates. ${ }^{[197]}$ Ultrasound stimulation activated the calcium channels of PC12 cells seeded on the piezoelectric substrate to promote neurogenesis through a cyclic adenosine monophosphate dependent pathway. The subsequent polarization of the piezoelectric polymer sheets induced an influx of calcium ions, leading to a differentiation efficiency similar to in vitro differentiation with neural growth factors.

While ultrasound can wirelessly control electric stimulation, targeted delivery and in situ differentiation of neural cells are persisting challenges. ${ }^{[198]}$ As a solution, Dong and colleagues demonstrated that magnetoelectric stimulation can also control neural activity. ${ }^{[198]}$ The researchers developed soft and magnetic microswimmers which were adsorbed into magnetoelectric nanoparticles to impart magnetic actuation and loaded with SH-SY5Y cells. A rotating magnetic field propelled and controlled the microswimmer motion, while further application of alternating magnetic fields induced differentiation by straining and altering the surface transient charge to convert magnetic inputs to electrical outputs. Proteinases from cells eventually degrade the microswimmers to release the nanoparticle and cell payloads, as indicated by Figure 8B. Thus, this dual functionality enabled both targeted delivery and controlled, non-invasive electric field activation. 


\section{WILEY-VCH}

(A)

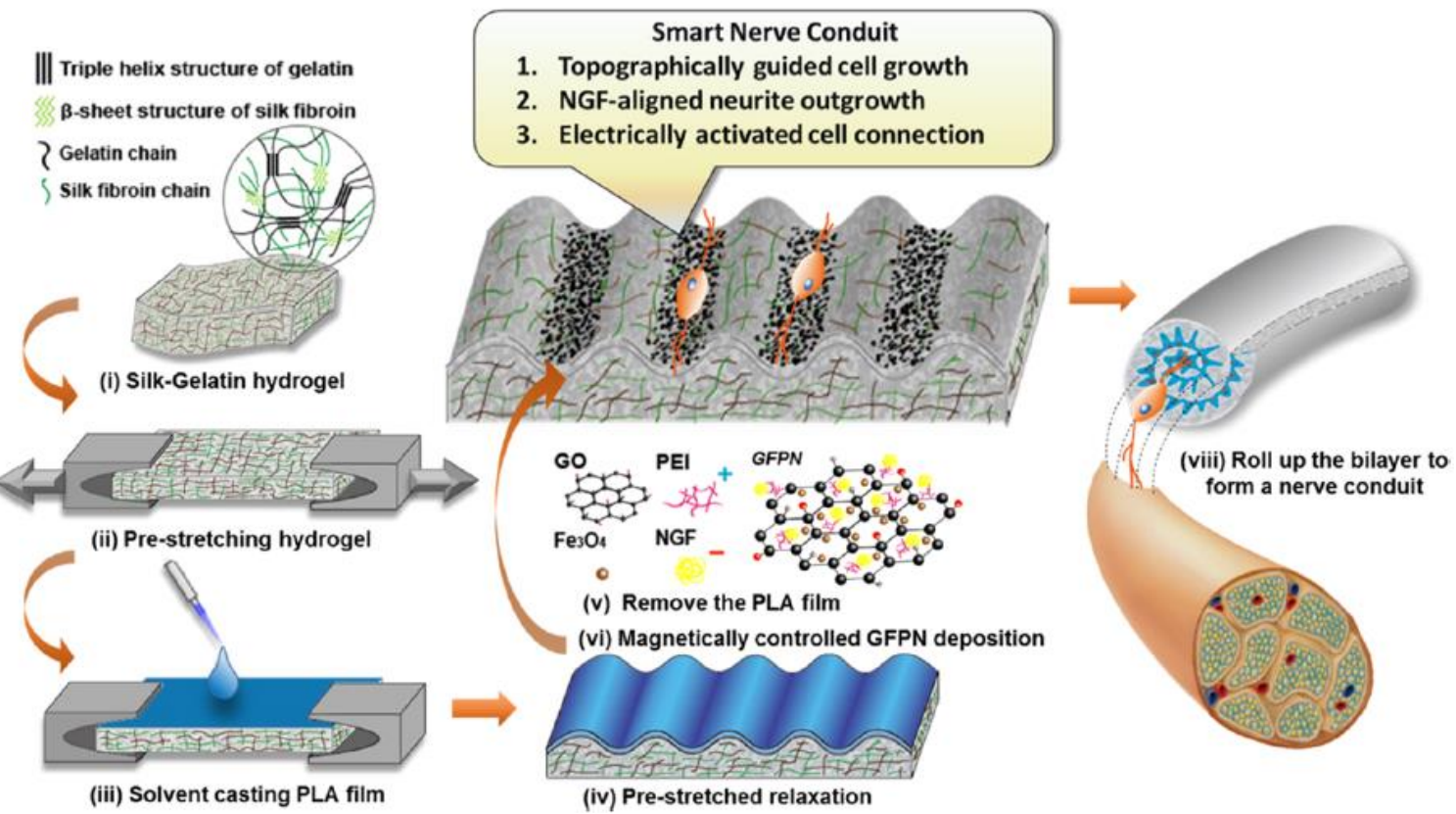

(B)
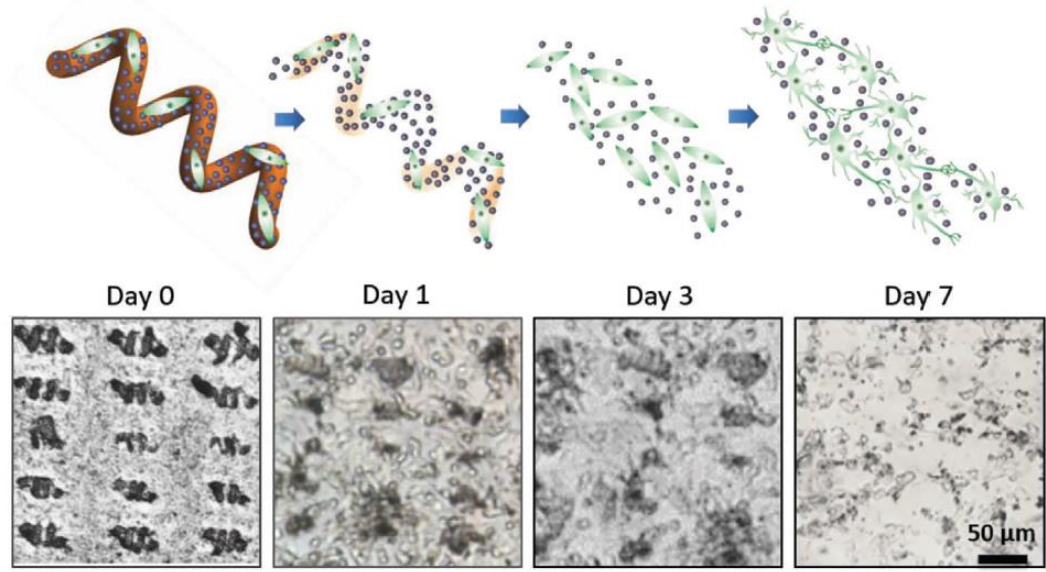

Figure 8. Electroresponsive hydrogels for neural tissue engineering applications. (A) Schematic representation of micropatterned silk-gelatin scaffolds with topographical, biological, and electrical cues for regulating neuronal cells. (i) Hydrogel synthesis with silk and gelatin. (ii) After swelling, hydrogels were pre-stretched to 50\%. (iii) A solution of polylactic acid was added to the pre-stretched hydrogel. (iv) The pre-strain on the hydrogel was released and corrugation patterns were formed. (v) The film was removed and (vi) graphene nanoparticles were magnetically and topographically deposited on the grooves. (vii) The cells were electrically stimulated and (viii) the film was rolled to form a nerve conduit. Reproduced with permission. ${ }^{[17]}$ Copyright 2020, American Chemical Society. (B) Schematic diagram and corresponding optical image of degradation process for cell encapsulated microswimmers and subsequent differentiation of SH-SY5Y cells exposed to electromagnetic stimulation. Adapted with permission. ${ }^{[198]}$ Copyright 2020, John Wiley and Sons.

\subsubsection{Key Challenges}

A prominent challenge in developing scaffolds for neuron repair is balancing hydrogel stability with its biodegradation rate. All the reported studies which assessed hydrogel cytotoxicities demonstrated biocompatibility with cells, and all the platforms remained stable long enough to 


\section{WILEY-VCH}

promote neurogenesis and/or NSC differentiation upon exposure to an electric field, as indicated by Table 2. While the neurite outgrowth, differentiation, and proliferation of neural cells were closely monitored, the degradation data for the hydrogels were not assessed, even when the hydrogels were purportedly biodegradable. It is important to accurately identify scaffold degradation rates in vivo, as hydrogels ought to be tuned to match the time required for integration with cells during neuronal repair. Even if the scaffold is not cytotoxic, it is prudent to ensure degradation products and any starting reagents which may leach out do not cause deleterious effects to the surrounding neural tissue.

Optimizing the porosity of neural scaffolds is also challenging. For neural regeneration, the scaffold porosity requires a balance between cell encapsulation and nutrient exchange. Lee and colleagues note that there is contradictory guidance on the optimal scaffold pore size for different types of cells. ${ }^{[174]}$ As such, pore size experiments should be performed for each specific combination of neural cells and scaffold during optimization. It is also difficult to tailor hydrogel formulations for the correct compromise between matching mechanical properties to neural tissues and enhancing conductivity for electric signal transmission. Increasing the concentration of conducting materials may affect the mechanical properties and compressive moduli, while varying the mechanical properties can likewise influence the electroconductivity. For example, Bordoni and colleagues discovered that well crosslinked alginate penetrated through CNT chains to obstruct interconnective networks and decrease conductivity, while noncrosslinked networks had a higher conductivity. ${ }^{[115]}$ Yet, increasing the conductivity also decreased the cell attachment to the hydrogels due to an elevated cytotoxicity. Hence, rheological tests should be performed and coupled to cell culture studies to assess the neurogenesis and differentiation capacities of the hydrogels.

Another major challenge in the field is directing the cell alignment, outgrowth, and differentiation in scaffolds. Specifically, a uniform electric field with a homogeneous current density through the scaffold is necessary to subject all cells to the same electric stimulation parameters. Such a uniform electric field may be important for cellular responses to electric signals, as Hinkle and colleagues noted that primary dissociated neuroblasts required electric stimulation with a minimum of $7 \mathrm{~V} / \mathrm{m}$ for neurite outgrowth. ${ }^{[199]}$ Strategies to tailor these neural tissue engineering applications for more clinically relevant outcomes are discussed further in the future perspectives in section 7.2. Table 2 summarizes the hydrogel material components, 


\section{WILEY-VCH}

electric stimulation parameters, cell culture or animal models, and the resulting outcomes from each of the discussed studies on electroresponsive hydrogels for promoting NSC differentiation and neurogenesis upon electric stimulation. 


\section{WILEY-VCH}

Table 2. Electroresponsive hydrogels for directing neural stem cell differentiation and promoting neurogenesis with electric stimulation.

\begin{tabular}{|c|c|c|c|c|c|c|c|}
\hline $\begin{array}{c}\text { Hydrogel Polymer and } \\
\text { Electroconductive } \\
\text { Materials }\end{array}$ & Injury/Disease & $\begin{array}{c}\text { Cell Model/Animal } \\
\text { Model/Human Subject }\end{array}$ & $\begin{array}{l}\text { Electric Stimulation } \\
\text { Parameters }\end{array}$ & $\begin{array}{l}\text { Hydrogel } \\
\text { Electric } \\
\text { Properties }\end{array}$ & $\begin{array}{c}\text { Hydrogel } \\
\text { Biocompatibility }\end{array}$ & Outcome & Ref \\
\hline $\begin{array}{l}\text { Poly(3,4- } \\
\text { ethylenedioxythiophene) } \\
\text { polystyrene sulfonate } \\
\text { (PEDOT:PSS), Liquid } \\
\text { Crystalline Graphene Oxide } \\
\text { (LCGO), and Polyurethane } \\
\text { (PU) }\end{array}$ & --- & $\begin{array}{l}\text { Human neural stem cells } \\
\text { (hNSCs) }\end{array}$ & $\begin{array}{l} \pm 0.25 \mathrm{~mA} \mathrm{~cm}^{-2} \text { biphasic } \\
\text { waveform with } 100 \mu \mathrm{s} \\
\text { pulses, } 20 \mu \mathrm{s} \text { interphase } \\
\text { at } 250 \mathrm{~Hz} \text {, stimulated for } \\
8 \mathrm{~h} \text { every day for } 3 \text { days }\end{array}$ & $\begin{array}{l}12.5 \mathrm{~S} / \mathrm{cm} \\
\text { conductivity }\end{array}$ & $>80 \%$ cell viability & $\begin{array}{l}\text { PEDOT:PSS and LCGO synergistically } \\
\text { improve mechanical and electrical properties } \\
\text { of hydrogel and support differentiation and } \\
\text { neurite extension. }\end{array}$ & [110] \\
\hline $\begin{array}{l}\text { Graphene oxide (GO) and } \\
\text { Poly(acrylic acid) (PAA) }\end{array}$ & --- & $\begin{array}{l}\text { Rat bone marrow } \\
\text { derived mesenchymal } \\
\text { stem cells (BMSCs) }\end{array}$ & $\begin{array}{l}5 \mathrm{~V} \text { of direct current for } 1 \\
\mathrm{~h} / \text { day }\end{array}$ & $\begin{array}{l}(17-33) \times 10^{-4} \\
\mathrm{~S} / \mathrm{cm} \\
\text { conductivity }\end{array}$ & $\begin{array}{l}\text { No cytotoxicity, } \\
\text { biocompatible with } \\
\text { over } 100 \% \text { cell } \\
\text { proliferation rate }\end{array}$ & $\begin{array}{l}\text { GO-PAA coupling influences morphology of } \\
\text { adhesive cells, regulates cytoskeleton under } \\
\text { electric stimulation, and promotes neural stem } \\
\text { cell differentiation. }\end{array}$ & [24] \\
\hline $\begin{array}{l}\text { Polyacrylamide (PA), } \\
\text { Poly(ethylene glycol) (PEG), } \\
\text { and Multiwalled carbon } \\
\text { nanotubes (MWCNT) }\end{array}$ & --- & $\begin{array}{l}\text { PC12 rat adrenal } \\
\text { pheochromocytoma } \\
\text { cells }\end{array}$ & $\begin{array}{l}0.7 \mathrm{~V} \text { of } \\
\text { direct current for } 1 \mathrm{~h}\end{array}$ & $\begin{array}{l}0.94 \pm 0.07 \Omega m \\
\text { resistivity }\end{array}$ & --- & $\begin{array}{l}\text { Formulation with } 20 \%(\mathrm{w} / \mathrm{v}) \mathrm{PEG} \text { and } 0.1 \% \\
\text { MWCNTs, upon electric stimulation, led to } \\
\text { longest neurite and largest total outgrowth. }\end{array}$ & [187] \\
\hline $\begin{array}{l}\text { Polyaniline (PANI) and } \\
\text { Poly(2-vinyl-4,6-diamino- } \\
1,3,5 \text {-triazine)/Poly(1- } \\
\text { vinylimidazole) (PVV), and } \\
\text { Poly(ethylene glycol) } \\
\text { diacrylate (PEGDA) }\end{array}$ & --- & $\begin{array}{l}\text { Human neural stem cells } \\
\text { (hNSCs) }\end{array}$ & $\begin{array}{l}75 \mathrm{mV} \text { of biphasic electric } \\
\text { field at } 200 \mathrm{~Hz} \text {, stimulated } \\
\text { every } 6 \mathrm{~h} \text { for } 1,3,5,7 \text { days }\end{array}$ & $\begin{array}{l}13.27 \pm 0.04 \\
\mathrm{mS} / \mathrm{cm} \\
\text { conductivity } \\
\text { and } 2 \Omega \\
\text { impedance }\end{array}$ & $90 \%$ cell viability & $\begin{array}{l}\text { Hydrogels supported the attachment, } \\
\text { proliferation, and differentiation of the neural } \\
\text { stem cells, and applying electric stimulation } \\
\text { further enhanced neural and glial } \\
\text { differentiation. }\end{array}$ & [112] \\
\hline $\begin{array}{l}\text { Poly(3,4- } \\
\text { ethylenedioxythiophene) } \\
\text { polystyrene sulfonate } \\
\text { (PEDOT:PSS) and } \\
\text { Poly(ethylene glycol) } \\
\text { diacrylate (PEGDA) }\end{array}$ & --- & $\begin{array}{l}\text { Human adipose derived } \\
\text { stem cells (ADSC) }\end{array}$ & $\begin{array}{l}1000 \mathrm{mV} \text { of direct current } \\
\text { for } 10 \text { days }\end{array}$ & --- & $\begin{array}{l}\text { Cell viabilities } \\
\text { unaffected }\end{array}$ & $\begin{array}{l}\text { Electrically stimulating ADSC aggregates in } \\
\text { hydrogel microwells increased neurogenic } \\
\text { differentiation. }\end{array}$ & [29] \\
\hline $\begin{array}{l}\text { Multiwalled carbon } \\
\text { nanotubes (MWCNTs) and } \\
\text { Poly(ethylene glycol) } \\
\text { diacrylate (PEGDA) }\end{array}$ & --- & $\begin{array}{l}\text { NE-4C-GFP neural stem } \\
\text { cells from mouse } \\
\text { neuroectoderm }\end{array}$ & $\begin{array}{l}500 \mu \mathrm{A} \text { biphasic pulses at } \\
100 \mathrm{~Hz} \text { for } 100 \mu \mathrm{s}\end{array}$ & $\begin{array}{l}2.21 \pm 0.12 \mathrm{mC} \\
\mathrm{cm}^{-2} \text { charge } \\
\text { storage } \\
\text { capacity }\end{array}$ & $\begin{array}{l}\text { Cell viability } \\
\text { increased on } \\
\text { hydrogel with electric } \\
\text { stimulation }\end{array}$ & $\begin{array}{l}\text { Amine-functionalized MWCNTs on scaffolds } \\
\text { enhanced cell growth and applying a } 500 \mu \mathrm{A} \\
\text { electric stimulation was optimal for neural } \\
\text { differentiation. }\end{array}$ & [174] \\
\hline $\begin{array}{l}\text { Poly (ethylene glycol) } \\
\text { (PEG), Polypyrrole (PPy), }\end{array}$ & --- & $\begin{array}{l}\text { PC12 rat adrenal } \\
\text { pheochromocytoma } \\
\text { cells }\end{array}$ & $\begin{array}{l}100 \mathrm{mV} / \mathrm{cm} \text { for } 1 \mathrm{~h} / \text { day for } \\
3 \text { days }\end{array}$ & $\begin{array}{l}0.22 \mathrm{~S} / \mathrm{m} \\
\text { conductivity }\end{array}$ & $\begin{array}{l}\text { High } \\
\text { cytocompatibility and } \\
\text { bioactivity }\end{array}$ & $\begin{array}{l}\text { Hydrogel and electric stimulation } \\
\text { synergistically upregulated calcium ion } \\
\text { channel expression to promote neurogenesis. }\end{array}$ & [3] \\
\hline
\end{tabular}




\section{WILEY-VCH}

Poly(vinyl alcohol) (PVA),

and Type I Collagen Poly(ethylene glycol) (PEG)
and Silver Nanowire

(AgNW)

Alzheimer/

Parkinson/

Huntington

Polylactic acid (PLA), SilkGelatin (SG),

Polyethylenimine (PEI), and

Reduced Graphene Oxide

(rGO)

Polyvinylidene fluoride

trifluoroethylene (PVDF-

TrFE)

Gelatin-methacryloy (GelMA)

Alzheimer/
Primary neural stem

cells from E12 C57BL/6 $\quad \mu \mathrm{Hz}$ every $2 \mathrm{~h}$ for 6 days

mice cortex tissue

PC12 rat adrenal

pheochromocytoma

cells

Alternate current at 250

$\mu \mathrm{A}$ for $5 \mathrm{~ms}$ duration with

two cycles of $5 \mathrm{~min}$

stimulations followed by 3

min of rest in biphasic

mode

Human neural stem cells

(hNSCs) and neural

progenitor cells (NPCs)

SH-SY5Y and mice

Parkinson/

Amyotrophic lateral

sclerosis/

Huntington
Highest neurite growth when voltages

between $5-10 \mathrm{~V}$ applied, outgrowth align

with micropatterned ridges during electric

stimulation.

Topographical, electrical, and biological cues

from hydrogel synergistically promoted

neuronal growth, differentiation, and alignment

on nerve conduits.

Annealed, microaligned scaffolds enhanced

differentiation and led to highest neurite

extensions through contact guidance with

hydrogel's piezoelectric properties.

Negligible

Magnetoelectric nanoparticles delivered

neuronal cells in a targeted manner with

SY5Y cells and no

magnetically mediated electrostimulation.
[113]

inflammation in mice 


\section{WILEY-VCH}

\subsection{Neural Biosensors in vivo}

Functions in the brain are regulated by neurotransmission events at the subsecond scale, which is why neuroscientists rely on electrochemical methods to detect instantaneous changes in neurotransmitters in vivo. ${ }^{[200]}$ Biosensors utilize these electrochemical methods to monitor nonelectroactive molecules ${ }^{[201]}$ with precise, rapid, and continuous measurements of metabolites in situ. ${ }^{[202]}$ While alternative methods such as nuclear magnetic resonance and microdialysis have limitations in spatial and temporal resolutions, the electrodes of electrochemical sensors can be placed directly in target tissues for real time monitoring and convert the analytes at the electrode site within seconds for fast response times. ${ }^{[202]}$ Clinicians can then quickly detect physiological or metabolic changes and administer treatments or interventions as needed. ${ }^{[34]}$ As an example, acetylcholine is a crucial neurotransmitter for motor neuron function, ${ }^{[203]}$ and microsensors can detect its release in specific regions of the brain to elucidate chemical information on diseases for developing treatments. ${ }^{[204]}$

Many biosensors use immobilized enzymes which confer specificity to catalyze the production of electrochemically active byproducts from the target metabolite. ${ }^{[34]}$ Amperometry is commonly employed as the electroanalytical detection method for enzyme immobilized biosensors due to their sensitive, selective, and fast detection of analytes both in vitro and in vivo. ${ }^{[205,206]}$ Subjecting the electrode to a potential drives a redox reaction process, with the resulting current being proportional to the concentration of the target analyte electrolyzed. ${ }^{[201]}$ In 1962, Clark and Lyons were the first group to develop a glucose oxidase enzyme based electrode for detecting glucose and hydrogen peroxide $\left(\mathrm{H}_{2} \mathrm{O}_{2}\right) .{ }^{[207]}$ Fast scan cyclic voltammetry (FSCV) is another detection method which can distinguish between the target analyte and interfering molecules. ${ }^{[200]}$ Its voltammetric method is multivariate, and the cyclic voltammogram's shape indicates the amount of analyte present in the tissue. ${ }^{[200]}$ However, FSCV is limited to electroactive molecules and measurements of non-electroactive analytes like glucose are ambiguous. ${ }^{[200]}$ Coating biosensors with hydrogels can enhance the performances of biosensors in a myriad of ways to improve the detection of target analytes, as highlighted in the subsequent section.

\subsubsection{Key Tunable Parameters and Properties}

Most biosensor research focuses on optimizing the stability, specificity, response times, and operating potential. The addition of permselective polymer coatings on the electrode surface of amperometric biosensors can improve selectivity, which is a critical parameter since any 


\section{WILEY-VCH}

molecule in the brain which becomes electrochemically active at the applied potential can interfere with and contribute to current outputs. ${ }^{[206]}$ The biosensor limit of detection should be optimized for the target analyte, since it depends on the properties of the specific molecule. For example, the limit of detection for enzyme substrates should be within the $\mu \mathrm{m}$ range, while DNA requires a limit of detection that is several orders of magnitude lower. ${ }^{[34]}$ In addition to improving biocompatibility, conductive hydrogel coatings can covalently or physically immobilize the enzymes ${ }^{[208]}$ and reduce the interference from nonspecific protein adsorption on the electrode surfaces during implantation. ${ }^{[209]}$ It is therefore important to optimize the hydrogel properties, as the selectivity, performance, and stability of biosensors are dependent on the diffusion coefficients of the target analytes as they traverse through the hydrogel on the electrode surface. ${ }^{[210]}$

\subsubsection{State of the Field}

Although amperometric sensors commonly employ two immobilized enzymes in a reaction sequence, enzyme wiring can covalently bond three enzyme sensors into a hydrogel coating to improve sensitivity by five times, improve stability of the electrode, and prevent immobilized enzymes from leaching out. ${ }^{[204]}$ Larrson and colleagues developed a three enzyme amperometric acetylcholine biosensor in an osmium redox hydrogel and separately assessed three different coating methods. ${ }^{[204]}$ A single layer with sequential addition of the enzymes yielded the highest sensitivity, minimized the diffusion between reaction sites, increased the $\mathrm{H}_{2} \mathrm{O}_{2}$ collection efficiency, and improved electron transfer by producing more homogenous mixtures. ${ }^{[204,211]}$ Oldenziel and coworkers also developed an osmium-based redox polymer comprising three immobilized enzymes to detect neuronally derived glutamate levels at high enough spatiotemporal resolutions, since these neurotransmitters are involved in normal cognitive processes and CNS plasticity. ${ }^{[208]}$ The presence of ascorbic and uric acid in the brain $^{[206]}$ can reduce the microsensor performances through signal interference, and the researchers observed the physiologic concentrations of these acids reduced the sensitivity of the sensor during their diffusion into the hydrogel by electrostatic attraction. ${ }^{[212]}$ However, the microsensor's linear operating range detected physiologic glutamate concentrations of $100 \mu \mathrm{M}$ with anesthetized rats. ${ }^{[213,214]}$

The development process and operation of neural biosensors can damage their performance over time. For example, covalently binding enzymes on polymers can denature the enzymes on the electrode sensing layer, lower biosensor life, and decrease sensitivity. ${ }^{[206]}$ Tian and 


\section{WILEY-VCH}

colleagues resolved this issue by developing a hydrogel that can undergo a solution-gel transition. ${ }^{[206]}$ When cathodic potentials are high enough, hydroxyl ions produced on the electrode surface catalyze the polymerization of the hydrolyzed solution to entrap glucose oxidase uniformly in a silica gel layer. The dynamic L-glutamate levels in the dorsal medullary nucleus of anesthetized rats were assessed, and the sensors demonstrated fast response times with arterial blood pressure changes. On the other hand, rigid biosensors also risk breakage when they cannot bend during implantation. ${ }^{[202]}$ Weltin and colleagues therefore used waferlevel fabrication to develop a flexible biosensor comprising a polyimide substrate with a high enough stiffness for mechanical durability and a high flexibility for bending in tissue. ${ }^{[202]}$ The biosensor geometries can be altered through controlled layering to vary sensitivity. Intracerebral measurements on the neocortex of rats detected both micromolar and nanoliter ranges of glutamate levels with a temporal resolution and high reproducibility. The researchers similarly developed lactate sensors with variable pHEMA hydrogel thicknesses to serve as a diffusion barrier and increase linear operating ranges through increased oxygen diffusion.

The relationship between neural functions and glucose concentrations needs to be investigated to understand neurological disorders and diseases. ${ }^{[200]}$ Dynamic glucose metabolic processes depend on local pathological and physiological conditions in different regions of the brain, ${ }^{[215]}$ as recording sites even $75 \mu \mathrm{m}$ apart are heterogeneous with significant chemical changes at the subsecond timescale. ${ }^{[216]}$ However, current techniques do not directly monitor these dynamic glucose levels with a high spatiotemporal resolution. ${ }^{[200]}$ Lugo-Morales and colleagues addressed these limitations by applying FSCV in chitosan based glucose biosensors to detect $\mathrm{H}_{2} \mathrm{O}_{2}$ and other electroactive analytes in real time through a single recording site. ${ }^{[200]}$ These sensors demonstrated a high glucose selectivity and were not impacted by interfering molecules in the physiologic range. As such, this method does not require diffusion limiting coatings to minimize interference. The biosensor was implanted in the caudate putamen of anesthetized rats and detected subsecond glucose fluctuations in live brain tissue. In a follow up study, Smith and colleagues compared three different glucose oxidase immobilization strategies: physical adsorption, hydrogel entrapment, and entrapment in electrospun fibers, as illustrated by the schematic diagram in Figure 9A. ${ }^{[201]}$ The results indicated that enzyme entrapment in chitosan hydrogels led to the most stable response and highest sensitivity across all the time points studied, as indicated by the high signal detection (Figure 9B and 9C). This technique is restricted to a linear response of glucose concentrations less than $3 \mathrm{mM}$, but it is still within the physiological ranges observed in the brain. 


\section{WILEY-VCH}

(A)
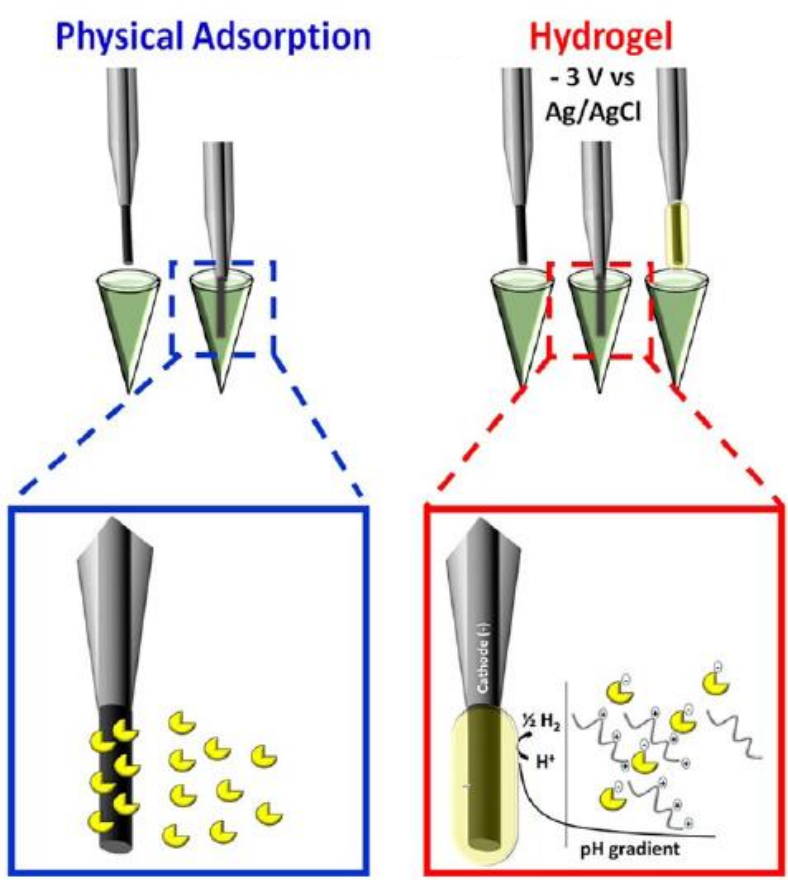

\section{Electrospun}

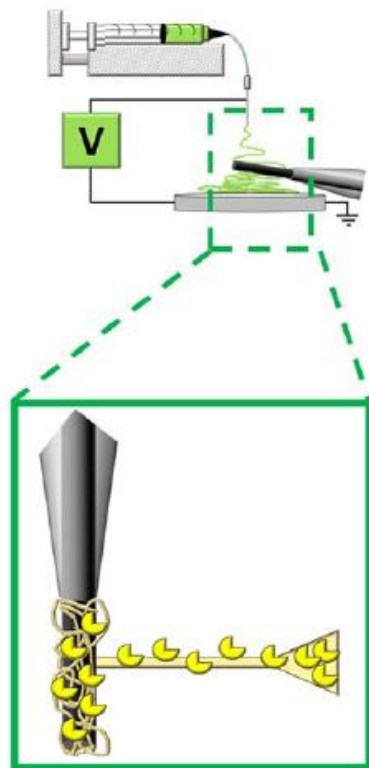

Physical Adsorption

(B)

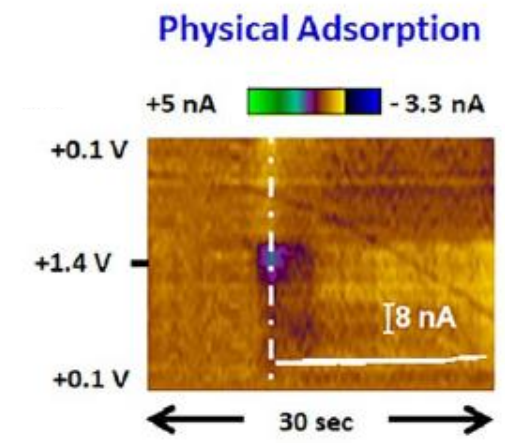

(C)
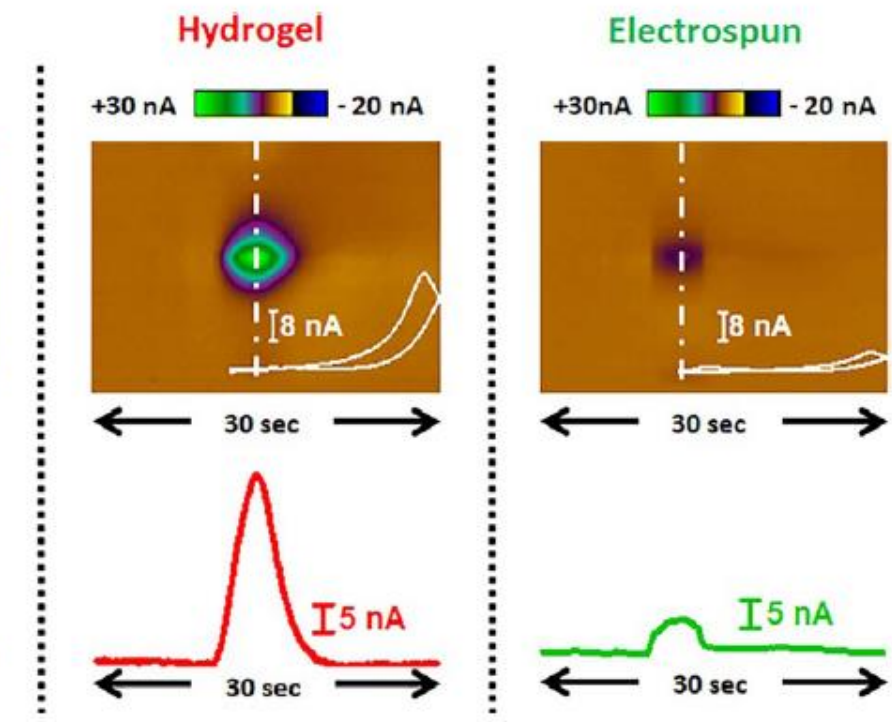

Figure 9. Techniques for immobilizing glucose oxidase onto microbiosensors through physical adsorption of glucose oxidase (blue), hydrogel entrapment of glucose oxidase (red), or entrapment of glucose oxidase in electrospun nanofibers (green). (A) Schematic diagram of immobilization techniques. (B) Fast scan cyclic voltammetry monitored glucose using carbon microbiosensors. Microbiosensor response to a 2 second bolus of $1.6 \mathrm{mM}$ glucose. (C) Current vs time profile of the color plots in (B). Adapted with permission. ${ }^{[201]}$ Copyright 2018 , John Wiley and Sons.

\subsubsection{Key Challenges}

When assessing neural biosensor performances, microdialysis techniques can cause significant damage to brain tissues during probe insertion, leading to an underestimation of the neurotransmitter levels. ${ }^{[217,218]}$ However, the data cannot simply be adjusted accordingly, since 


\section{WILEY-VCH}

microdialysis can also overestimate neurotransmitters when cellular high affinity uptake mechanisms are damaged with neural probes. ${ }^{[219]}$ This issue is further exacerbated by biofouling when cells, proteins, and biomolecules accumulate on biosensor surfaces and deteriorate the performance. ${ }^{[208]}$ Biofouling is the most significant contributing factor for a decline in biosensor sensitivity 24 hours after its implantation, ${ }^{[220]}$ since such processes can lead to fibrous capsules which form around the electrode and reduce the signal-to-noise ratios and current responses. ${ }^{\text {[221] }}$ Techniques to mitigate biofouling in neural biosensors are discussed in section 7.3. Table 3 provides a comprehensive summary of the hydrogel material components, electrode type, electric stimulation parameters, cell culture or animal models, the analyte sensed and its sensitivity or limit of detection, and the resulting outcomes from each of the discussed studies which developed electroresponsive hydrogels for neural biosensors. 
WILEY-VCH

Table 3. Electroresponsive hydrogels for real time monitoring with in vivo neural biosensors.

\begin{tabular}{|c|c|c|c|c|c|c|c|}
\hline $\begin{array}{l}\text { Hydrogel Polymer and } \\
\text { Electroconductive } \\
\text { Materials }\end{array}$ & Disease & $\begin{array}{l}\text { Electrode } \\
\text { Type }\end{array}$ & $\begin{array}{c}\text { Cell Model/Animal } \\
\text { Model/Human } \\
\text { Subject }\end{array}$ & $\begin{array}{l}\text { Electric Stimulation } \\
\text { Parameters }\end{array}$ & $\begin{array}{l}\text { Analyte Sensed and } \\
\text { Limit of Detection or } \\
\text { Sensitivity }\end{array}$ & Outcome & Ref \\
\hline $\begin{array}{l}\text { Poly(ethylene glycol) } \\
\text { diglycidyl ether } \\
\text { (PEGDGE) and } \\
\text { Poly(1-vinylimidazole) } \\
\text { (PVI) }\end{array}$ & $\begin{array}{l}\text { Alzheimer/ } \\
\text { Parkinson/ } \\
\text { Epilepsy }\end{array}$ & $\begin{array}{l}\text { Spectroscopic } \\
\text { graphite and } \\
\text { glassy carbon }\end{array}$ & Rat brain & $-50 \mathrm{mV}$ & $\begin{array}{l}\text { Acetylcholine: } 0.3 \mu \mathrm{M} \text { limit } \\
\text { of detection and } 0.088 \mathrm{M} \\
\mathrm{cm}^{2} \text { sensitivity }\end{array}$ & $\begin{array}{l}\text { Developed a three-enzyme based biosensor to monitor } \\
\text { acetylcholine in brain microdialysates. }\end{array}$ & [204] \\
\hline $\begin{array}{l}\text { Poly(ethylene glycol) } \\
\text { diglycidyl ether } \\
\text { (PEGDGE) and Poly(4- } \\
\text { vinylpyridine) }\end{array}$ & $\begin{array}{l}\text { Epilepsy/Stroke/ } \\
\text { Schizophrenia }\end{array}$ & Carbon fiber & $\begin{array}{l}\text { Albino Wistar rats } \\
\text { and organic } \\
\text { hippocampal brain } \\
\text { slices }\end{array}$ & $-150 \mathrm{mV}$ & $\begin{array}{l}\text { Glutamate: } 0.55 \pm 0.07 \\
\mathrm{pA} / \mu \mathrm{M} \text { sensitivity }\end{array}$ & $\begin{array}{l}\text { Five-component redox hydrogel coated microsensor's } \\
\text { response decreased due to interference from reducing } \\
\text { agents, biofouling, and oxygen deprivation. }\end{array}$ & [208] \\
\hline $\begin{array}{l}\text { Poly(phenylene diamine) } \\
\text { (PPD) }\end{array}$ & Stroke/Epilepsy & Platinum & $\begin{array}{l}\text { Sprague-Dawley } \\
\text { rats }\end{array}$ & $+600 \mathrm{mV}$ & $\begin{array}{l}\text { L-glutamate: } 279.4 \pm 2.0 \\
\mu A \\
(\mathrm{mmol} / \mathrm{L})^{-1} / \mathrm{cm}^{2} \text { sensitivity }\end{array}$ & $\begin{array}{l}\text { Sol-gel electrodeposition technique and entrapment of } \\
\text { L-glutamate oxidase enabled a high selectivity, } \\
\text { sensitivity, quick response time, and a strong stability } \\
\text { to monitor analyte. }\end{array}$ & [206] \\
\hline $\begin{array}{l}\text { Polyimide for glutamate } \\
\text { sensor and } \\
\text { Poly(2-hydroxyethyl } \\
\text { methacrylate) (pHEMA) } \\
\text { for lactate sensor }\end{array}$ & --- & Platinum & $\begin{array}{l}\text { Sprague-Dawley } \\
\text { rats }\end{array}$ & $450 \mathrm{mV}$ & $\begin{array}{l}\text { Glutamate: } 2.16 \mathrm{nA} \mathrm{mm^{-2 }} \\
\mu \mathrm{M}^{-1} \text { sensitivity and } 220 \\
\mathrm{nM} \text { limit of detection } \\
\text { Lactate: } 32 \mathrm{nA} \\
\mathrm{mm}^{-2} \mu \mathrm{M}^{-1} \text { sensitivity and } \\
2 \mu \mathrm{M} \text { limit of detection }\end{array}$ & $\begin{array}{l}\text { Multiparametric in vivo monitoring system which } \\
\text { conferred flexibility in positioning biosensor in different } \\
\text { tissues. }\end{array}$ & [202] \\
\hline Chitosan & $\begin{array}{l}\text { Stroke/ } \\
\text { Alzheimer/ } \\
\text { Parkinson/ } \\
\text { Huntington/ } \\
\text { Cancer/ } \\
\text { Schizophrenia }\end{array}$ & Carbon fiber & $\begin{array}{l}\text { Sprague-Dawley } \\
\text { rats }\end{array}$ & $1 \mathrm{~V}$ at $3 \mathrm{kHz}$ & $\begin{array}{l}\text { Glucose: } 13.1 \pm 0.7 \mu \mathrm{M} \\
\text { sensitivity and } 19.4 \pm 0.2 \\
\mathrm{nA} \mathrm{mM}^{-1} \text { limit of detection }\end{array}$ & $\begin{array}{l}\text { Microbiosensor selectively monitored dynamic glucose } \\
\text { fluctuations in live brain tissue with fast scan cyclic } \\
\text { voltammetry at subsecond temporal resolution. }\end{array}$ & [200] \\
\hline Chitosan & --- & Carbon fiber & $\begin{array}{l}\text { Sprague-Dawley } \\
\text { rats }\end{array}$ & $\begin{array}{l}120 \text { pulses, } 200 \mu \mathrm{A} \text {, } \\
\text { applied at } 60 \mathrm{~Hz} \text {, } \\
\text { pulse width of } 2 \mathrm{~ms}\end{array}$ & $\begin{array}{l}\text { Glucose: } 14.8 \pm 0.3 \\
\mathrm{nA} / \mathrm{mM} \text { sensitivity }\end{array}$ & $\begin{array}{l}\text { Entrapment of glucose oxidase in chitosan hydrogel } \\
\text { resulted in glucose microbiosensing with highest } \\
\text { sensitivity and stability. }\end{array}$ & [201] \\
\hline
\end{tabular}




\section{WILEY-VCH}

\subsection{Neural Interfaces for Electrodes}

Neural electrodes can electrically stimulate neurons and/or record neural activity in the brain. However, their surfaces can undergo chemical redox reactions which corrode the metal and release toxic, reactive oxygen species that result in neural cell death. ${ }^{[70]} \mathrm{Hydrogel}$ coatings thus act as a protective layer and minimize the tissue-electrode mechanical mismatch to decrease inflammatory reactions. ${ }^{[22]}$ Yet, even with the addition of conductive materials, Salatino and colleagues note that hydrogels often still possess a Young's modulus which is higher than the surrounding tissue and can result in device failures as well as foreign body reactions. ${ }^{[223]}$ Therefore, electrode hydrogel coatings and their properties need to be tuned to address these issues.

\subsubsection{Key Tunable Parameters and Properties}

A reduction in hydrogel coated electrode recording quality is often associated with increased impedances. ${ }^{[224,225]}$ During recording, the hydrogel interface contacts both the metallic surface of the probe and the neuron cytomembrane to enable the exchange of matter such as water and ions and transforms action potentials to electric currents which are detected by the electrode. ${ }^{[85]}$ The hydrogel impedance is therefore a critical parameter, since it reflects the charge transport at the tissue-electrode interface. ${ }^{[22]}$ This impedance is impacted by the extracellular fluids and the surface adsorption of biological molecules around the electrode, ${ }^{[226]}$ with high impedances indicating an inflammatory response. ${ }^{[227]}$ Researchers who study neural electrodes collect impedance data at $1 \mathrm{kHz}$, as this frequency is a standard reference for neuroprosthetic devices, is correlated to the power consumption during neural electric stimulation, and is relevant to neural recording signals. ${ }^{[15,228,229]}$ Many research efforts focus on developing hydrogel neural interfaces which electrochemically and mechanically mimic the local neural environment to reduce immunological rejections while still promoting and recording neural signals. ${ }^{\left[{ }^{[5]}\right.}$

\subsubsection{State of the Field}

Brain functions can be studied through brain oscillation measurements ${ }^{[13]}$ like visual evoked potentials (VEPs), which are changes in electric potential due to visual stimuli through optic nerves in the visual cortex. ${ }^{[230]}$ While electrodes mounted on scalps detect abnormalities in the VEP waveform non-invasively, ${ }^{[230]}$ the skin cell layer is a source of high impedance for recording signals. ${ }^{[231]}$ Strasser and colleagues developed gold-cup electrodes with hydrogel water beads to solve this issue, as mounting the electrode on the head allowed tight contact without scalp abrasion. ${ }^{[232]}$ However, in comparison to traditional gold-cup electrodes with 


\section{WILEY-VCH}

impedances below $5 \mathrm{k} \Omega,{ }^{[233]}$ the hydrogel coated electrodes had larger impedances. In contrast, Ferlauto and colleagues developed an alginate hydrogel coating with much lower impedances (Table 4) for recording VEP with platinum microelectrodes inserted directly into brain tissue. ${ }^{[15]}$ The researchers' coating process for developing the electrode-hydrogel interface is outlined by Figure 10A - 10C. Overlaying 3D neurospheres on these electrodes resulted in strong tissue adhesion, while inserting the probes into the visual cortex of mice successfully recorded light stimulated VEPs. Overall, the addition of electroconductive alginate increased charge storage capacities and signal-to-noise ratios during recording while also reducing impedances, as demonstrated by the data from Figure 10D.

(A)

(C)

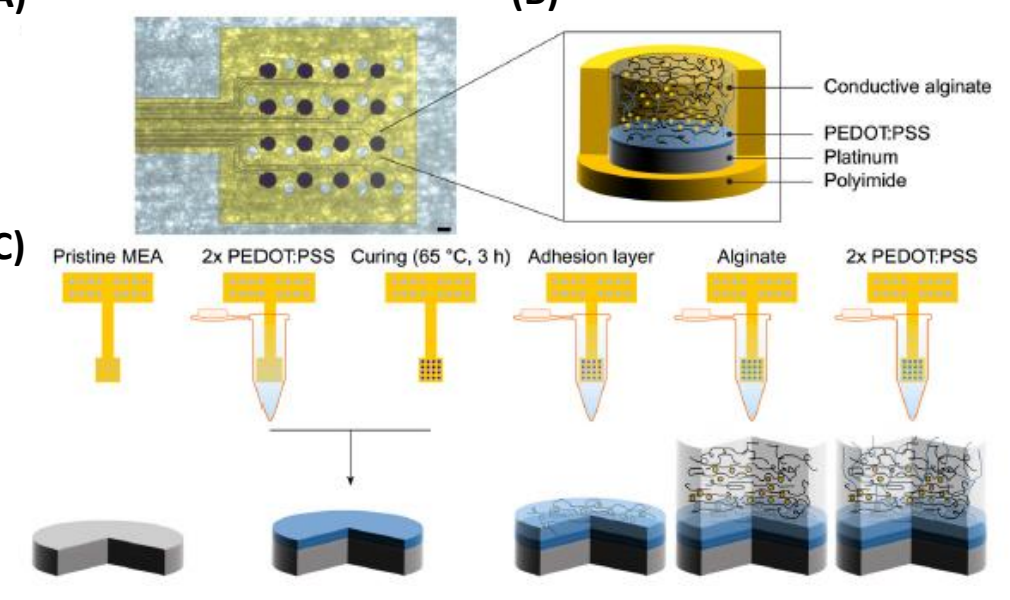

(B)
(D)

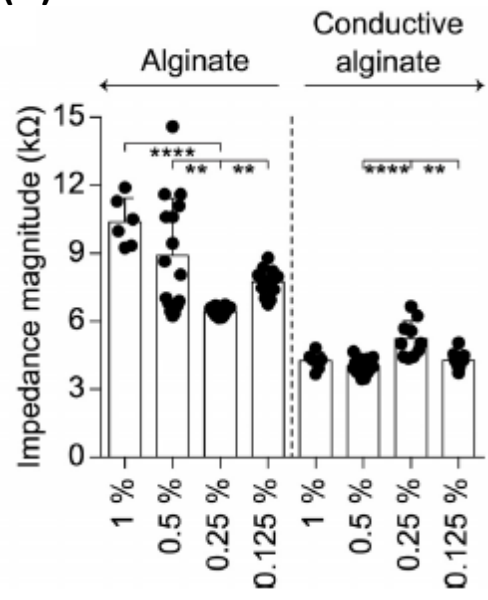

Figure 10. Development and characterization of soft microelectrodes with PEDOT:PSS and alginate hydrogel coating. (A-B) Schematic diagram of the conductive alginate based electrode and its structural components. (C) The sequential process for coating the electrodes with the hydrogel. (D) Impedance magnitudes of the hydrogel coated electrode at $1 \mathrm{kHz}$ for different concentrations of the alginate and conductive alginate. Reproduced under the terms of the Creative Commons Attribution License (CC-BY). ${ }^{[15]}$ Copyright 2018, Frontiers.

For clinical compatibility, neural electrode interfaces must withstand the heat during sterilization. Castagnola and colleagues developed a PEDOT-CNT nanocomposite hydrogel coating and process which can tolerate $122^{\circ} \mathrm{C}$ temperatures for 20 minutes. ${ }^{[72]}$ Thermosensitive fibrin hydrogel was added post-sterilization to avoid denaturing its proteins from high temperatures. This hydrogel encapsulated the nanocoating and ensured no particles detached and dispersed into the brain. The electrodes were implanted in the somatosensory cortex of rats, verifying that fibrin did not affect the impedances upon electric stimulation and remained adherent, thereby protecting tissue from direct exposure to the electrodes. However, the 


\section{WILEY-VCH}

hydrogel was absorbed by brain tissue within 14 days of implantation, which is why the researchers replaced fibrin with pHEMA in a follow up study. ${ }^{[234]}$ This new coating prolonged the timespan for action, withstood sterilization, and did not alter action potentials or signal-tonoise ratios. Moreover, chronic implantations in the cerebral cortex of rats indicated that recordings could be collected for up to 28 days without affecting impedances. Compared to fibrin hydrogels which are quickly metabolized, resorbed within several weeks, and more appropriate for acute neural electrodes, ${ }^{[235]}$ the synthetic hydrogel can better control degradation and polymerization with its chemical inertness, thereby decreasing the risk of an immunological rejection upon implantation. ${ }^{[236]}$

The structural properties of hydrogel coatings impact their conductive properties and electroresponsive behavior. For example, Kim and colleagues galvanostatically grew PPy/PSS through their hydrogel without impacting adjacent neural probe sites. ${ }^{[65]}$ However, the hydrogel pore sizes were not large enough for neuron cell growth and neovascularization, and hence the researchers investigated the impact of freezing and lyophilizing the hydrogels to create larger pores, as demonstrated previously. ${ }^{[237]}$ With a larger pore size, PPy monomers diffused more easily into the hydrogels during polymerization, generating more densely packed conducting polymers and enabling tuned impedances at constant current density. Yet, the hydrogels still reduced signaling detection by reswelling upon implantation and pushing neural cells away from the electrode surface. ${ }^{[238]}$ Thus, the researchers further investigated the effect of altering coating thicknesses by changing the number of dips during electrodeposition. ${ }^{[238]}$ Acute recordings with implanted electrodes in the auditory cortex of guinea pigs revealed that increasing the thickness decreased the number of detectable units by increasing the distance of neural soma from the electrode tip, which interfered with signal transmission and decreased the amplitude of the extracellular spike. ${ }^{[239]}$ Therefore, the proximity of neural cells to the electrode surface is an important consideration for obtaining high quality neural recordings.

The loose contact between metal electrodes and the cortex can inaccurately acquire signals for misdiagnosis in a clinical setting. ${ }^{[84]}$ The structural properties of hydrogels can be altered at the nanoscale level through sequence and structural modulations with self-assembling peptides ${ }^{[13]}$ to address this limitation. Nam and colleagues ${ }^{[13]}$ used self-assembling $\beta$-peptide peptidomimetic foldamers developed previously ${ }^{[240]}$ to show that these nanofibers can tightly enclose bundled CNTs to prevent uncontrolled CNT aggregation and improve the folding stability. The hydrogels can percolate to neuronal cells and seamlessly integrate with local 


\section{WILEY-VCH}

neural networks and tissues without obstructing cerebral blood flow. Upon implanting the coated electrodes in the somatosensory cortex of chronically epileptic mice, the tight contact improved signal amplitude by 2.4 times. In a separate study, Oribe and colleagues used shape conformability to tightly adhere a hydrogel-based electrocorticography (ECoG) electrode to the grooves, ridges, and curved surfaces of the brain for efficacious mapping with electrohemodynamic coupling and combined fMRI and ECoG analysis. ${ }^{[58]}$ The integration of PVA into the 3D mesh structure of carbon fiber increased its toughness, while ex vivo experiments with porcine and rat brains indicated its water swelled surface conformed to curved brain surfaces with nearly $100 \%$ adherence. In contrast, commercially available, hydrophobic silicone ECoG electrodes left gaps at the rim due to only $40 \%$ adherences. Implanting these electrodes in the cerebral cortex of rats revealed that the brainwaves can be detected with the same amplitude, waveform, and power spectrum as other research groups. ${ }^{[241]}$

While conventional probes possess electrode sites at the surface or tip ${ }^{[56]}$, an alternative design by Kennedy and coworkers illustrated that electrodes containing a small glass cone filled with sciatic nerve segments and either matrigel or neurotrophins can improve neural detection by attracting cell growth and increasing adherence. ${ }^{[242]}$ Since labor intensive fabrication limited its widespread implementation, Parylene sheath electrodes (PSE) eventually replaced the glass and reduced mechanical mismatches with soft tissue. ${ }^{[56]}$ Lee and colleagues developed PSEs coated with matrigel to promote neurite ingrowth during recordings ${ }^{[56]}$ and further encapsulated the matrigel with brain derived neurotrophic factors, nerve growth factors, as well as DEX to inhibit the immune response. ${ }^{[243]}$ However, all the loaded components eluted too fast to confer therapeutic benefits. Since a prolonged DEX release over the course of several days ${ }^{[244]}$ to weeks ${ }^{[245]}$ can reduce astrocyte growth near electrodes, Lee and colleagues suggest that further encapsulation of DEX in biodegradable microparticles prior to loading in the matrigel can slow the elution, as demonstrated previously. ${ }^{[246]}$

Hydrogel neural interfaces can also improve user comfort during direct electric stimulation regimes. For instance, conventional tDCS electrodes possess a "wet" surface with a fluid or viscous electrolyte which can irritate the skin upon contact. ${ }^{[247]}$ To address this issue, Khadka and colleagues developed the first "dry" tDCS electrodes comprising a flexible, printed circuit board sensor based on PVA polymers to monitor current distribution during electric stimulation. $^{[248]}$ Weak current electric stimulation on human subjects revealed a lack of 


\section{WILEY-VCH}

significant adverse effects with hydrogel electrodes, while the conventional sponge electrode had a higher incidence of adverse events.

In addition to comfort, electric stimulation regimes ought to be safe without excessive and tissue damaging overpotentials. ${ }^{[249]}$ Electrode delamination under high charge densities can also deposit particles to adjacent tissues. ${ }^{[250]}$ Zhou and colleagues ${ }^{[226]}$ therefore developed electrodes layered with an electrodeposited iridium oxide film and further encapsulated the film with a previously optimized PVA/PAA formulation ${ }^{[249]}$ to reduce inflammation and decrease direct tissue contact. The coated microelectrodes were implanted into the motor cortex of rats and lowered the impedance even after 21 days of biphasic electric stimulation. Thus, the hydrogel acts as an ionic conductive layer to stabilize charge transfer. ${ }^{[249]}$ An efficient electrode charge injection capability is also important, since charge transfers need to surpass neuronal depolarization within a narrow window of $100-200 \mu \mathrm{s},{ }^{[249]}$ while a high charge injection limit raises safety margins during electric stimulation. ${ }^{[251]}$ Hence, the same research team separately investigated electrodeposition with different materials ${ }^{[251]}$ and determined that PPy/SWCNT led to the highest charge storage capacity due to a high number of redox reactions between surrounding electrolytes and the polymer films containing $\mathrm{CNTs},{ }^{[252]}$ which served as an electron conducting network. Furthermore, the porous structure of SWCNT ensured a fast and safe charge transfer capacity, as large pore surfaces widen the electrode-electrolyte interface for ion transfer. This finding was further corroborated by a follow up study in which the researchers determined that in situ co-deposition/polymerization of PEDOT/MWCNT composites under galvanostatic modes improved the electrochemical stabilities compared to potentiostatic modes when microelectrodes were subjected to continuous, high charge density electric fields. ${ }^{[135]}$ The porous structure of galvanostatic films lowered impedances and increased the surface area, conductivity, charge storage capacity, and charge injection limits. Applying a clinically relevant electric stimulation protocol with $1 \mathrm{mC} / \mathrm{cm}^{2[253]}$ indicated that the cathodic charge storage capacity losses were much lower than potentiotstatic films, which aligned with an assertion by Giuseppi-Elie ${ }^{[34]}$ that greater kinetic control is achieved under galvanostatic modes.

Recently, strong interest has been garnered in developing multifunctional neural interfaces with simultaneous drug release, electric stimulation, and neural recording capabilities. ${ }^{[254]}$ Such interfaces can be developed by selectively patterning the hydrogel at resolutions of a few 


\section{WILEY-VCH}

micrometers. ${ }^{[254]}$ Traditional coating processes lack site-specificity, and a partially conducting hydrogel may limit the recording resolutions, lead to spike sorting, and risk creating short circuits on densely spaced electrodes. ${ }^{[254]}$ Individual probes should therefore be tailored independently on an array to optimize each site separately, as Kleber and colleagues demonstrated by integrating a wafer scale coating process into the probe fabrication step on a single chip level. ${ }^{[254]}$ This flexible photolithographic coating procedure tuned the electrochemical properties and controlled the hydrogel layering step to reach a predefined thickness. Zhang and colleagues also developed a multifunctional PEGDA hydrogel ${ }^{[125]}$ through an interfacial chemical polymerization process. ${ }^{[255]}$ The researchers doped DEX anions to bind electrostatically with PPy to reduce glial scars by releasing DEX during electric stimulation. ${ }^{[125]}$ Exposing the hydrogel to RAW cells demonstrated that the DEX was released in a sustained manner during cyclic voltammetry and retained its bioactivity by inhibiting macrophage activation.

Ideal electrode coatings should conform to the brain microenvironment. Spyropoulos and colleagues developed an aloe vera hydrogel material to coat TES electrodes. ${ }^{[41]}$ The optimized formulation molded to rat skulls in vivo with a stable contact and low impedances, as aloe vera increased the charge capacity with its porous structures. These coated electrodes enabled neuromodulation for both electrically inducing and recording epileptic activity in multiple regions of rat brains. In another study, Sheng and colleagues developed a PEG-based hydrogel containing artificial cerebrospinal fluid and demonstrated that a single fiber can concurrently provide optical stimulation and capture neural recording of moving mice. ${ }^{[85]}$ These hydrogels mimicked neural extracellular fluid on a chemical and electric level, while their soft mechanical properties minimized mismatch with neural tissue. The hydrogels served as a neural interface upon implantation in free moving mice and distinguished signals between wake and sleep states. A neural interface should ideally be stiff for insertion into brain tissue and soft after implantation to reduce mechanical mismatch. ${ }^{[85]}$ The researchers further enhanced their hydrogel by insulating with a tube of dielectric elastomer. This tube remained frozen to increase stiffness prior to implantation, yet the water in the hydrogel melted and softened the material after insertion.

To precisely stimulate and accurately obtain electric recordings without significant signal dissipation, a tight cell-electrode interface is needed for signal transmission. ${ }^{[256]}$ While cells can 


\section{WILEY-VCH}

be loaded onto electrodes, they often attach randomly with low patterning yields, extend neurites in an uncontrolled manner, or do not adhere to specified areas. ${ }^{[257]}$ Furthermore, the detaching cells perturb the cell physiology and morphology. ${ }^{[257]}$ Previous research has shown that mobile cell-laden electrodes conserve adherent properties and extract well-defined cells from a mixed population, ${ }^{[258,259]}$ which can promote cell-cell interactions and construct neural networks. ${ }^{[260]}$ In their study, Teshima and colleagues developed a mobile electrode coating at a nanoscale level thickness capable of interfacing with adherent neural cells. ${ }^{[257]}$ The composite was lithographically micropatterned to control its shape and size, while ECM was encapsulated inside to enable loaded neural hippocampal cells to attach with high affinities. The elongated neurites established cell-cell contact for synaptic plasticity and signal transmission, and the nanopallets further reduced the electrode impedance signal losses through a tight electrodehydrogel interface. ${ }^{[257]}$ The signal collection efficiencies improved by allowing action potentials to integrate with the microelectrode array. Thus, the cells on the composites can be delivered with microscale positioning to form designed neural networks through selective, spatiotemporally controlled activation during electric stimulation.

\subsubsection{Key Challenges}

One of the biggest challenges in developing electroconductive hydrogel coatings for neural probes is to safely deliver a high density charge. ${ }^{[135]}$ Repeated and long term electric stimulation can eventually erode the hydrogel coating, which is why chronic electric stimulation electrodes ought to be both mechanically and electrochemically stable while reducing the power consumption. ${ }^{[135]}$ These coatings must also be biocompatible with an interface stability, ${ }^{[18,261]}$ especially considering that a low adhesion to cells not only leads to electrode functional loss and a reduction in the therapeutic benefits, but can also harm the surrounding neural tissue. ${ }^{[262]}$ Methods to improve cellular adhesion on the hydrogel-coated electrodes during electric stimulation and neural recording are discussed in greater detail in section 7.4. As was highlighted earlier, astrogliosis and an inflammation in response to the electrode implantation can further impede electric signal transmissions. Several studies reportedly conducted impedance measurements under bench scale, in vitro settings only. Zhou and colleagues noted that in vitro measurements of bare electrode impedances were much lower than the in vivo impedance data in animal models for the same electrodes. ${ }^{[226]}$ Since impedances are critical for the performances of hydrogel-based neural interfaces, these properties should be assessed under physiologically relevant conditions, as the data may otherwise falsely indicate high electric signal transmissions in vitro. On the other hand, in vitro experiments can also falsely 


\section{WILEY-VCH}

demonstrate a decrease in signal with time if cell viabilities decrease due to cell culture conditions, as opposed to any hydrogel erosion. A summary of the hydrogel material components and electrochemical properties, electrode type, electric stimulation parameters, cell culture or animal models, and the resulting outcomes from each of the studies which developed electroresponsive hydrogels for neural electrode interfaces is provided by Table 4 . 
WILEY-VCH

Table 4. Electroresponsive hydrogels as neural interfaces.

\begin{tabular}{|c|c|c|c|c|c|c|}
\hline $\begin{array}{c}\text { Hydrogel Polymer and } \\
\text { Electroconductive Materials }\end{array}$ & $\begin{array}{l}\text { Electrode } \\
\text { Type }\end{array}$ & $\begin{array}{c}\text { Cell Model/Animal } \\
\text { Model/Human Subject }\end{array}$ & $\begin{array}{c}\text { Electric Stimulation } \\
\text { Parameters }\end{array}$ & $\begin{array}{c}\text { Hydrogel Electric } \\
\text { Properties }\end{array}$ & $\begin{array}{c}\text { Hydrogel } \\
\text { Biocompatibility }\end{array}$ & Outcome \\
\hline Polyacrylic acid (PAA) & Gold & Human subjects & $\begin{array}{l}\text { Visually evoked } \\
\text { potentials at } 1000 \\
\mathrm{~Hz}\end{array}$ & $\begin{array}{l}20-80 \mathrm{k} \Omega \text { impedance } \\
\text { at } 1 \mathrm{kHz}\end{array}$ & No scalp abrasion & $\begin{array}{l}\text { Hydrogel coating had } 10 \text { times higher impedance } \\
\text { than standard gold electrodes, but visual evoked } \\
\text { potentials can still be recorded with comfort to } \\
\text { user. }\end{array}$ \\
\hline $\begin{array}{l}\text { Poly(3,4-ethylene- } \\
\text { dioxythiophene)- polystyrene } \\
\text { sulfonate (PEDOT:PSS) and } \\
\text { Alginate }\end{array}$ & Platinum & $\begin{array}{l}\text { Human neural stem } \\
\text { cells (hNSCs) from } \\
\text { induced pluripotent } \\
\text { stem cells and } \\
\text { C57BL6J mice }\end{array}$ & $\begin{array}{l}\text { On mice, visually } \\
\text { evoked cortical } \\
\text { potentials filtered } \\
\text { from } 0.1-300 \mathrm{~Hz}\end{array}$ & $\begin{array}{l}4.26 \pm 0.29 \mathrm{k} \Omega \\
\text { impedance at } 1 \mathrm{kHz}\end{array}$ & --- & $\begin{array}{l}\text { Coated microelectrodes had lower impedance } \\
\text { magnitude, higher charge storage capacities, } \\
\text { more resistive behavior, and improved signal-to- } \\
\text { noise ratio during neural recordings compared to } \\
\text { uncoated electrodes. }\end{array}$ \\
\hline $\begin{array}{l}\text { Fibrin, Carbon nanotube } \\
\text { (CNT), Poly(3,4-ethylene- } \\
\text { dioxythiophene) (PEDOT) }\end{array}$ & $\begin{array}{l}\text { Gold and } \\
\text { Copper }\end{array}$ & Long-Evans rats & $\begin{array}{l}18.1 \mu \mathrm{V} \text { to } 99.6 \mu \mathrm{V} \\
\text { at } 10 \mathrm{~Hz}\end{array}$ & $\begin{array}{l}3.4-3.9 \mathrm{k} \Omega \\
\text { impedance at } 100 \mathrm{~Hz}\end{array}$ & Biocompatible & $\begin{array}{l}\text { Fibrin encapsulation of nanocoatings did not } \\
\text { reduce electrical performance or neural signals } \\
\text { from rat cortex, but hydrogel resorbed in } 14 \text { days. }\end{array}$ \\
\hline $\begin{array}{l}\text { Poly(2-hydroxyethyl } \\
\text { methacrylate) (pHEMA), } \\
\text { Polystyrene sulfonate (PSS), } \\
\text { Carbon nanotube (CNT), } \\
\text { Poly(3,4-ethylene- } \\
\text { dioxythiophene) (PEDOT) }\end{array}$ & Platinum & Wistar rat model & $24,414 \mathrm{~Hz}$ & $\begin{array}{l}1.2 \pm 0.9 \mathrm{k} \Omega \\
\text { impedance at } 1 \mathrm{kHz}\end{array}$ & $\begin{array}{l}\text { Glial response to } \\
\text { chronic implantation, } \\
\text { but without } \\
\text { detectable neuronal } \\
\text { cell loss }\end{array}$ & $\begin{array}{l}\text { The hydrogel preserved recording quality and } \\
\text { electrochemical performance while decreasing } \\
\text { mechanical mismatch of electrode with tissue. }\end{array}$ \\
\hline $\begin{array}{l}\text { Polypyrrole (PPy), Polystyrene } \\
\text { Sulfonate (PSS), and Alginate }\end{array}$ & Gold & Guinea pig & --- & $\begin{array}{l}7 \mathrm{k} \Omega \text { impedance at } 1 \\
\mathrm{kHz}\end{array}$ & --- & $\begin{array}{l}\text { Uniform coatings with different thicknesses } \\
\text { developed by controlling dipping method, and } \\
\text { polymers can be steadily grown by disrupting } \\
\text { microstructure with freeze drying. }\end{array}$ \\
\hline $\begin{array}{l}\text { Alginate and Poly(3,4- } \\
\text { ethylene-dioxythiophene) } \\
\text { (PEDOT) }\end{array}$ & Gold & Guinea pig & --- & --- & --- & $\begin{array}{l}\text { Neural signal quality decreased with increase in } \\
\text { hydrogel thickness. PEDOT improved recording } \\
\text { function with signal-to-noise ratios. }\end{array}$ \\
\hline $\begin{array}{l}\text { betaVhex beta peptides and } \\
\text { carbon nanotubes (CNTs) }\end{array}$ & Silver & $\begin{array}{l}\text { C57BL/6N mice and } \\
\text { C57BL/6J-Tg (Thyl- } \\
\text { GCaMP6f) } \\
\text { GP5.17Dkim/J mice }\end{array}$ & $200 \mathrm{~Hz}$ & $\begin{array}{l}\text { From } 0-200 \mathrm{~Hz} \text { : less } \\
\text { than } 0.2 \mathrm{M} \Omega \\
\text { impedance }\end{array}$ & $\begin{array}{l}\text { No robust microglial } \\
\text { activation and } \\
\text { therefore } \\
\text { biocompatible }\end{array}$ & $\begin{array}{l}\text { Intracortical and epidural neural signals recorded } \\
\text { with hydrogel were enhanced in the high } \\
\text { frequency range and exhibited an increased } \\
\text { contact area through tight tissue/hydrogel } \\
\text { coupling. }\end{array}$ \\
\hline $\begin{array}{l}\text { Poly(3,4-ethylene- } \\
\text { dioxythiophene) carbon fiber } \\
\text { (PEDOT-CF) and Polyvinyl } \\
\text { alcohol (PVA) }\end{array}$ & Gold & $\begin{array}{l}\text { Porcine brain slices, rat } \\
\text { brain slices, and } \\
\text { ARPE- } 19 \text { human } \\
\text { retinal epithelial cells }\end{array}$ & $\begin{array}{l}5 \mathrm{~Hz} \text { to } 1 \mathrm{kHz} \text { with } \\
\text { sinusoidal waves }\end{array}$ & $\begin{array}{l}\text { At } 1 \mathrm{kHz} \text {, impedance } \\
\text { was } 60 \Omega / \mathrm{cm}^{2} \text { in rat } \\
\text { brain }\end{array}$ & $\begin{array}{l}\text { Non-toxic with } \\
\text { human retinal } \\
\text { epithelial cells }\end{array}$ & $\begin{array}{l}\text { Coated electrodes conformed to the curved and } \\
\text { grooved surfaces of brain slices, while } \\
\text { simultaneous electrocorticography and fMRI } \\
\text { measurements can be obtained without image } \\
\text { artifacts. }\end{array}$ \\
\hline
\end{tabular}




\section{WILEY-VCH}

Poly(vinyl alcohol) (PVA) and Poly(acrylic acid) (PAA)

Polypyrrole (PPy) and Single Wall Carbon Nanotubes (SWCNT)

Multiwalled carbon nanotubes (MWCNT), and Poly(3,4 ethylenedioxythiophene) (PEDOT)

P(DMAA-co-5\%MABP-co$2,5 \% \mathrm{SSNa}$ ) (PDMAAp) and Poly(3,4-ethylene-

dioxythiophene) (PEDOT) nanotubes (SWCNTs) Polypyrrole (PPy),

Poly(ethylene) dimethacrylate (PEGDA), and Polyacrylamide (PAAm)

macrophages
$10 \mathrm{mV}$ at sinusoid $\mathrm{kHz}$ applied to rats current applied fo 20 minutes

Platinum and Sprague-Dawley rats Iridium frequencies varying from $1 \mathrm{~Hz}$ to 100 implanted with electrode

From $1 \mathrm{~Hz}$ to $100 \mathrm{kHz}$ requencies, impedances were about $70 \mathrm{k} \Omega$ for coate electrodes with and without growth factors at week 1 post implantation

$-$

Biphasic current pulses with $50 \mu \mathrm{A}$ pulse width at 100 pulses per second

Platinum

PC12 rat cells and SpragueDawley rats

Platinum

PC12 rat

pheochromocytoma cells and SpragueDawley rats

Platinum

SH-SY5Y neuroblastoma cells

$50 \mathrm{~Hz}$ of anodic first current pulses at 3.0 $\mathrm{mC} / \mathrm{cm}^{2}$ charge injection density for $12 \mathrm{~h}$ (over $2.1 \times 10^{6}$ cycles)

Symmetric cathodic Symmetric cathodic first pulses at $50 \mathrm{~Hz}$ for $96 \mathrm{~h}$ with charge density of $1 \mathrm{mC} / \mathrm{cm}^{2}$

\section{Biphasic cathodic-} first current pulse with width of $200 \mu \mathrm{s}$ anodic pulses with width of $800 \mu \mathrm{s}$, at $200 \mathrm{~Hz}$ for 8 days with charge density

Cyclic voltammetry

\section{PC12 rat}

pheochromocytoma ranging from -0.1 to cells and RAW 264.7 $+0.5 \mathrm{~V}$ at scan rate mouse leukemic

monocyte of $100 \mathrm{mV} / \mathrm{s}$

About $10^{4} \Omega$

$2.06 \mathrm{k} \Omega$ impedance at $1 \mathrm{kHz}$

\section{$2.8 \pm 0.1 \mathrm{k} \Omega$}

mpedance

at $1 \mathrm{kHz}$

$10 \mathrm{k} \Omega$ to $10 \mathrm{M} \Omega$

impedance over

range from 0.1 to

$100,000 \mathrm{~Hz}$ amplitude, $100 \mu \mathrm{s}$

No significant astrocytic density between probes coated with MG only + loaded with dexamethasone

Skin tingling, burning, itching most common most common

impedance at $1 \mathrm{kHz}$

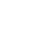

Probes coated with MG and loaded with bioactive molecules did not improve performance over probes coated with MG alone due to fast elution of payload.

Tolerability improved and adverse events decreased with hydrogel coating.

Hydrogel coating stabilized the electric charge ransfer at the tissue-electrode interface an reduced impedance by $40 \%$ compared to uncoated electrodes. PC12 cells and

reduced

inflammatory

response in rats

Biocompatible with PC12 cells and rats

Cell viabilities between $80-90 \%$ when cultured on hydrogel substrates

Biocompatible and non-cytotoxic
Biocompatible with
PPy/SWCNT composite compatible with other microfabrication processes and improved capacitance, impedance, and the charge injection capacity.

Galvanostatic modes demonstrated best electrochemical performance and stability while promoting cell adhesion, neurite outgrowth, and low tissue response upon in vivo implantation.

Batch wafer-scale fabricated and coated probes possessed stable performance for up to a year. Tuning PEDOT affects charge injection limits.

All drugs delivered after 6000 pulses with electric stimulation. Drug release increased with PPy as linear and sustaining release profile. SWCNT concentration of $0.4 \mathrm{mg} / \mathrm{mL}$ and scan rate of 100 $\mathrm{mV} / \mathrm{s}$ are optimal for drug release. 


\section{WILEY-VCH}

Aloe vera and Poly $(3,4-$

ethylenedioxythiophene)

polystyrene sulfonate

(PEDOT:PSS)

Poly(ethylene glycol diacrylate) (PEGDA)
Gold

\section{Long Evans rats}

Platinum and

Silver eYFP mice, C57BL/6 mice, and cats

Indium tin oxide

\section{Neural hippocampa} cells and Chinese cells and Chinese
VGAT-ChR2(H134R)

Silk Fibroin and Poly(3,4ethylenedioxythiophene)

polystyrene sulfonate (PEDOT:PSS)
10 ms duration

About $5.5 \times 10^{5} \Omega$ $\mathrm{s}$ at $3 \mathrm{~mA}$ and $60 \mathrm{~Hz}$

$10 \mathrm{kHz}$ and $40 \mathrm{kHz}$ At $1 \mathrm{kHz}$

Biocompatible

owered impedance, and modulated neuron

activity in vivo to induce focal epileptic seizures

and simultaneously record neural activity.

A single hydrogel fiber can simultaneously record and optically stimulate free moving mice.

immunochemical

reaction than bare

electrodes in mice

Biphasic square waves with $10 \mathrm{~Hz}$ frequencies at 100

At $10 \mathrm{~Hz}, 62.1 \Omega$ impedance with cell laden nanopallets
Biocompatible
Hydrogel nanopallet conductivity was tunable and activated the adherent cells in a non-cytotoxic manner upon electric stimulation. 


\section{WILEY-VCH}

\section{Future Perspectives}

Many treatments involving the electroresponsive hydrogels discussed in this review require invasive procedures. For instance, probes may need to remain inserted in soft brain tissue for neural recordings or electric stimulation. However, patient comfort can be augmented by controlling electric stimulation externally and non-invasively. A closed-circuit electroresponsive hydrogel would enable wireless electric stimulation in vivo, without requiring an electrode to generate electric fields. Hydrogels responsive to endogenous electric fields, such as the changes in charge distribution during epilepsy, can treat patients without electric stimulation. On another note, mechanoresponsive piezoelectric materials integrated into hydrogels can induce electric fields through non-invasive, controlled stimulations with externally directed changes in ultrasound or mechanical pressure. ${ }^{[32]}$ As an example, Rojas and colleagues demonstrated that piezoelectric barium titanate nanoparticles modulate electrophysiological neural network activity with low intensity, pulsed acoustic stimulation. ${ }^{[263]}$ Guo and colleagues also developed an electrogenetic layered hydrogel membrane containing charged nanopillars in between graphene sheets to serve as a nanofluidic generator and convert the hydraulic motion to an electric field. ${ }^{[264]}$ Closed-loop, electroresponsive hydrogel materials also enable precision medicine, as Grahne and colleagues reported that when closed-loop systems are used for deep brain electric stimulation, the combinatorial electrophysiological recording and neurochemical detection can tailor treatments toward patient specific needs. ${ }^{\text {[265] }}$

Modifications to biomaterials can also improve patient comfort. Hydrogels that undergo gelation during a transition from room to physiologic temperature provide a unique opportunity for minimally invasive, injectable materials. The crosslinking conditions can also be altered to tune its injectable delivery properties. For instance, thiol-Michael addition reaction hydrogels rapidly crosslink at physiologic temperature under basic conditions and can be injected into the appropriate site without the need for invasive surgery. ${ }^{[266]}$ Additionally, injectable hydrogels may better adhere to the tissue environment by crosslinking in situ and conforming to patient specific anatomy.

This review revealed that the relationships among the tunable hydrogel parameters and their electric and mechanical properties are complex and often contradictory for optimization. Shi and colleagues reviewed natural electroconductive polymer-based hydrogels and also reported that it is difficult to compare different hydrogels based on their electric properties, since the 


\section{WILEY-VCH}

characterization protocols vary from paper-to-paper. ${ }^{[32]}$ Hence, computational methods ought to be coupled with experimental results to optimize electroresponsive hydrogel formulations. Most of the reported studies did not systematically vary the hydrogel parameters which are important for electric signal transmission. Researchers should vary the concentration of the electroconductive material, chemical properties of hydrogel polymers such as the molecular weight or functional groups, mechanical properties such as the viscoelastic characteristics, and structural properties like the porosity/pore size. A systematic design of experiment will help researchers derive the complex relationships among all these different parameters. The experimental data can then be supplied into a model to predict the optimal properties for specific outcomes.

For instance, Campbell and coworkers computationally modeled an alginate based hydrogel and optimized the mesh sizes for delivering therapeutic agents. ${ }^{[267]}$ Upon establishing their model, the researchers further validated it with other PEG and fibrin based hydrogels. Moreover, the researchers integrated a full factorial and Box-Behnken design of experiment to predict the maximum and minimum mesh sizes for controlling delivery. On a similar note, Farooqi and colleagues developed a computational model to optimize an electroactive hydrogel for cartilage-tissue repair through electric stimulation. ${ }^{[268]}$ In a separate study, these researchers demonstrated that numerical simulations through finite element modeling can determine the effect of electric stimulation on hydrogels during the cartilage-tissue repair process. ${ }^{[269]}$ Upon implantation in vivo, electroresponsive hydrogels need to endure complex mechanical loads, and mathematical models can predict these mechanical behaviors. ${ }^{[270]}$ Therefore, computational methods can elucidate the complex relationships among the hydrogel viscoelastic and electromechanical properties, as well as responses to electric stimulation and mechanical loads.

Future research should also aim to develop more multifunctional electroresponsive hydrogels to simultaneously detect electric signals for neural recording or biosensing, release drugs, and enable electric stimulation. Multiple functionalities can improve treatments with a single implant and may even unearth novel relationships in complex neural pathways. For instance, Shin and colleagues developed a multifunctional and multi-shank neural probe to optically control stimulation, induce drug delivery through integrated microchannels, and contain a microarray for neural recording. ${ }^{[271]}$ The researchers demonstrated that their device could elucidate the connection between the hippocampal CA1 and CA3 regions in the brain in vivo. 


\section{WILEY-VCH}

Some of these strategies to improve the clinical applications of electroresponsive hydrogels in the brain are highlighted by Figure 11. Further insights into future perspectives and recommendations for each of the four applications discussed in this review are provided in greater detail in the subsequent sections.

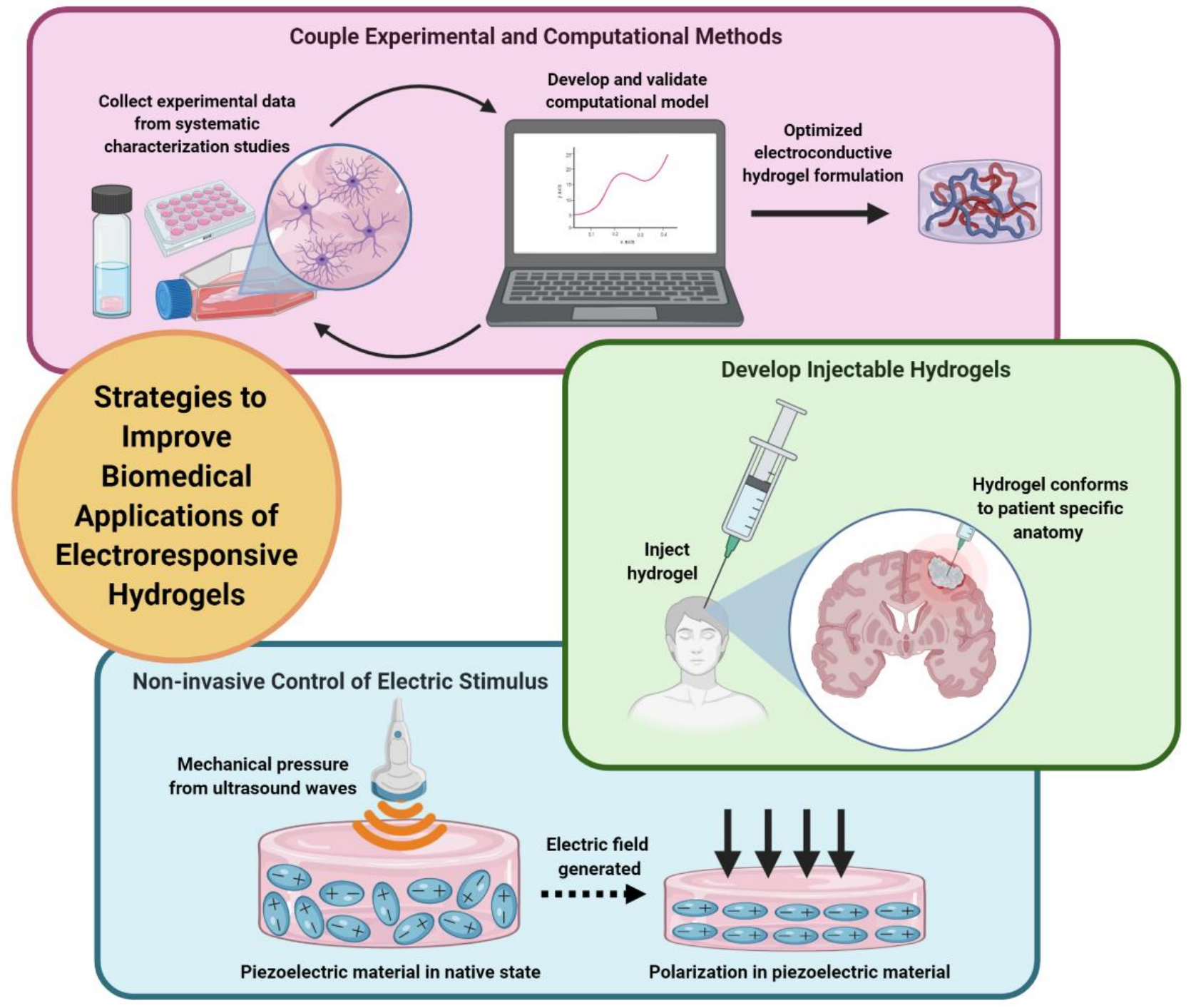

Figure 11. Schematic overview of strategies to improve the administration and implementation of electroresponsive hydrogels in the brain. Created with BioRender.com.

\subsection{Controlled Delivery}

Hydrogel pore sizes and porosity are important considerations for drug delivery, since they affect the swelling/deswelling behaviors and control the payload releases in response to electric stimulation. However, most studies do not characterize these properties when optimizing hydrogels for controlled delivery applications. Some common methods which can be employed to characterize pore sizes and porosity include diffusion studies with molecules of various sizes and small angle X-ray scattering. Both methods will elucidate molecule sizes which are able to 


\section{WILEY-VCH}

diffuse in and out of the hydrogel, including immune cells and markers, while also precisely measuring the pore size for comparison. Cadotte and colleagues report that drug diffusion profiles from hydrogels also depend on the initial drug concentration loaded into the platform. ${ }^{[96]}$ While saturation can lead to premature burst release, very low loading concentrations may slow the release too much to confer any therapeutic benefits, as demonstrated by Dong and colleagues. ${ }^{[272]}$ Although no study reported in this review investigated the impact of the loading concentration on the electrically stimulated release profiles, this property should be investigated in future research as well.

As mentioned previously, the passive diffusion of therapeutic agents can lead to undesired side effects, but it can be minimized by developing binding sites on the hydrogel to anchor the drugs in place. Ideally, electric stimulation should break these bonds to release the agents, or otherwise control the bulk erosion to degrade the hydrogel and release the payload. Other options include developing 'smart' materials that incorporate cleavable bonds which can break in response to stimulation such as $\mathrm{pH}$ change, UV light, or surrounding cell infiltration. The hydrogel polymer backbone can also be functionalized with end groups to covalently attach the drugs. Modifications to copolymers can impact the matrix solubilization and stability by creating hydrophobic regions for nonpolar agents and hydrophilic regions for polar agents. ${ }^{[96]}$ Alternatively, electrostatic interactions can keep drugs embedded by enabling drug anions to attract and interact with positively charged polymers or end groups in the hydrogel. For example, Giuseppi-Elie reported that pendant anions like sulfonates can be internally doped or reactive groups such as alcohols and carboxylic acids can be covalently bonded into electroconductive hydrogels through copolymerization to keep biomolecules anchored. ${ }^{[34]}$ Since increasing the hydrogel crosslinking density can reduce diffusion rates, crosslinking agents can be added to modulate the diffusion ${ }^{[96]}$ and drug release. If a longer sustained release is desired, the therapeutic agents can also be encapsulated into microparticles or nanoparticles to prolong the elution process and ensure that even after diffusive transport, the particle erosion will slowly release the entrapped agents.

Off target effects can be minimized by attaching a targeting ligand to the drug to deliver it to tissues and cells of interest. For instance, Affinito and colleagues recently identified RNA aptamers that selectively bind to glioma cancer stem cells and developed bifunctional aptamer conjugates to carry drugs and concurrently target cancer cells for glioblastoma treatment. ${ }^{[273]}$ 


\section{WILEY-VCH}

Protein-based targeting ligands, such as monoclonal antibodies, can also deliver drugs to appropriate neural tissues. Additionally, nanosized hydrogel drug carriers can pass through the BBB upon systemic drug administration ${ }^{[274]}$ and evade invasive neurosurgical implantation. If brain cell targeting ligands are attached to these nanocarriers and the treatments are combined with electric stimulation, then drug release can be controlled spatiotemporally.

\subsection{Neural Stem Cell Differentiation and Neurogenesis}

Natural ECM-based polymers are highly suitable to support neural growth and cell survival. These hydrogels promote cell-cell contact, adhesion, and the formation of neural networks. Natural ECM-based polymers also mimic the 3D microenvironment necessary for inducing cell aggregates and recapitulating physiologic conditions. Coupling these natural polymers with conducting materials in hydrogels can provide cues to activate gene expression and regulate calcium ion concentrations during neurogenesis. Hence, electric fields and material properties can synergistically enhance the cellular responses to electric stimulation. Additional optimization of topography and micropatterns on the scaffolds can then direct the neural cell growth and differentiation, since specific dimensions and geometries influence these biological properties.

According to Table 2, the electric field parameters and pulsing schemes are specific to the cell line or animal model used in each study. Since stimulation protocols need to be optimized for different in vitro or in vivo models, it is difficult to identify standard practices for promoting neural regeneration through electric stimulation and configuring these parameters for human subjects under clinical settings. For example, Imaninezhad and colleagues report the voltage dosages in their study are specific to PC12 cells and need to be readjusted for other cell lines. ${ }^{[187]}$ Researchers can minimize this limitation by integrating more translational techniques into experiments. By opting to use primary human cell lines, such as normal human astrocytes instead of animal cell lines, the experiments can better recapitulate patients' physiologic environments. Ravi and colleagues recently established a protocol for human organotypic brain slice cultures which can develop a 3D, physiologically relevant model for diseased states by collecting tissue samples from patients with brain tumors or epilepsy to maintain the neuronal tissue environment for an extended period of time. ${ }^{[275]}$ Hence, these translational models can mimic the microenvironment to better assess the impact of electric fields on NSC differentiation and neurogenesis in electroresponsive hydrogels. 


\section{WILEY-VCH}

Translational research techniques can also be implemented through patient specific in vitro models with 3D printing. For instance, MRI can capture patient specific anatomical structures of the brain, and computer-aided design can transform these images into models for 3D printed structures. Bordoni and colleagues recently developed the freeform reversible embedding hydrogel (FRESH) technique to 3D print a brain-slice-like construct with high resolution in a gelatin support to obtain a scaffold that maintains the realistic, intricate surfaces of the brain. ${ }^{[15]}$ Such microfabrication methods can develop novel, 3D in vitro models to test patient specific, in situ neuronal regeneration and repair. Furthermore, targeted treatments will minimize random neural outgrowth by localizing neural repair to specific tissues.

\subsection{Neural Biosensors}

As highlighted previously, biosensors implanted in vivo often lead to biofouling and denature the electrode surface due to non-specific protein adsorption. The consequent inflammatory response can form a fibrous capsule around the implant and reduce sensitivity to the target analyte, which is why researchers should actively incorporate strategies to minimize biofouling. As is evident from Table 3, the most widely used biosensor is carbon based. Carbon electrodes are non-toxic and resist biofouling, ${ }^{[201]}$ rendering them ideal as chronic biosensors. Antibiofouling strategies which target and modify the biomaterials can also be implemented, such as tuning the hydrophilicity/hydrophobicity of surface properties to avoid protein adhesion. Hydrophobic surfaces can release adhered proteins, while hydrophilic surfaces form a hydration layer to prevent protein adhesion altogether. ${ }^{[276]}$ Shin and colleagues demonstrated that a PEDOT/PEG nanocomposite possessing anti-fouling properties can rapidly detect cytokines in whole blood, ${ }^{[277]}$ since PEG-based hydrogels can inhibit protein adsorption. ${ }^{[278]}$ Hydrogel surface architectures can also be altered to reduce protein adhesion. Zwitterionic or polyampholyte polymer brushes grafted onto the surface resist non-specific protein conjugation on hydrogel coatings. ${ }^{[279]}$ Tailored topographies and micropatterning also roughen the surface coating of electrodes. Shi and colleagues showed that imprinting nanocavities on their electrode surface enabled only specific proteins to interlock with the cavity and reduced non-specific protein adhesion. ${ }^{[280]}$

In an alternative strategy, researchers may encapsulate anti-inflammatory agents to minimize protein adhesion on hydrogels. Wang and coworkers synthesized a poly(lactic-co-glycolic acid) (PLGA) and PVA composite coating for a glucose sensor and demonstrated that the slow 


\section{WILEY-VCH}

elution of DEX from the film prevented a fibrous capsule from forming even after one month of implantation in rats. ${ }^{[281]}$ Loading hydrogels with anti-inflammatory agents prevents a local immune response by modulating the tissue-material interactions at the interface. ${ }^{[282]}$

The hydrogel coating process, thickness, and porosity all impact biosensor performances, since the diffusion of target analytes are affected by how they traverse through the hydrogel layers. As such, 3D microfabrication techniques may be best suited for developing hydrogel-based biosensors, as different geometries, layering techniques, and thicknesses can be precisely controlled. Li and colleagues showed that a polypeptide-DNA based hydrogel which can rapidly form in situ upon 3D multilayer printing can customize tissue engineering scaffolds. ${ }^{[283]}$

Researchers should also consider developing dual biosensors to detect more than one analyte with a single electrode. Weltin and colleagues illustrated their biosensor can detect both lactate and glutamate, albeit each with its own separate sensor. ${ }^{[202]}$ However, a dual sensing electrode can simultaneously monitor multiple neurotransmitters without requiring numerous surgeries to implant different biosensors, thereby easing patient comfort with a single implant. Furthermore, a dual sensing biosensor may detect multiple neurotransmitters involved in complex neural networks to elucidate pathologies in signaling pathways.

\subsection{Neural Interfaces for Electrodes}

According to Table 4, PEDOT is one of the most popular conducting materials in hydrogel electrode coatings for neural applications. PEDOT impedance at the same frequency as the brain is reportedly lower than other electroconductive polymers due to its superior chemical stability and electric properties. ${ }^{[284]}$ Table 4 also indicates that platinum-based electrodes are common, likely due to their biostability and resistance to corrosion. ${ }^{[285]}$

In contrast to natural polymers, synthetic polymers may be more suitable as neural electrode interfaces, as their tunable properties confer greater control over biocompatibility, polymerization, and degradation. Synthetic polymers are inert and more chemically defined, which decreases the probability of an immune response during chronic implantations. ${ }^{[286]}$ In contrast, ECM-based hydrogel coatings, such as fibrin and silk fibroin, are more adherent to the electrode and surrounding neural tissue. Yet, these natural polymers are more quickly resorbed by tissues and may be more suitable for acute instead of chronic implantations. 


\section{WILEY-VCH}

As discussed in section 6.4, a major challenge in neural electrode interfaces is the low adhesion of cells on the surface. Researchers can implement several strategies to increase adhesion of hydrogel coatings to surrounding neural cells to improve signal transmission. One method is to optimize the hydrogel thickness, as excessively thick coatings increase the distance between cells and the electrode, thereby decreasing signal transmission. The hydrogel thicknesses are often constrained to under $100 \mu \mathrm{m}$ to also reduce hypoxia and prevent oxygen deprivation for encapsulated neurons. ${ }^{[287]}$ Similar to biosensors, lithographic and 3D printing methods can further tailor the coating process to tune its electrochemical properties and control the layering for specific probes.

Although the quality of electric signals can decline if neural cells are not proximal to the electrode surface, swelled and hydrophilic hydrogels can increase adhesion and address this issue. Therefore, the hydrogel swelling properties should be characterized and optimized to improve adherence of neural cells. Swelled hydrogels tighten the electrode-tissue interface and improve the ionic conductivity by increasing the electroactive surface area for better signal transmission and detection. Increasing the hydrogel pore size and porosity can also improve adhesion by enabling cells to interact more closely with the electrode surface, lowering the impedance, and increasing the conductivity. Shi and colleagues note that the distribution of pore sizes for electroconductive hydrogels should range from the millimeter to nanometer magnitudes for electron and ion transport during electric stimulation. ${ }^{[32]}$

The addition of functional groups such as the Arg-Gly-Asp (RGD) sequence to attract cellular interactions is also worth considering. Harris and colleagues developed spatially defined RGDligand gradients with polymer brushes to control cell adhesion on a substrate without compromising cell viability. ${ }^{[288]}$ Even the grafting of polymer brushes with simple synthetic polymers like pHEMA can improve neural cell interactions and charge storage capacities. ${ }^{[124]}$ The integration of natural polymers with synthetic polymers can enhance cell attachment, as Hassarati and colleagues showed that adding $1 \mathrm{wt} \%$ gelatin in their hydrogel coating significantly increased the attachment of olfactory ensheathing cells on the electrode surface compared to non-functionalized hydrogels. ${ }^{[77]}$ 


\section{WILEY-VCH}

Similar to the neural tissue engineering applications from the previous section, the data from Table 4 highlight the absence of standard electric stimulation schemes, as the electric field parameters were tailored to each individual study. However, researchers should still adhere to some standard practices when assessing the stability of electroresponsive hydrogels. For example, a cathodic pulse with a $200 \mu$ s width is commonly applied to characterize neural interfaces, and the voltage drop during this pulse can monitor the electrode stability. ${ }^{[289,290]}$ Furthermore, cathodic first current pulses are preferred for their physiologic relevance. ${ }^{[285]}$ Compared to voltage controlled stimulation, current controlled regimes provide a more constant charge injection to prevent electric tissue injury from high electric currents. ${ }^{[291]}$ Lastly, researchers should aim to keep impedances below $1 \mathrm{M} \Omega$ to obtain better in vivo neural signals during recordings. ${ }^{[86]}$

\section{Conclusion}

Electroresponsive hydrogels are versatile biomaterials which can interact with cells and transmit electric signals upon electric stimulation. Their hydrogel properties such as electroconductivity, stiffnesses, hydration, degradation, and biocompatibility can be tuned toward specific therapeutic outcomes. This review highlighted research on electroresponsive hydrogels as neural interfaces in the brain for controlling delivery of therapeutic agents, directing neural stem cell differentiation and neurogenesis, enhancing biosensors, as well as enhancing neural electrode coatings. A synthesis of these advances revealed several key findings, including the fact that a complex relationship exists among the mechanical, electrochemical, and biological properties of these hydrogels. Future research should couple experimental data from systematic hydrogel characterization studies to computational methods in order to optimize and adapt hydrogel formulations toward specific therapeutic outcomes in the brain. Particular attention should be paid to optimizing characteristics like porosities and pore sizes, since these structural properties impact the cellular interactions in vivo and regulate hydrogel adhesion to neural tissue. By integrating microfabrication and 3D printing techniques into the synthesis process, researchers can also control the hydrogel coating procedure and thickness on neural devices to tailor the implants to patient specific needs. These and other strategies highlighted in this review can enhance the electroresponsive behavior of hydrogels and pave the way for improved patient outcomes upon electric stimulation in the brain. 


\section{WILEY-VCH}

\section{Acknowledgements}

The authors would like to acknowledge Barath Udayasuryan for helpful feedback on the review paper process. This work was supported by the National Science Foundation CAREER Award [Grant CBET-1652112] to S.S.V. and the Natural Sciences and Engineering Research Council of Canada Postgraduate Doctoral Scholarship to Z.M.K.

\section{Conflict of Interest}

The authors declare no conflict of interest.

Received: ((will be filled in by the editorial staff))

Revised: ((will be filled in by the editorial staff))

Published online: ((will be filled in by the editorial staff)) 


\section{WILEY-VCH}

\section{References}

[1] M. Galarreta, S. Hestrin, Nature reviews. Neuroscience 2001, 2, 425.

[2] S. B. Laughlin, T. J. Sejnowski, Science 2003, 301, 1870.

[3] C. H. Wu, A. Liu, S. P. Chen, X. F. Zhang, L. Chen, Y. D. Zhu, Z. W. Xiao, J. Sun, H.

R. Luo, H. S. Fan, Acs Applied Materials \& Interfaces 2019, 11, 22152.

[4] M. Voroslakos, Y. Takeuchi, K. Brinyiczki, T. Zombori, A. Oliva, A. Fernandez-Ruiz, G. Kozak, Z. T. Kincses, B. Ivanyi, G. Buzsaki, A. Berenyi, Nat Commun 2018, 9, 483.

[5] P. Henrich-Noack, E. G. Sergeeva, B. A. Sabel, Neural Regen Res 2017, 12, 1590.

[6] A. Priori, Clinical neurophysiology : official journal of the International Federation of Clinical Neurophysiology 2003, 114, 589.

[7] S. H. Kennedy, P. Giacobbe, Annals of clinical psychiatry: official journal of the American Academy of Clinical Psychiatrists 2007, 19, 279.

[8] V. Novakovic, L. Sher, K. A. Lapidus, J. Mindes, A. G. J, R. Yehuda, Eur J Psychotraumatol 2011, 2.

[9] W. M. Grill, S. E. Norman, R. V. Bellamkonda, Annual review of biomedical engineering 2009, 11, 1.

[10] A. Jackson, J. Mavoori, E. E. Fetz, Nature 2006, 444, 56.

[11] L. Rao, H. H. Zhou, T. Li, C. Y. Li, Y. W. Y. Duan, Acta Biomaterialia 2012, 8, 2233.

[12] J. Y. Lee, Z. Z. Khaing, J. J. Siegel, C. E. Schmidt, Rsc Advances 2015, 5, 39228.

[13] J. Nam, H. K. Lim, N. H. Kim, J. K. Park, E. S. Kang, Y. T. Kim, C. Heo, O. S. Lee, S. G. Kim, W. S. Yun, M. Suh, Y. H. Kim, Acs Nano 2020, 14, 664.

[14] J. Goding, C. Vallejo-Giraldo, O. Syed, R. Green, Journal of materials chemistry. B 2019, 7, 1625 .

[15] L. Ferlauto, A. N. D'Angelo, P. Vagni, M. Leccardi, F. M. Mor, E. A. Cuttaz, M. O. Heuschkel, L. Stoppini, D. Ghezzi, Frontiers in Neuroscience 2018, 12. 


\section{WILEY-VCH}

[16] L. He, D. M. Lin, Y. P. Wang, Y. H. Xiao, J. F. Che, Colloids and Surfaces B-

Biointerfaces 2011, 87, 273.

[17] C. C. Lin, J. J. Chang, M. C. Yung, W. C. Huang, S. Y. Chen, Acs Biomaterials

Science \& Engineering 2020, 6, 1144.

[18] R. A. Green, N. H. Lovell, G. G. Wallace, L. A. Poole-Warren, Biomaterials 2008, 29, 3393.

[19] J. P. Gong, I. Kawakami, V. G. Sergeyev, Y. Osada, Macromolecules 1991, 24, 5246.

[20] J. M. Fonner, L. Forciniti, H. Nguyen, J. D. Byrne, Y. F. Kou, J. Syeda-Nawaz, C. E. Schmidt, Biomedical materials (Bristol, England) 2008, 3, 034124.

[21] R. A. Green, R. T. Hassarati, J. A. Goding, S. Baek, N. H. Lovell, P. J. Martens, L. A. Poole-Warren, Macromol Biosci 2012, 12, 494.

[22] A. Guiseppi-Elie, A. M. Wilson, A. R. Sujdak, K. E. Brown, Polymer Preprints 1997, $38,608$.

[23] L. Ghasemi-Mobarakeh, M. P. Prabhakaran, M. Morshed, M. H. Nasr-Esfahani, H. Baharvand, S. Kiani, S. S. Al-Deyab, S. Ramakrishna, J Tissue Eng Regen Med 2011, 5, e17. [24] K. Qiao, S. L. Guo, Y. D. Zheng, X. T. Xu, H. Y. Meng, J. Peng, Z. Y. Fang, Y. J. Xie, Materials Science \& Engineering C-Materials for Biological Applications 2018, 93, 853.

[25] A. Datta, V. Bansal, J. Diaz, J. Patel, D. Reato, M. Bikson, Brain Stimul 2009, 2, 201.

[26] D. Adair, D. Truong, Z. Esmaeilpour, N. Gebodh, H. Borges, L. Ho, J. Douglas

Bremner, B. W. Badran, V. Napadow, V. P. Clark, M. Bikson, Brain Stimul 2020, 13, 717.

[27] A. V. Peterchev, T. A. Wagner, P. C. Miranda, M. A. Nitsche, W. Paulus, S. H.

Lisanby, A. Pascual-Leone, M. Bikson, Brain Stimul 2012, 5, 435.

[28] L. Angius, A. Pascual-Leone, E. Santarnecchi, Prog Brain Res 2018, 240, 317.

[29] D. N. Heo, N. Acquah, J. Kim, S. J. Lee, N. J. Castro, L. G. Zhang, Tissue

Engineering Part A 2018, 24, 537.

[30] H. Blumenfeld, Epilepsia 2007, 48 Suppl 4, 18. 


\section{WILEY-VCH}

[31] M. F. Lythgoe, N. R. Sibson, N. G. Harris, British medical bulletin 2003, 65, 235.

[32] Z. J. Shi, X. Gao, M. W. Ullah, S. X. Li, Q. Wang, G. Yang, Biomaterials 2016, 111, 40.

[33] S. Kim, Y. Jang, M. Jang, A. Lim, J. G. Hardy, H. S. Park, J. Y. Lee, Acta Biomaterialia 2018, 80, 258.

[34] A. Guiseppi-Elie, Biomaterials 2010, 31, 2701.

[35] T. Radman, R. L. Ramos, J. C. Brumberg, M. Bikson, Brain Stimul 2009, 2, 215.

[36] C. L. Faingold, Med Hypotheses 2008, 71, 668.

[37] C. L. Faingold, "Anticonvulsant Drugs Are Neuronal Network-Modifying Agents (NMAs)", in Reference Module in Neuroscience and Biobehavioral Psychology, Elsevier, 2017.

[38] S. Rowny, S. H. Lisanby, "Brain Stimulation in Psychiatry", in Psychiatry, A. Tasman, J. Kay, J.A. Lieberman, M.B. First, and M. Maj, Eds., 2008, p. 2354.

[39] J. D. Putzke, R. E. Wharen, Jr., Z. K. Wszolek, M. F. Turk, A. J. Strongosky, R. J. Uitti, Parkinsonism Relat Disord 2003, 10, 81.

[40] A. B. Aparna Wagle Shukla, Roger Walz, "Troublelshooting in DBS", in Deep Brain Stimulation, R. Mehanna, Ed., Nova Science Publishers, 2015.

[41] G. D. Spyropoulos, J. Savarin, E. F. Gomez, D. T. Simon, M. Berggren, J. N. Gelinas, E. Stavrinidou, D. Khodagholy, Advanced Materials Technologies 2019, 5.

[42] M. Bikson, P. Grossman, C. Thomas, A. L. Zannou, J. Jiang, T. Adnan, A. P. Mourdoukoutas, G. Kronberg, D. Truong, P. Boggio, A. R. Brunoni, L. Charvet, F. Fregni, B. Fritsch, B. Gillick, R. H. Hamilton, B. M. Hampstead, R. Jankord, A. Kirton, H. Knotkova, D. Liebetanz, A. Liu, C. Loo, M. A. Nitsche, J. Reis, J. D. Richardson, A. Rotenberg, P. E. Turkeltaub, A. J. Woods, Brain Stimul 2016, 9, 641.

[43] A. K. Gellner, J. Reis, B. Fritsch, Front Cell Neurosci 2016, 10, 188.

[44] F. Fregni, A. Pascual-Leone, Nature clinical practice. Neurology 2007, 3, 383. 


\section{WILEY-VCH}

[45] M. A. Nitsche, L. G. Cohen, E. M. Wassermann, A. Priori, N. Lang, A. Antal, W.

Paulus, F. Hummel, P. S. Boggio, F. Fregni, A. Pascual-Leone, Brain Stimul 2008, 1, 206.

[46] M. A. Nitsche, W. Paulus, The Journal of physiology 2000, 527 Pt 3, 633.

[47] R. Schulz, C. Gerloff, F. C. Hummel, Neuropharmacology 2013, 64, 579.

[48] R. Ferrucci, F. Mameli, I. Guidi, S. Mrakic-Sposta, M. Vergari, S. Marceglia, F.

Cogiamanian, S. Barbieri, E. Scarpini, A. Priori, Neurology 2008, 71, 493.

[49] J. Reis, B. Fritsch, Neurology International Open 2017, 01, E142.

[50] R. George, M. Salinsky, R. Kuzniecky, W. Rosenfeld, D. Bergen, W. B. Tarver, J. F. Wernicke, F. I. V. N. S. S. Group, Epilepsia 1994, 35, 637.

[51] T. Kurimoto, S. Oono, H. Oku, Y. Tagami, R. Kashimoto, M. Takata, N. Okamoto, T. Ikeda, O. Mimura, Clinical ophthalmology (Auckland, N.Z.) 2010, 4, 1441.

[52] M. H. Histed, V. Bonin, R. C. Reid, Neuron 2009, 63, 508.

[53] A. N. Karabanov, G. B. Saturnino, A. Thielscher, H. R. Siebner, Front Psychol 2019, $10,213$.

[54] M. Bola, C. Gall, C. Moewes, A. Fedorov, H. Hinrichs, B. A. Sabel, Neurology 2014, $83,542$.

[55] N. Grossman, D. Bono, N. Dedic, S. B. Kodandaramaiah, A. Rudenko, H. J. Suk, A. M. Cassara, E. Neufeld, N. Kuster, L. H. Tsai, A. Pascual-Leone, E. S. Boyden, Cell 2017, $169,1029$.

[56] C. D. Lee, S. A. Hara, L. Yu, J. T. W. Kuo, B. J. Kim, T. Hoang, V. Pikov, E. Meng, Journal of Biomedical Materials Research Part B-Applied Biomaterials 2016, 104, 357.

[57] S. J. Smith, Journal of neurology, neurosurgery, and psychiatry 2005, 76 Suppl 2, ii2.

[58] S. Oribe, S. Yoshida, S. Kusama, S. Osawa, A. Nakagawa, M. Iwasaki, T. Tominaga, M. Nishizawa, Scientific Reports 2019, 9.

[59] M. Jorfi, J. L. Skousen, C. Weder, J. R. Capadona, J Neural Eng 2015, 12, 011001. 


\section{WILEY-VCH}

[60] L. Grand, L. Wittner, S. Herwik, E. Göthelid, P. Ruther, S. Oscarsson, H. Neves, B.

Dombovári, R. Csercsa, G. Karmos, I. Ulbert, J Neurosci Methods 2010, 189, 216.

[61] J. Agorelius, F. Tsanakalis, A. Friberg, P. T. Thorbergsson, L. M. Pettersson, J.

Schouenborg, Front Neurosci 2015, 9, 331.

[62] K. Tatsumi, S. Haga, H. Matsuyoshi, M. Inoue, T. Manabe, M. Makinodan, A.

Wanaka, Neurochemistry international 2005, 46, 381.

[63] S. Kyrkanides, M. K. O'Banion, P. E. Whiteley, J. C. Daeschner, J. A. Olschowka, Journal of neuroimmunology 2001, 119, 269.

[64] J. Thelin, H. Jörntell, E. Psouni, M. Garwicz, J. Schouenborg, N. Danielsen, C. E. Linsmeier, PLoS One 2011, 6, e16267.

[65] D. H. Kim, M. Abidian, D. C. Martin, Journal of Biomedical Materials Research Part A 2004, 71A, 577.

[66] V. S. Polikov, P. A. Tresco, W. M. Reichert, J Neurosci Methods 2005, 148, 1.

[67] C. Marin, E. Fernández, Frontiers in neuroengineering 2010, 3, 8.

[68] S. R. Kane, S. F. Cogan, J. Ehrlich, T. D. Plante, D. B. McCreery, Conference proceedings : ... Annual International Conference of the IEEE Engineering in Medicine and Biology Society. IEEE Engineering in Medicine and Biology Society. Annual Conference 2011, 2011, 5416 .

[69] S. Suner, M. R. Fellows, C. Vargas-Irwin, G. K. Nakata, J. P. Donoghue, IEEE transactions on neural systems and rehabilitation engineering : a publication of the IEEE Engineering in Medicine and Biology Society 2005, 13, 524.

[70] K. A. Potter-Baker, J. R. Capadona, ACS Macro Letters 2015, 4, 275.

[71] R. Alizadeh, P. Zarrintaj, S. K. Kamrava, Z. Bagher, M. Farhadi, F. Heidari, A. Komeili, T. J. Gutierrez, M. R. Saeb, Carbohydrate Polymers 2019, 224.

[72] E. Castagnola, A. Ansaldo, E. Maggiolini, G. N. Angotzi, M. Skrap, D. Ricci, L. Fadiga, Acs Nano 2013, 7, 3887. 


\section{WILEY-VCH}

[73] B. Guo, P. X. Ma, Biomacromolecules 2018, 19, 1764.

[74] X. Cui, V. A. Lee, Y. Raphael, J. A. Wiler, J. F. Hetke, D. J. Anderson, D. C. Martin, Journal of Biomedical Materials Research 2001, 56, 261.

[75] R. A. Green, R. T. Hassarati, L. Bouchinet, C. S. Lee, G. L. Cheong, J. F. Yu, C. W. Dodds, G. J. Suaning, L. A. Poole-Warren, N. H. Lovell, Biomaterials 2012, 33, 5875.

[76] H. Vara, J. E. Collazos-Castro, ACS Applied Materials \& Interfaces 2015, 7, 27016.

[77] R. T. Hassarati, H. Marcal, L. John, R. Foster, R. A. Green, Journal of Biomedical Materials Research Part B-Applied Biomaterials 2016, 104, 712.

[78] R. A. Green, N. H. Lovell, L. A. Poole-Warren, Acta Biomater 2010, 6, 63.

[79] R. V. Ulijn, N. Bibi, V. Jayawarna, P. D. Thornton, S. J. Todd, R. J. Mart, A. M. Smith, J. E. Gough, Materials Today 2007, 10, 40.

[80] R. Trigo, M. Blanco, P. Heurta, R. Olmo, J. Teijon, Polym Bull 1993, 31, 577.

[81] K. Miller, K. Chinzei, Comput Methods Biomech Biomed Eng. (Proceedings of the Third International Symposium) 1997.

[82] A. Banerjee, M. Arha, S. Choudhary, R. S. Ashton, S. R. Bhatia, D. V. Schaffer, R. S. Kane, Biomaterials 2009, 30, 4695.

[83] H. K. Pokharna, Y. Zhong, D. J. Smith, M. J. Dunphy, Journal of Bioactive and Compatible Polymers 1990, 5, 42.

[84] F. M. Martínez Santiesteban, S. D. Swanson, D. C. Noll, D. J. Anderson, IEEE transactions on bio-medical engineering 2006, 53, 547.

[85] H. Sheng, X. M. Wang, N. Kong, W. Xi, H. Yang, X. T. Wu, K. L. Wu, C. H. Li, J. Hu, J. D. Tang, J. X. Zhou, S. M. Duan, H. Wang, Z. G. Suo, Extreme Mechanics Letters 2019, 30 .

[86] D. H. Kim, M. Abidian, D. C. Martin, Journal of biomedical materials research. Part A 2004, 71, 577.

[87] P. Pissis, A. Kyritsis, Solid State Ionics 1997, 97, 105. 


\section{WILEY-VCH}

[88] G. C. Psarras, Composites Part A: Applied Science and Manufacturing 2006, 37, 1545.

[89] J. Goding, A. Gilmour, P. Martens, L. Poole-Warren, R. Green, Advanced Healthcare Materials 2017, 6 .

[90] C. Kleber, M. Bruns, K. Lienkamp, J. Ruhe, M. Asplund, Acta Biomaterialia 2017, 58,365 .

[91] N. R. Wevers, R. van Vught, K. J. Wilschut, A. Nicolas, C. Chiang, H. L. Lanz, S. J. Trietsch, J. Joore, P. Vulto, Scientific Reports 2016, 6, 38856.

[92] B. Ghane-Motlagh, T. Javanbakht, F. Shoghi, K. J. Wilkinson, R. Martel, M. Sawan, Materials Science \& Engineering C-Materials for Biological Applications 2016, 68, 642.

[93] K. Y. Lee, D. J. Mooney, Chemical Reviews 2001, 101, 1869.

[94] Y. Lu, D. F. Wang, T. Li, X. Q. Zhao, Y. L. Cao, H. X. Yang, Y. Y. Duan, Biomaterials 2009, 30, 4143.

[95] T. Alfrey Jr., E. F. Gurnee, W. G. Lloyd, Journal of Polymer Science Part C: Polymer Symposia 1966, 12, 249.

[96] A. J. Cadotte, T. B. DeMarse, Journal of Neural Engineering 2005, 2, 114.

[97] J. P. Frampton, M. R. Hynd, J. C. Williams, M. L. Shuler, W. Shain, Journal of Neural Engineering 2007, 4, 399.

[98] M. C. McNamara, A. E. Niaraki-Asli, J. S. Guo, J. Okuzono, R. Montazami, N. N. Hashemi, Frontiers in Materials 2020, 7.

[99] V. Kuzmenko, T. Kalogeropoulos, J. Thunberg, S. Johannesson, D. Hägg, P. Enoksson, P. Gatenholm, Materials science \& engineering. C, Materials for biological applications 2016, 58, 14.

[100] C. Cui, Q. Fu, L. Meng, S. Hao, R. Dai, J. Yang, ACS Applied Bio Materials 2021, 4, 85.

[101] W. Suginta, P. Khunkaewla, A. Schulte, Chem Rev 2013, 113, 5458. 


\section{WILEY-VCH}

[102] C. E. Schmidt, V. R. Shastri, J. P. Vacanti, R. Langer, Proc Natl Acad Sci U S A 1997, 94, 8948.

[103] M. Gerritsen, A. Kros, V. Sprakel, J. A. Lutterman, R. J. Nolte, J. A. Jansen, Biomaterials 2000, 21, 71 .

[104] G. Justin, A. Guiseppi-Elie, Journal of Bioactive and Compatible Polymers 2010, 25, 121.

[105] O. D. Akilo, P. Kumar, Y. E. Choonara, L. C. du Toit, P. Pradeep, G. Modi, V. Pillay, International Journal of Pharmaceutics 2019, 559, 255.

[106] G. Thrivikraman, P. S. Lee, R. Hess, V. Haenchen, B. Basu, D. Scharnweber, ACS Appl Mater Interfaces 2015, 7, 23015.

[107] H. Yamato, M. Ohwa, W. Wernet, Journal of Electroanalytical Chemistry 1995, 397, 163.

[108] L. Pan, G. Yu, D. Zhai, H. R. Lee, W. Zhao, N. Liu, H. Wang, B. C. Tee, Y. Shi, Y. Cui, Z. Bao, Proc Natl Acad Sci U S A 2012, 109, 9287.

[109] M. Sasaki, B. C. Karikkineth, K. Nagamine, H. Kaji, K. Torimitsu, M. Nishizawa, Adv Healthc Mater 2014, 3, 1919.

[110] M. Javadi, Q. Gu, S. Naficy, S. Farajikhah, J. M. Crook, G. G. Wallace, S. Beirne, S. E. Moulton, Macromolecular Bioscience 2018, 18.

[111] J.-M. Pernaut, J. R. Reynolds, The Journal of Physical Chemistry B 2000, 104, 4080.

[112] B. Xu, T. Bai, A. Sinclair, W. Wang, Q. Wu, F. Gao, H. Z. Jia, S. Y. Jiang, W. G. Liu, Materials Today Chemistry 2016, 1-2, 15.

[113] J. M. Lee, J. Y. Moon, T. H. Kim, S. W. Lee, C. D. Ahrberg, B. G. Chung, Sensors and Actuators B-Chemical 2018, 258, 1042.

[114] E. W. Keefer, B. R. Botterman, M. I. Romero, A. F. Rossi, G. W. Gross, Nature nanotechnology 2008, 3, 434. 


\section{WILEY-VCH}

[115] M. Bordoni, E. Karabulut, V. Kuzmenko, V. Fantini, O. Pansarasa, C. Cereda, P. Gatenholm, Cells 2020, 9.

[116] K. S. Novoselov, V. I. Fal'ko, L. Colombo, P. R. Gellert, M. G. Schwab, K. Kim, Nature 2012, 490, 192.

[117] W. C. Huang, H. S. Chi, Y. C. Lee, Y. C. Lo, T. C. Liu, M. Y. Chiang, H. Y. Chen, S. J. Li, Y. Y. Chen, S. Y. Chen, Acs Applied Materials \& Interfaces 2019, 11, 11270.

[118] N. O. Weiss, H. Zhou, L. Liao, Y. Liu, S. Jiang, Y. Huang, X. Duan, Advanced materials (Deerfield Beach, Fla.) 2012, 24, 5782.

[119] T. Kuilla, S. Bhadra, D. Yao, N. H. Kim, S. Bose, J. H. Lee, Progress in Polymer Science 2010, 35, 1350.

[120] S. Liu, T. H. Zeng, M. Hofmann, E. Burcombe, J. Wei, R. Jiang, J. Kong, Y. Chen, ACS Nano 2011, 5, 6971.

[121] A. Servant, V. Leon, D. Jasim, L. Methven, P. Limousin, E. V. Fernandez-Pacheco,

M. Prato, K. Kostarelos, Advanced Healthcare Materials 2014, 3, 1334.

[122] C. Chung, Y. K. Kim, D. Shin, S. R. Ryoo, B. H. Hong, D. H. Min, Acc Chem Res 2013, 46, 2211.

[123] Y. Wang, Z. Li, J. Wang, J. Li, Y. Lin, Trends Biotechnol 2011, 29, 205.

[124] S. Baek, R. Green, A. Granville, P. Martens, L. Poole-Warren, Journal of Materials Chemistry B 2013, 1, 3803.

[125] D. Y. Zhang, F. Di, Y. Y. Zhu, Y. H. Xiao, J. F. Che, Journal of Bioactive and Compatible Polymers 2015, 30, 600.

[126] J. A. Goding, A. D. Gilmour, P. J. Martens, L. A. Poole-Warren, R. A. Green, Journal of materials chemistry. B 2015, 3, 5058.

[127] D. E. Tallman, C. Vang, G. G. Wallace, G. P. Bierwagen, Journal of The Electrochemical Society 2002, 149, C173. 


\section{WILEY-VCH}

[128] R. A. Green, S. Baek, L. A. Poole-Warren, P. J. Martens, Science and technology of advanced materials 2010, 11, 014107.

[129] C. B. Gorman, H. A. Biebuyck, G. M. Whitesides, Chemistry of Materials 1995, 7, 526.

[130] F. Zhou, W. Liu, J. Hao, T. Xu, M. Chen, Q. Xue, Advanced Functional Materials 2003, 13, 938 .

[131] J. A. Goding, A. D. Gilmour, P. J. Martens, L. A. Poole-Warren, R. A. Green, Journal of Materials Chemistry B 2015, 3, 5058.

[132] R. A. Green, N. H. Lovell, L. A. Poole-Warren, Biomaterials 2009, 30, 3637.

[133] S. Baek, R. A. Green, L. A. Poole-Warren, Journal of Biomedical Materials Research Part A 2014, 102, 2743.

[134] S. Bhandari, N. K. Singha, D. Khastgir, Journal of Applied Polymer Science 2013, 129, 1264.

[135] H. H. Zhou, X. Cheng, L. Rao, T. Li, Y. W. Y. Duan, Acta Biomaterialia 2013, 9, 6439.

[136] Y. Xiao, L. M. He, J. Che, Journal of materials chemistry. B 2012, 22, 8076.

[137] S. I. Brahim, D. Maharajh, D. Narinesingh, A. Guiseppi-Elie, Analytical Letters 2002, $35,797$.

[138] M. Imaninezhad, I. Kuljanishvili, S. P. Zustiak, Macromolecular Bioscience 2017, 17, 1600261.

[139] G. Jia, H. Wang, L. Yan, X. Wang, R. Pei, T. Yan, Y. Zhao, X. Guo, Environmental science \& technology 2005, 39, 1378.

[140] K. Shah, D. Vasileva, A. Karadaghy, S. P. Zustiak, J. Mater. Chem. 2015, B3, 7950.

[141] R. T. Hassarati, W. F. Dueck, C. Tasche, P. M. Carter, L. A. Poole-Warren, R. A. Green, IEEE transactions on neural systems and rehabilitation engineering : a publication of the IEEE Engineering in Medicine and Biology Society 2014, 22, 411. 


\section{WILEY-VCH}

[142] G. L. Mario Cheong, K. S. Lim, A. Jakubowicz, P. J. Martens, L. A. Poole-Warren, R.

A. Green, Acta Biomaterialia 2014, 10, 1216.

[143] E. H. Nafea, L. A. Poole-Warren, P. J. Martens, Journal of biomedical materials research. Part A 2015, 103, 3727.

[144] B. Sarkar, X. Ma, A. Agas, Z. Siddiqui, P. Iglesias-Montoro, P. K. Nguyen, K. K.

Kim, J. Haorah, V. A. Kumar, Chemical Engineering Journal 2021, 408, 127295.

[145] S. Merino, C. Martín, K. Kostarelos, M. Prato, E. Vázquez, ACS Nano 2015, 9, 4686.

[146] D. Morales, E. Palleau, M. D. Dickey, O. D. Velev, Soft Matter 2014, 10, 1337.

[147] E. Ozdemir-Kaynak, A. A. Qutub, O. Yesil-Celiktas, Front Physiol 2018, 9, 170.

[148] N. R. Saunders, M. D. Habgood, K. Mollgard, K. M. Dziegielewska, F1000Research 2016, 5 .

[149] B. Cheng, C. Bing, R. Chopra, Scientific Reports 2019, 9, 20020.

[150] C. Poon, C. Pellow, K. Hynynen, Theranostics 2021, 11, 1655.

[151] C. Edsall, Z. M. Khan, L. Mancia, S. Hall, W. Mustafa, E. Johnsen, A. L. Klibanov, Y. Y. Durmaz, E. Vlaisavljevich, Ultrasound in Medicine \& Biology 2021, 47, 620.

[152] M. F. Lorenzo, S. C. Thomas, Y. Kani, J. Hinckley, M. Lee, J. Adler, S. S. Verbridge, F. C. Hsu, J. L. Robertson, R. V. Davalos, J. H. Rossmeisl, Jr., Cancers 2019, 11.

[153] M. Lorenzo, S. Thomas, S. Verbridge, J. Robertson, J. Rossmeisl, R. Davalos, NeuroOncology 2020, 22, ii212.

[154] K. Yamane, T. Mazaki, Y. Shiozaki, A. Yoshida, K. Shinohara, M. Nakamura, Y.

Yoshida, D. Zhou, T. Kitajima, M. Tanaka, Y. Ito, T. Ozaki, A. Matsukawa, Scientific Reports 2018, 8 .

[155] F. Qian, Y. Han, Z. Han, D. Zhang, L. Zhang, G. Zhao, S. Li, G. Jin, R. Yu, H. Liu, Biomaterials 2021, 270, 120675.

[156] H. Kim, S.-M. Jeong, J.-W. Park, Journal of the American Chemical Society 2011, $133,5206$. 


\section{WILEY-VCH}

[157] M. Hamidi, A. Azadi, P. Rafiei, Advanced drug delivery reviews 2008, 60, 1638.

[158] D. Roy, J. N. Cambre, B. S. Sumerlin, Progress in Polymer Science 2010, 35, 278.

[159] X. Y. Ying, Y. Wang, J. Liang, J. X. Yue, C. L. Xu, L. N. Lu, Z. H. Xu, J. Q. Gao, Y.

Z. Du, Z. Chen, Angewandte Chemie-International Edition 2014, 53, 12436.

[160] V. R. Rao, D. H. Lowenstein, Current biology : CB 2015, 25, R742.

[161] Y. Wang, X. Y. Ying, L. Y. Chen, Y. Liu, Y. Wang, J. Liang, C. L. Xu, Y. Guo, S.

Wang, W. W. Hu, Y. Z. Du, Z. Chen, Neurotherapeutics 2016, 13, 603.

[162] H. Xin, X. Sha, X. Jiang, L. Chen, K. Law, J. Gu, Y. Chen, X. Wang, X. Fang, Biomaterials 2012, 33, 1673.

[163] M. C. Walker, M. S. Alavijeh, S. D. Shorvon, P. N. Patsalos, Epilepsia 1996, 37, 421.

[164] A. Servant, L. Methven, R. P. Williams, K. Kostarelos, Advanced Healthcare Materials 2013, 2, 806.

[165] J. Siepmann, N. A. Peppas, Advanced drug delivery reviews 2001, 48, 139.

[166] J. Noble, C. A. Munro, V. S. Prasad, R. Midha, The Journal of trauma 1998, 45, 116.

[167] B. R. Selecki, I. T. Ring, D. A. Simpson, G. K. Vanderfield, M. F. Sewell, The Australian and New Zealand journal of surgery 1982, 52, 93.

[168] C. E. Schmidt, J. B. Leach, Annual review of biomedical engineering 2003, 5, 293.

[169] H. Mizuno, Journal of Nippon Medical School = Nippon Ika Daigaku zasshi 2009, 76, 56.

[170] Y. S. Lee, T. L. Arinzeh, Tissue Engineering Part A 2012, 18, 2063.

[171] C. L. Weaver, X. T. Cui, Advanced Healthcare Materials 2015, 4, 1408.

[172] S. R. Hynes, E. B. Lavik, Graefe's archive for clinical and experimental ophthalmology = Albrecht von Graefes Archiv fur klinische und experimentelle Ophthalmologie 2010, 248, 763.

[173] K. A. Krishna, K. S. Krishna, R. Berrocal, K. S. Rao, K. R. Sambasiva Rao, Journal of pharmacy \& bioallied sciences 2011, 3, 182. 


\section{WILEY-VCH}

[174] S. J. Lee, W. Zhu, M. Nowicki, G. Lee, D. N. Heo, J. Kim, Y. Y. Zuo, L. G. Zhang, Journal of Neural Engineering 2018, 15.

[175] Y. Li, G. Huang, X. Zhang, L. Wang, Y. Du, T. J. Lu, F. Xu, Biotechnology advances $\mathbf{2 0 1 4}, 32,347$.

[176] A. I. Teixeira, S. Ilkhanizadeh, J. A. Wigenius, J. K. Duckworth, O. Inganäs, O. Hermanson, Biomaterials 2009, 30, 4567.

[177] S. Kargozar, S. J. Hashemian, M. Soleimani, P. B. Milan, M. Askari, V. Khalaj, A. Samadikuchaksaraie, S. Hamzehlou, A. R. Katebi, N. Latifi, M. Mozafari, F. Baino, Materials Science and Engineering: C 2017, 75, 688.

[178] E. Eisenbarth, Advanced Engineering Materials 2007, 9, 1051.

[179] Y. Wu, L. Wang, B. Guo, Y. Shao, P. X. Ma, Biomaterials 2016, 87, 18.

[180] R. F. Valentini, T. G. Vargo, J. A. Gardella, Jr., P. Aebischer, Biomaterials 1992, 13, 183.

[181] R. J. Cork, M. E. McGinnis, J. Tsai, K. R. Robinson, Journal of neurobiology 1994, $25,1509$.

[182] A. N. Koppes, A. M. Seggio, D. M. Thompson, J Neural Eng 2011, 8, 046023.

[183] L. Hinkle, C. D. McCaig, K. R. Robinson, The Journal of physiology 1981, 314, 121.

[184] M. Yamada, K. Tanemura, S. Okada, A. Iwanami, M. Nakamura, H. Mizuno, M.

Ozawa, R. Ohyama-Goto, N. Kitamura, M. Kawano, K. Tan-Takeuchi, C. Ohtsuka, A.

Miyawaki, A. Takashima, M. Ogawa, Y. Toyama, H. Okano, T. Kondo, STEM CELLS 2007, 25,562 .

[185] T. Morimoto, H. Kanda, M. Kondo, H. Terasaki, K. Nishida, T. Fujikado, Invest Ophthalmol Vis Sci 2012, 53, 4254.

[186] G. Abagnale, M. Steger, V. H. Nguyen, N. Hersch, A. Sechi, S. Joussen, B. Denecke, R. Merkel, B. Hoffmann, A. Dreser, U. Schnakenberg, A. Gillner, W. Wagner, Biomaterials $\mathbf{2 0 1 5}, 61,316$. 


\section{WILEY-VCH}

[187] M. Imaninezhad, K. Pemberton, F. L. Xu, K. Kalinowski, R. Bera, S. P. Zustiak, Journal of Neural Engineering 2018, 15.

[188] S. B. Jun, M. R. Hynd, K. L. Smith, J. K. Song, J. N. Turner, W. Shain, S. J. Kim, Medical \& biological engineering \& computing 2007, 45, 1015.

[189] A. Kotwal, C. E. Schmidt, Biomaterials 2001, 22, 1055.

[190] J. Y. Hwang, U. S. Shin, W. C. Jang, J. K. Hyun, I. B. Wall, H. W. Kim, Nanoscale 2013, 5, 487.

[191] N. C. Spitzer, Nature 2006, 444, 707.

[192] Y. Ko, J. Kim, D. Kim, Y. Yamauchi, J. H. Kim, J. You, Sci Rep 2017, 7, 2282.

[193] J. H. Bae, J. M. Lee, B. G. Chung, Biomedical Materials 2016, 11, 015019.

[194] J. Wang, L. Tian, N. Chen, S. Ramakrishna, X. Mo, Materials Science and Engineering: C 2018, 91, 715 .

[195] A. Bleckert, R. O. Wong, BioEssays : news and reviews in molecular, cellular and developmental biology 2011, 33, 61.

[196] G. G. Genchi, L. Ceseracciu, A. Marino, M. Labardi, S. Marras, F. Pignatelli, L. Bruschini, V. Mattoli, G. Ciofani, Adv Healthc Mater 2016, 5, 1808.

[197] M. Hoop, X. Z. Chen, A. Ferrari, F. Mushtaq, G. Ghazaryan, T. Tervoort, D. Poulikakos, B. Nelson, S. Pane, Sci Rep 2017, 7, 4028.

[198] M. Dong, X. P. Wang, X. Z. Chen, F. Mushtaq, S. Y. Deng, C. H. Zhu, H. Torlakcik, A. Terzopoulou, X. H. Qin, X. Z. Xiao, J. Puigmarti-Luis, H. Choi, A. P. Pego, Q. D. Shen, B. J. Nelson, S. Pane, Advanced Functional Materials 2020, 30.

[199] L. Hinkle, C. D. McCaig, K. R. Robinson, The Journal of physiology 1981, 314, 121.

[200] L. Z. Lugo-Morales, P. L. Loziuk, A. K. Corder, J. V. Toups, J. G. Roberts, K. A. McCaffrey, L. A. Sombers, Analytical Chemistry 2013, 85, 8780.

[201] S. K. Smith, L. Z. Lugo-Morales, C. Tang, S. P. Gosrani, C. A. Lee, J. G. Roberts, S. W. Morton, G. S. McCarty, S. A. Khan, L. A. Sombers, Chemphyschem 2018, 19, 1197. 


\section{WILEY-VCH}

[202] A. Weltin, J. Kieninger, B. Enderle, A. K. Gellner, B. Fritsch, G. A. Urban, Biosensors \& Bioelectronics 2014, 61, 192.

[203] L. Stryer, "Biochemistry", W.H. Freeman and Company New York, 1981.

[204] N. Larsson, T. Ruzgas, L. Gorton, M. Kokaia, P. Kissinger, E. Csoregi, Electrochimica Acta 1998, 43, 3541.

[205] G. S. Wilson, R. Gifford, Biosens Bioelectron 2005, 20, 2388.

[206] F. M. Tian, A. V. Gourine, R. T. R. Huckstepp, N. Dale, Analytica Chimica Acta 2009, 645, 86 .

[207] L. C. Clark, Jr., C. Lyons, Annals of the New York Academy of Sciences 1962, 102, 29.

[208] W. H. Oldenziel, G. Dijkstra, T. Cremers, B. H. C. Westerink, Analytical Chemistry 2006, 78,3366 .

[209] D. L. Robinson, A. Hermans, A. T. Seipel, R. M. Wightman, Chemical Reviews 2008, $108,2554$.

[210] A. J. Bard, L. R. Faulkner, "Electrochemical Methods: Fundamentals and Applications, 2nd Edition", Wiley, New York, 2000.

[211] T. J. Ohara, M. S. Vreeke, F. Battaglini, A. Heller, Electroanalysis 1993, 5, 825.

[212] T. Chen, K. A. Friedman, I. Lei, A. Heller, Analytical Chemistry 2000, 72, 3757.

[213] N. C. Danbolt, Prog Neurobiol 2001, 65, 1.

[214] N. V. Kulagina, L. Shankar, A. C. Michael, Analytical Chemistry 1999, 71, 5093.

[215] E. M. Reiman, R. J. Caselli, L. S. Yun, K. Chen, D. Bandy, S. Minoshima, S. N. Thibodeau, D. Osborne, The New England journal of medicine 1996, 334, 752.

[216] R. M. Wightman, M. L. Heien, K. M. Wassum, L. A. Sombers, B. J. Aragona, A. S. Khan, J. L. Ariansen, J. F. Cheer, P. E. Phillips, R. M. Carelli, The European journal of neuroscience 2007, 26, 2046.

[217] J. L. Peters, H. Yang, A. C. Michael, Analytica Chimica Acta 2000, 412, 1. 


\section{WILEY-VCH}

[218] A. S. Khan, A. C. Michael, TrAC Trends in Analytical Chemistry 2003, 22, 503.

[219] P. Cavelier, M. Hamann, D. Rossi, P. Mobbs, D. Attwell, Progress in biophysics and molecular biology 2005, 87, 3.

[220] N. Wisniewski, F. Moussy, W. M. Reichert, Fresenius' Journal of Analytical Chemistry 2000, 366, 611.

[221] I. C. Saldarriaga Fernández, H. C. van der Mei, M. J. Lochhead, D. W. Grainger, H. J. Busscher, Biomaterials 2007, 28, 4105.

[222] J. Agorelius, F. Tsanakalis, A. Friberg, P. T. Thorbergsson, L. Pettersson, J. Schouenborg, Frontiers in Neuroscience 2015, 9.

[223] J. W. Salatino, K. A. Ludwig, T. D. Y. Kozai, E. K. Purcell, Nature Biomedical Engineering 2017, 1, 862 .

[224] A. B. Schwartz, Annual review of neuroscience 2004, 27, 487.

[225] R. J. Vetter, J. C. Williams, J. F. Hetke, E. A. Nunamaker, D. R. Kipke, IEEE transactions on bio-medical engineering 2004, 51, 896.

[226] H. H. Zhou, T. Li, Y. W. Y. Duan, Sensors and Actuators B-Chemical 2012, 161, 198.

[227] Y. Y. Duan, G. M. Clark, R. S. C. Cowan, Biomaterials 2004, 25, 3813.

[228] Y. Lu, Z. Cai, Y. Cao, H. Yang, Y. Y. Duan, Electrochemistry Communications 2008, 10,778 .

[229] M. R. Abidian, D. C. Martin, Biomaterials 2008, 29, 1273.

[230] D. J. Creel, Handbook of clinical neurology 2019, 160, 501.

[231] E. Huigen, A. Peper, C. A. Grimbergen, Medical \& biological engineering \& computing 2002, 40, 332.

[232] T. Strasser, S. Kramer, M. Kempf, T. Peters, A. Kurtenbach, E. Zrenner, Sensors 2019, 19.

[233] J. V. Odom, M. Bach, M. Brigell, G. E. Holder, D. L. McCulloch, A. P. Tormene, Vaegan, Documenta ophthalmologica. Advances in ophthalmology 2010, 120, 111. 


\section{WILEY-VCH}

[234] E. Castagnola, E. Maggiolini, L. Ceseracciu, F. Ciarpella, E. Zucchini, S. De Faveri, L. Fadiga, D. Ricci, Frontiers in Neuroscience 2016, 10.

[235] S. De Faveri, E. Maggiolini, E. Miele, F. De Angelis, F. Cesca, F. Benfenati, L. Fadiga, Frontiers in neuroengineering 2014, 7, 7.

[236] E. R. Aurand, K. J. Lampe, K. B. Bjugstad, Neuroscience research 2012, 72, 199.

[237] L. Shapiro, S. Cohen, Biomaterials 1997, 18, 583.

[238] D. H. Kim, J. A. Wiler, D. J. Anderson, D. R. Kipke, D. C. Martin, Acta Biomaterialia $2010,6,57$.

[239] D. A. Henze, Z. Borhegyi, J. Csicsvari, A. Mamiya, K. D. Harris, G. Buzsáki, Journal of neurophysiology 2000, 84, 390.

[240] I. V. Korendovych, Y. H. Kim, A. H. Ryan, J. D. Lear, W. F. DeGrado, S. J. Shandler, Organic Letters 2010, 12, 5142.

[241] L. Xu, S. R. Gutbrod, A. P. Bonifas, Y. Su, M. S. Sulkin, N. Lu, H. J. Chung, K. I. Jang, Z. Liu, M. Ying, C. Lu, R. C. Webb, J. S. Kim, J. I. Laughner, H. Cheng, Y. Liu, A. Ameen, J. W. Jeong, G. T. Kim, Y. Huang, I. R. Efimov, J. A. Rogers, Nat Commun 2014, 5, 3329.

[242] P. R. Kennedy, J Neurosci Methods 1989, 29, 181.

[243] M. R. Abidian, D. C. Martin, Advanced Functional Materials 2009, 19, 573.

[244] Y. Zhong, G. C. McConnell, J. D. Ross, S. P. DeWeerth, R. V. Bellamkonda, "A Novel Dexamethasone-releasing, Anti-inflammatory Coating for Neural Implants", in Conference Proceedings. 2nd International IEEE EMBS Conference on Neural Engineering, 2005., 2005522.

[245] W. Shain, L. Spataro, J. Dilgen, K. Haverstick, S. Retterer, M. Isaacson, M. Saltzman, J. N. Turner, IEEE transactions on neural systems and rehabilitation engineering : a publication of the IEEE Engineering in Medicine and Biology Society 2003, 11, 186. [246] D. H. Kim, D. C. Martin, Biomaterials 2006, 27, 3031. 


\section{WILEY-VCH}

[247] D. R. Merrill, M. Bikson, J. G. R. Jefferys, Journal of Neuroscience Methods 2005, $141,171$.

[248] N. Khadka, H. Borges, A. L. Zannou, J. Jang, B. Kim, K. Lee, M. Bikson, Brain Stimulation 2018, 11, 1044.

[249] Y. Lu, D. Wang, T. Li, X. Zhao, Y. Cao, H. Yang, Y. Y. Duan, Biomaterials 2009, 30, 4143.

[250] S. F. Cogan, A. A. Guzelian, W. F. Agnew, T. G. H. Yuen, D. B. McCreery, Journal of Neuroscience Methods 2004, 137, 141.

[251] Y. Lu, T. Li, X. Q. Zhao, M. Li, Y. L. Cao, H. X. Yang, Y. W. Y. Duan, Biomaterials $2010,31,5169$.

[252] G. Z. Chen, M. S. P. Shaffer, D. Coleby, G. Dixon, W. Zhou, D. J. Fray, A. H. Windle, Advanced Materials 2000, 12, 522.

[253] X. Luo, C. L. Weaver, D. D. Zhou, R. Greenberg, X. T. Cui, Biomaterials 2011, 32, 5551.

[254] C. Kleber, K. Lienkamp, J. Ruhe, M. Asplund, Advanced Biosystems 2019, 3.

[255] Y. Xiao, L. He, J. Che, Journal of Materials Chemistry 2012, 22, 8076.

[256] M. E. Spira, A. Hai, Nature nanotechnology 2013, 8, 83.

[257] T. Teshima, H. Nakashima, N. Kasai, S. Sasaki, A. Tanaka, S. Tsukada, K. Sumitomo, Advanced Functional Materials 2016, 26, 8185.

[258] B. Radha, M. Arif, R. Datta, T. K. Kundu, G. U. Kulkarni, Nano Research 2010, 3, 738.

[259] T. Teshima, H. Onoe, K. Kuribayashi-Shigetomi, H. Aonuma, K. Kamiya, H. Ishihara, H. Kanuka, S. Takeuchi, Small (Weinheim an der Bergstrasse, Germany) 2014, 10, 912.

[260] S. Yoshida, T. Teshima, K. Kuribayashi-Shigetomi, S. Takeuchi, Advanced Healthcare Materials 2016, 5, 415. 


\section{WILEY-VCH}

[261] J. O. Winter, S. F. Cogan, J. F. Rizzo, 3rd, Journal of biomaterials science. Polymer edition 2007, 18, 1031.

[262] Y. Lu, T. Li, X. Zhao, M. Li, Y. Cao, H. Yang, Y. Y. Duan, Biomaterials 2010, 31, 5169.

[263] C. Rojas, M. Tedesco, P. Massobrio, A. Marino, G. Ciofani, S. Martinoia, R. Raiteri, J Neural Eng 2018, 15, 036016.

[264] W. Guo, C. Cheng, Y. Wu, Y. Jiang, J. Gao, D. Li, L. Jiang, Advanced Materials 2013, 25, 6064 .

[265] P. J. Grahn, G. W. Mallory, O. U. Khurram, B. M. Berry, J. T. Hachmann, A. J.

Bieber, K. E. Bennet, H.-K. Min, S.-Y. Chang, K. H. Lee, J. L. Lujan, Frontiers in Neuroscience 2014, 8 .

[266] N. G. Moon, A. M. Pekkanen, T. E. Long, T. N. Showalter, B. Libby, Polymer 2017, $125,66$.

[267] K. T. Campbell, K. Wysoczynski, D. J. Hadley, E. A. Silva, ACS Biomaterials Science \& Engineering 2020, 6, 308.

[268] A. R. Farooqi, J. Zimmermann, R. Bader, U. van Rienen, Computer Methods and Programs in Biomedicine 2020, 197, 105739.

[269] A. R. Farooqi, J. Zimmermann, R. Bader, U. van Rienen, Materials (Basel, Switzerland) 2019, 12.

[270] X. Gao, I. Sevostianov, Journal of Biomechanics 2016, 49, 765.

[271] H. Shin, Y. Son, U. Chae, J. Kim, N. Choi, H. J. Lee, J. Woo, Y. Cho, S. H. Yang, C. J. Lee, I.-J. Cho, Nature Communications 2019, 10, 3777.

[272] K. Dong, Y. Dong, C. You, W. Xu, X. Huang, Y. Yan, L. Zhang, K. Wang, J. Xing, Drug delivery 2016, 23, 174. 


\section{WILEY-VCH}

[273] A. Affinito, C. Quintavalle, C. L. Esposito, G. Roscigno, C. Vilardo, S. Nuzzo, L. Ricci-Vitiani, G. De Luca, R. Pallini, A. S. Kichkailo, I. N. Lapin, V. de Franciscis, G. Condorelli, Molecular therapy. Nucleic acids 2019, 18, 99.

[274] R. Karim, C. Palazzo, B. Evrard, G. Piel, Journal of controlled release : official journal of the Controlled Release Society 2016, 227, 23.

[275] V. M. Ravi, K. Joseph, J. Wurm, S. Behringer, N. Garrelfs, P. d'Errico, Y. Naseri, P. Franco, M. Meyer-Luehmann, R. Sankowski, M. J. Shah, I. Mader, D. Delev, M. Follo, J. Beck, O. Schnell, U. G. Hofmann, D. H. Heiland, Life science alliance 2019, 2.

[276] V. B. Damodaran, N. S. Murthy, Biomaterials research 2016, 20, 18.

[277] D. S. Shin, Z. Matharu, J. You, C. Siltanen, T. Vu, V. K. Raghunathan, G. Stybayeva, A. E. Hill, A. Revzin, Adv Healthc Mater 2016, 5, 659.

[278] Y. H. Sun, W. R. Gombotz, A. S. Hoffman, Journal of Bioactive and Compatible Polymers 1986, $1,316$.

[279] M. Bernards, Y. He, Journal of Biomaterials Science, Polymer Edition 2014, 25, 1479.

[280] H. Shi, W.-B. Tsai, M. D. Garrison, S. Ferrari, B. D. Ratner, Nature 1999, 398, 593.

[281] Y. Wang, F. Papadimitrakopoulos, D. J. Burgess, Journal of Controlled Release 2013, $169,341$.

[282] R. Wadhwa, C. F. Lagenaur, X. T. Cui, Journal of Controlled Release 2006, 110, 531.

[283] C. Li, A. Faulkner-Jones, A. R. Dun, J. Jin, P. Chen, Y. Xing, Z. Yang, Z. Li, W. Shu, D. Liu, R. R. Duncan, Angewandte Chemie International Edition 2015, 54, 3957.

[284] A. Kros, N. A. J. M. Sommerdijk, R. J. M. Nolte, Sensors and Actuators B: Chemical 2005, 106, 289.

[285] D. R. Merrill, M. Bikson, J. G. Jefferys, J Neurosci Methods 2005, 141, 171.

[286] E. R. Aurand, K. J. Lampe, K. B. Bjugstad, Neuroscience research 2012, 72, 199. 


\section{WILEY-VCH}

[287] R. Ottenbrite, S. Huang, K. I. Park, M. Raphael, "Hydrogels and biodegradable polymers for bioapplications", Oxford University Press, Washington, DC, 1996.

[288] B. P. Harris, J. K. Kutty, E. W. Fritz, C. K. Webb, K. J. L. Burg, A. T. Metters, Langmuir 2006, 22, 4467.

[289] C. Boehler, T. Stieglitz, M. Asplund, Biomaterials 2015, 67, 346.

[290] T. L. Rose, L. S. Robblee, IEEE transactions on bio-medical engineering 1990, 37, 1118.

[291] J. De Vry, P. Martínez-Martínez, M. Losen, G. H. Bode, Y. Temel, T. Steckler, H. W. Steinbusch, M. De Baets, J. Prickaerts, Molecular therapy: the journal of the American Society of Gene Therapy 2010, 18, 1183. 


\section{Biographies}

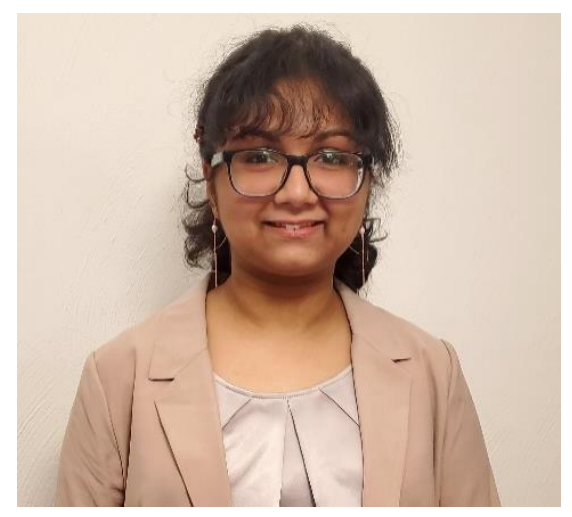
More specifically, her doctoral research focuses on
developing a stimuli-responsive injectable hydrogel platform to capture and eradicate glioblastoma cells with chemical and physical cues.

Zerin Mahzabin Khan previously graduated from the Biotechnology program at the University of Ottawa in 2018, where she completed her Bachelor's degrees in Biochemistry and Chemical Engineering with an option in Biomedical Engineering. She is currently a biomedical engineering $\mathrm{PhD}$ student in the Virginia Tech - Wake Forest University School of Biomedical Engineering and Sciences program and Computational Tissue Engineering program at Virginia Tech. Her research interests broadly lie in biomaterial strategies for treating glioblastoma multiforme. More specifically, her doctoral research focuses on
injectable hydrogel platform to capture and eradicate

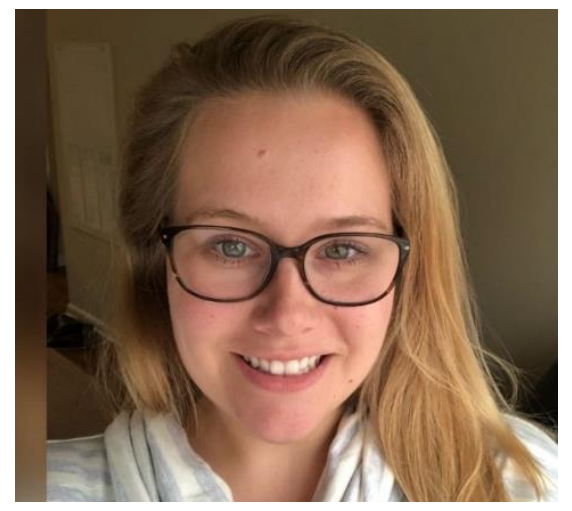

Dr. Emily M. Wilts earned her $\mathrm{PhD}$ in Macromolecular Science and Engineering at Virginia Tech in 2020 in the Timothy Long research group studying additive manufacturing of water-soluble polymers for biomedical applications. Currently, she is a Postdoctoral Research Fellow at the University of British Columbia. Under the supervision of Timothy Kieffer, she studies cell-based therapies for diabetes using immunomodulatory biomaterials for cell encapsulation.

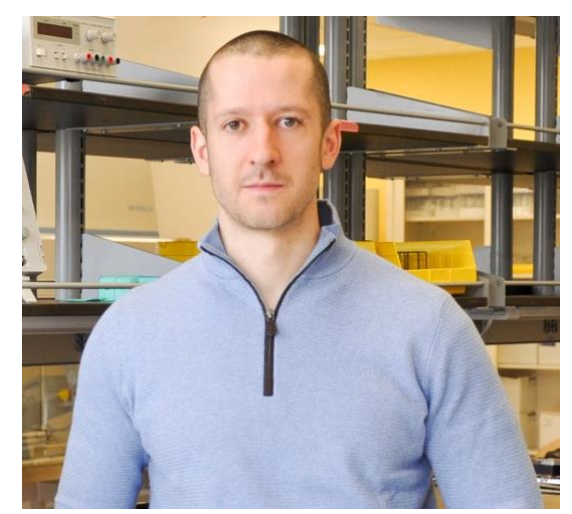

Dr. Eli Vlaisavljevich is an Assistant Professor of Biomedical Engineering and Mechanics at Virginia Polytechnic Institute and State University. His research interests include focused ultrasound, non-invasive tissue ablation (HIFU, histotripsy), cavitation physics, nanoparticle-mediated histotripsy $(\mathrm{NMH})$, biomaterials, tissue regeneration, cancer, non-invasive neuromodulation, and clinical translation. Prior to joining Virginia Tech, Dr. Vlaisavljevich conducted his graduate degrees in the Histotripsy Lab at the University of Michigan (2010-2015) and then spent two years working at HistoSonics (20152017) on the development of histotripsy for the treatment of liver cancer. More information about Dr. Vlaisavljevich's research group can be found at https://ultrasound-lab.beam.vt.edu/. 


\section{WILEY-VCH}

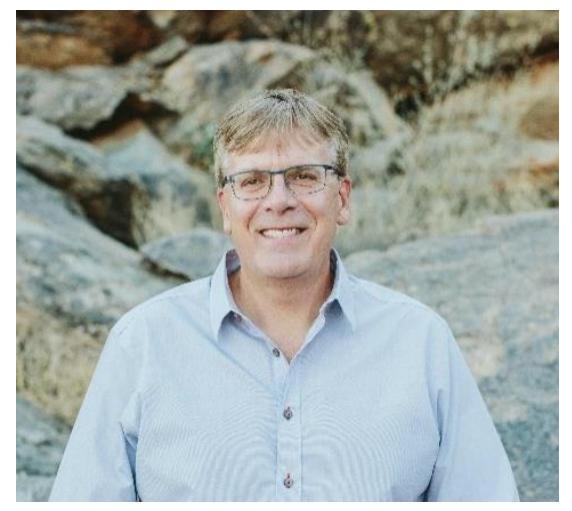

Dr. Timothy E. Long received his Ph.D. in Chemistry from Virginia Tech under Prof. James McGrath. He joined Eastman Kodak and Eastman Chemical companies and later as faculty in Department of Chemistry at Virginia Tech, where he was Director of the Macromolecules Innovation Institute until 2019. In 2020, Prof. Long accepted an interdisciplinary faculty position at Arizona State University to launch and lead Biodesign Center for Sustainable Macromolecular Materials and Manufacturing. His research interests span structure-property-processing relationships for polymers with a focus on multiphase systems including block copolymers, biomaterials and hydrogels, sustainable polymers and processes, renewable feed stocks, and green chemistry.

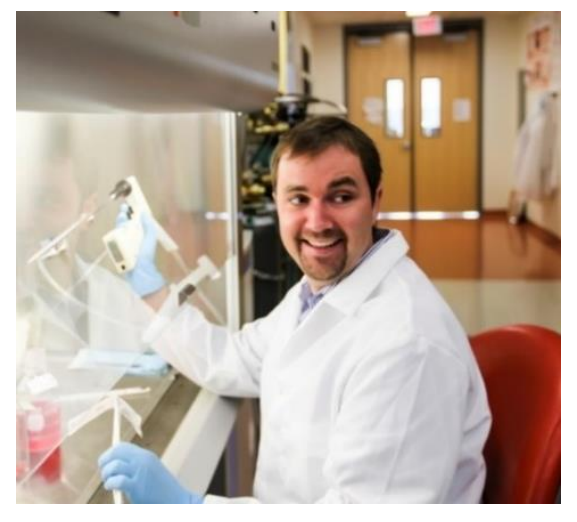

Dr. Scott Verbridge directs Laboratory of Integrative Tumor Ecology (LITE) as primary faculty member in Virginia Tech Department of Biomedical Engineering and Mechanics. He has affiliations in Virginia Tech Department of Mechanical Engineering, School of Neuroscience, Faculty of Health Sciences, and Wake Forest Comprehensive Cancer Center. LITE seeks to improve understanding of "Hallmarks of Cancer" as paradigmshifting targets for therapies. His recent work ranges from analyzing role of local tumor microbiome in enhancing malignant phenotypes, to developing a new method of nonthermal cellular ablation targeting cancer cells. He teaches undergraduate/graduate courses on biomedical engineering, quantitative cell biology, and cancer therapeutics. 


\section{WILEY-VCH}

\section{Table of Contents}

Zerin M. Khan, Emily Wilts, Eli Vlaisavljevich, Timothy E. Long, and Scott S. Verbridge*

\section{Electroresponsive Hydrogels for Therapeutic Applications in the Brain}

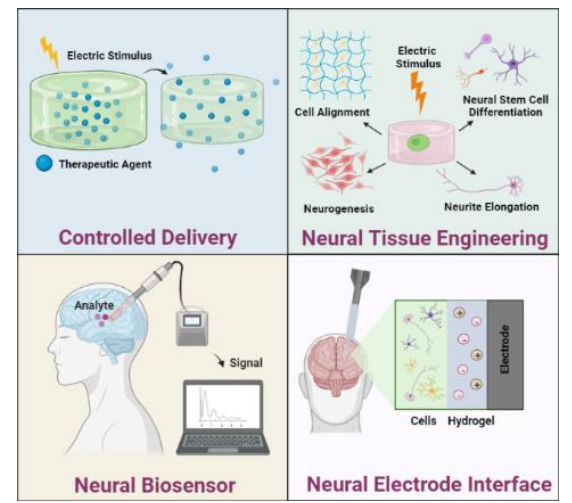

This review focuses on advances in electric stimulation of electroresponsive hydrogels. An overview of electric stimulation and electroresponsive hydrogels in the brain is provided. Four applications of electresponsive hydrogels in the brain are discussed, including controlled delivery, neural tissue engineering, and neural interfaces for electrodes and biosensors. The main challenges of each application and future perspectives are also provided. 